\title{
SOCIAL STRUCTURE OF THE PROTOGYNOUS FISH LABROIDES DIMIDIATUS
}

AUTHOR(S):

Kuwamura, Tetsuo

\section{CITATION:}

Kuwamura, Tetsuo. SOCIAL STRUCTURE OF THE PROTOGYNOUS FISH LABROIDES

DIMIDIATUS. PUBLICATIONS OF THE SETO MARINE BIOLOGICAL LABORATORY 1984, 29(13): $117-177$

ISSUE DATE:

1984-03-31

URL:

http://hdl.handle.net/2433/176083

RIGHT: 


\title{
SOCIAL STRUGTURE OF THE PROTOGYNOUS FISH LABROIDES DIMIDIATUS ${ }^{1)}$
}

\author{
Tetsuo KUWAMURA \\ Faculty of Liberal Arts, Chukyo University, 101-2 Yagoto-honmachi, \\ Nagoya 466, Japan
}

With Text-figures 1-22 and Tables 1-22

\begin{abstract}
Social relationships of the protogynous wrasse, Labroides dimidiatus, were investigated at the shallow rocky reefs of Shirahama, southern Japan, from 1972 to 1979 . Individuals were tagged, and their behaviour and movements were recorded for at least one month. Home ranges of males hardly overlapped. Within a male's home range, 2 to 12 females resided and spawned with the male. Home ranges of females in a male's harem did not always overlap. Individuals whose home ranges largely overlapped (=members of a "primary group") had different social relationships, both in quantity and quality, from those between primary groups: e.g. within primary groups size-based dominance hierarchies were present, while between primary groups territoriality was found. Therefore, primary groups are regarded as the most basic social unit of the species. This unit was rather open for smaller inđividuals. Such social structure was primarily based on the "size principle": individuals of similar body size could not overlap their home ranges and had territorial relationships, while individuals of different body size could overlap their home ranges and when overlapped they had size-based dominance relationships. The size principle was also loosely applicable to smaller individuals. The process of protogynous sex-change is suggested to be controlled by the size principle, or the cooperating function of a dominance hierarchy within a primary group and territoriality between primary groups. In males, territoriality and dominance hierarchies seem to be directly related to the acquisition of mates. However, in females, they do not seem to be directly related to resources such as food: feeding territoriality, as has been suggested, does not seem to be the fact. The social structure of this species is compared with those of other labrids and haremic fishes, and the ecological requirements of harems and the means of social control of sex-change are discussed.
\end{abstract}

\section{Introduction}

The cleaner wrasse Labroides dimidiatus (Valenciennes) is a monandric protogynous spceies (i.e. all males are derived from females), and the social control of sex reversal occurs within social groups consisting of a male and a harem of females (Robertson, 1972, 1974). The simultaneous occurrence of hermaphroditism and polygyny in this species appears to be an interesting subject of sociobiology.

Teleost fishes are the only vertebrates among which hermaphroditism, both synchronous and sequential (either protogyny or protandry), occurs as a normal phenomenon (Reinboth, 1970; Smith, 1975; Warner, 1978; Lepori, 1980). Most species

1) Contributions from the Seto Marine Biological Laboratory, No. 698.

Publ. Seto Mar. Biol. Lab., XXIX (1/3), 117-177, 1984.

(Article 3) 
of the family Labridae, which includes $L$. dimidiatus, possess protogynous hermaphrodites (Reinboth, 1970, 1975; Roede, 1972, 1975; Warner and Robertson, 1978; Nakazono, 1979; etc.; cf. Diener, 1976; Dipper and Pullin, 1979).

To explain the causal initiation of female to male sex reversal in fishes, several hypotheses have been proposed. These can be grouped under three headings: the size hypothesis, development hypothesis and social control hypothesis (see Shapiro, 1981). The idea that social factors might be involved in sex inversion was introduced by Fishelson (1970) during the laboratory study of a protogynous serranid fish Anthias squamipinnis. The social control of sex reversal was strongly suggested for the first time by field observations and experiments on L. dimidiatus (Robertson, 1972, 1974). Thenceforce, similar social control of sex reversal has been suggested not only in several protogynous species (Fricke and Holzberg, 1974; Warner et al., 1975; Fricke, 1977; Lassig, 1977; Robertson and Warner, 1978; Moyer and Nakazono, 1978a; Moyer, 1980a), but also in some protandrous species (Fricke and Fricke, 1977; Moyer and Nakazono, 1978b; Fricke, 1979).

In most cases, however, mechanisms of the social control of sex reversal have not been sufficiently explained in both physiological (see Reinboth, 1980) and behavioural (see Shapiro, 1981) respects. As to the latter point, it seems to be premature to conclude that sex reversal is controlled by aggression or dominance, and more detailed analyses of internal structure of groups, in which sex reversal occurs, are required to explain the mechanism of social control (Shapiro, 1981). This seems to hold also in the case of $L$. dimidiatus.

Polygynous mating systems are widespread among vertebrates (see reviews by Wilson, 1975; Ito, 1978), including fishes (see below). Haremic polygyny is rather frequently seen in protogynous fishes: several labrids (Robertson, 1972, 1974; Nakazono and Tsukahara, 1974; Moyer and Shepard, 1975; Robertson and Hoffman, 1977; Warner and Robertson, 1978; Nakazono, 1979; Thresher 1979; Moyer, 1980a, 1980b; Tribble, 1982) and also other protogynous species (Fricke and Holzberg, 1974; Choat and Robertson, 1975; Fricke, 1977; Robertson and Warner, 1978; Moyer and Nakazono, 1978a). It is also found in some gonochoristic fishes (Burchard, 1965; Moyer, 1979; Fricke, 1980).

Ecological factors that affect the degree and form of polygamous mating systems have been discussed by several authors (Emlen and Oring, 1977; Ito, 1978; Wittenberger, 1979; etc.). Such discussions have been made also on marine fishes including protogynous haremic species (Warner et al., 1975; Robertson and Hoffman, 1977; Moyer and Nakazono, 1978a; Robertson and Warner, 1978; Warner and Robertson, 1978; Moyer, 1979; Thresher, 1979; Fricke, 1980). In these discussions $L$. dimidiatus has been almost always cited, and the development of its haremic system has been suggested to have been permitted by the permanent feeding territoriality of females (Robertson and Hoffman, 1977; Warner and Robertson, 1978).

The haremic mating system of $L$. dimidiatus was found not only at the tropical coral reefs of Heron Island and Aldabra Island (Robertson, 1972, 1974; Robertson and Hoffman, 1977), but it was also found at the temperate rocky reefs of Shirahama, 
southern Japan, although it was apparent only in the warmer period of the year (Kuwamura, 1981a). However, by further analysis of the social organization of $L$. dimidiatus at Shirahama, I have become aware that it differs in some points from the previous views (i.e. Robertson, 1972, 1974; Robertson and Hoffman, 1977). For example, feeding territoriality of females does not seem to occur in this species of Shirahama. The difference might be regarded as a geographical one between Heron Island and Shirahama, as was found in the life history pattern (see Kuwamura, 1981a). However, on examination of the detailed description of Robertson (1974), I have found no significant difference in the facts observed between Heron Island and Shirahama. Therefore, the difference seems to lie in the viewpoint as to what is the most basic principle of $L$. dimidiatus' social organization. Previous works seem to be premature, especially in respect to the analysis of the relationships between social behaviours and the degree of home-range overlap among individuals.

The purpose of this paper is to re-examine the social structure of $L$. dimidiatus, to explain the mechanism of social control of sex reversal, and to speculate about the evolution of the haremic mating system in this species. Firstly, the degree and form of home-range overlap among individuals are described in relation to the degree of difference in body size. The body size seems to affect social relationships significantly, as size is related to sex in this species. Secondly, the social relationships among individuals are described in relation to the degree of their home-range overlap. Thirdly, dyramics in social relationships are examined both by long-term observations in natural conditions and by experimental disturbance of these relationships. Individual tagging used in the present study made it possible to analyse the mechanisms of social dynamics more clearly than in Robertson's work, in which individuals were discriminated by their colour variations and therefore long-distance movements were rather difficult to trace.

From the results, I propose the basic principle of the social structure of L. dimidiatus, which seems to be applicable to both Shirahama and Heron Island populations. This principle will explain the mechanism of the social control of sex reversal more clearly than before. I also refer to the relationship between territoriality and dominance hierarchy. Lastly, based on the present view of L. dimidiatus' social structure, the evolution of the haremic mating system in labrids is speculated upon in a somewhat different way than previously done.

\section{Study Areas and Methods}

The study areas and general methods employed during the present study have been previously described (Kuwamura, 1981a), and are briefly re-described and supplemented as follows.

Observations were made underwater using SCUBA in the coastal waters of Shirahama $\left(33^{\circ} 42^{\prime} \mathrm{N} ; 135^{\circ} 20^{\prime} \mathrm{E}\right)$ during the period from 1972 to 1979 . At three separate rocky reefs, i.e. Stations A, B and C (Fig. 1 and also see Kuwamura, 1981a), 


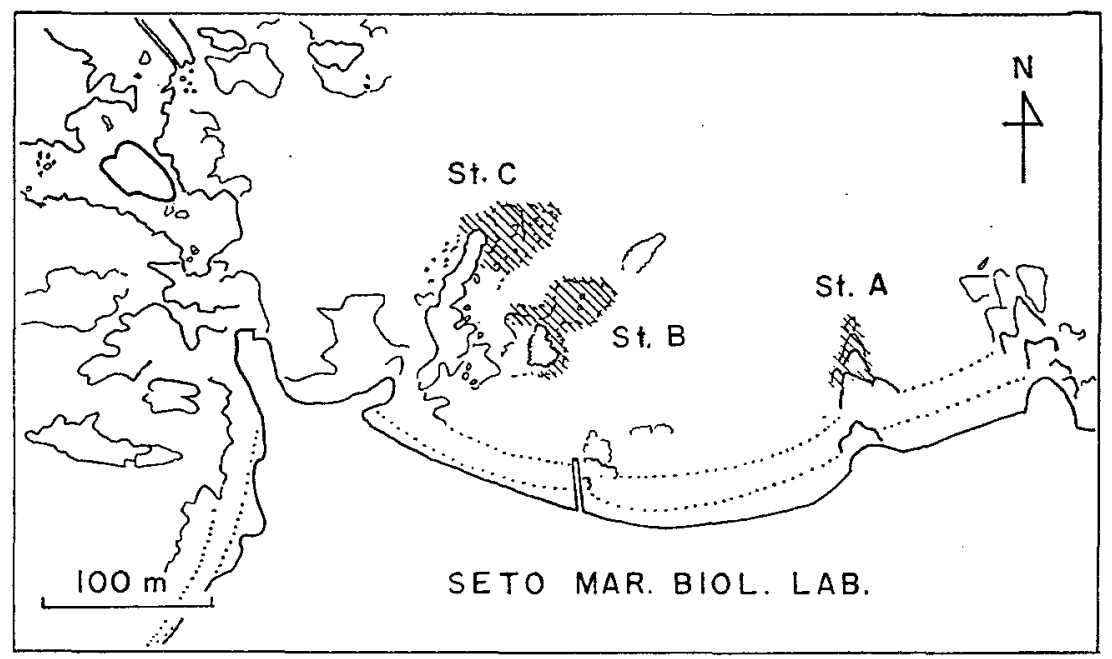

Fig. 1. Map of the study areas at Shirahama, southern Japan. Shaded areas show three stations at submerged rocky reefs.

almost all individuals of $L$. dimidiatus were tagged and individually discriminated in 1974 and 1975 at St. A, in 1975 at St. B, in 1977 at St. C. The methods of tagging and the durability of tags were described in Kuwamura (1981a). In addition to these, the fish were also individually marked by means of subcutaneous injection of coloured dyes in 1978 at St. A, or were individually discriminated by apparent differences in body size in 1976 at St. A. In this paper, the fish are individually represented by individual numbers (in the order of body size at each station) associated with symbols of sex (M: male; F: female): e.g. M1, M2, F1, F2, etc. The body size of each individual was measured when tagged, or estimated in the field. The sex was determined by observations on mating behaviour, but not by gonad examination.

During surveys, each lasting one to two hours at each station, data were collected for each individual for the following points: (1) locations of each individual, (2) whether it was solitary or with others, and (3) individual behaviour and that of others if it met with others. From these data, home ranges of each individual and social relationships between individuals were analysed.

In addition to observations in natural conditions, field and aquarium experiments were conducted to analyse dynamics in social relationships. Three types of experiments were made: (1) the introducing experiment in the aquarium: two individuals were introduced into a tank $\left(2.8 \mathrm{~m}^{3}\right.$ in volume) which had been already occupied by two other individuals; (2) the transfer experiment in the field: individuals were collected at St. B or the offshore reefs and introduced into St. A, on five occasions; and (3) the removing and returning experiment in the field: individuals were collected and returned again to their native reef (St. A) after one day's isolation in a tank, on ten occasions. Reciprocal responses between intruders and residents were recorded in these experiments. 
In this paper I treat home ranges and social relationships chiefly in the warmer periods, for L. dimidiatus was socially active only in that season at Shirahama (Kuwamura, 1981a).

\section{Results}

Degree of Home-range Overlap in Relation to Body Size

\section{Distribution of home ranges}

Home ranges of $L$. dimidiatus were illustrated by enclosing all the observed locations for each individual (e.g. Fig. 2A). The fish often moved over almost its

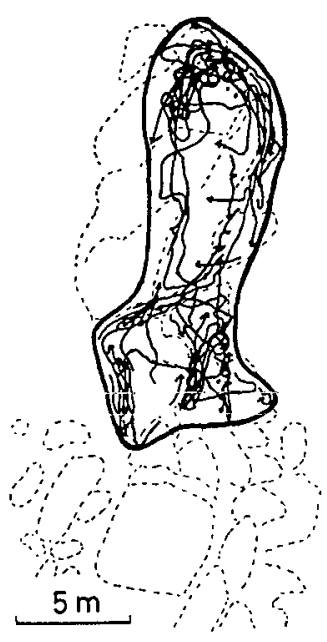

A

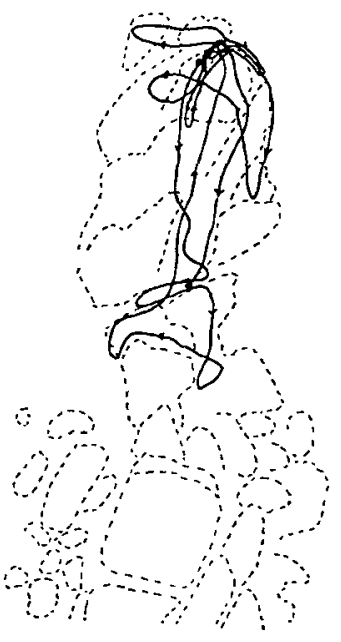

B

Fig. 2. An example of determining the home range of $L$. dimidiatus. Locations of a male (M2: $100 \mathrm{~mm}$ in total length) observed in the period from June 1 to 30 in 1975 (about 100 minutes observations in total by 11 surveys) at the north part of St. A, and its home range (broad line) illustrated by enclosing all the locations within it (A). Movements of M2 for 15 minutes observed on July 3, 1975 are also shown (B).

entire home range even in a short time (see the trace of movements during a 15minutes observation in Fig. 2B). Locations of apparently unusual and infrequent expeditions of individuals were not included in their home ranges. These expeditions are treated in detail in the section "Relationships between primary groups". Within home ranges determined as indicated above, individuals used certain sites more frequently than others (e.g. Fig. 2A). However, the area usually used by an individual seems to be roughly represented by the outline of home ranges illustrated above. The difference in the use of sites within the home range by an individual is referred to, in relation to feeding, mating and other behaviours of it, in the section "Relationships within primary groups". 

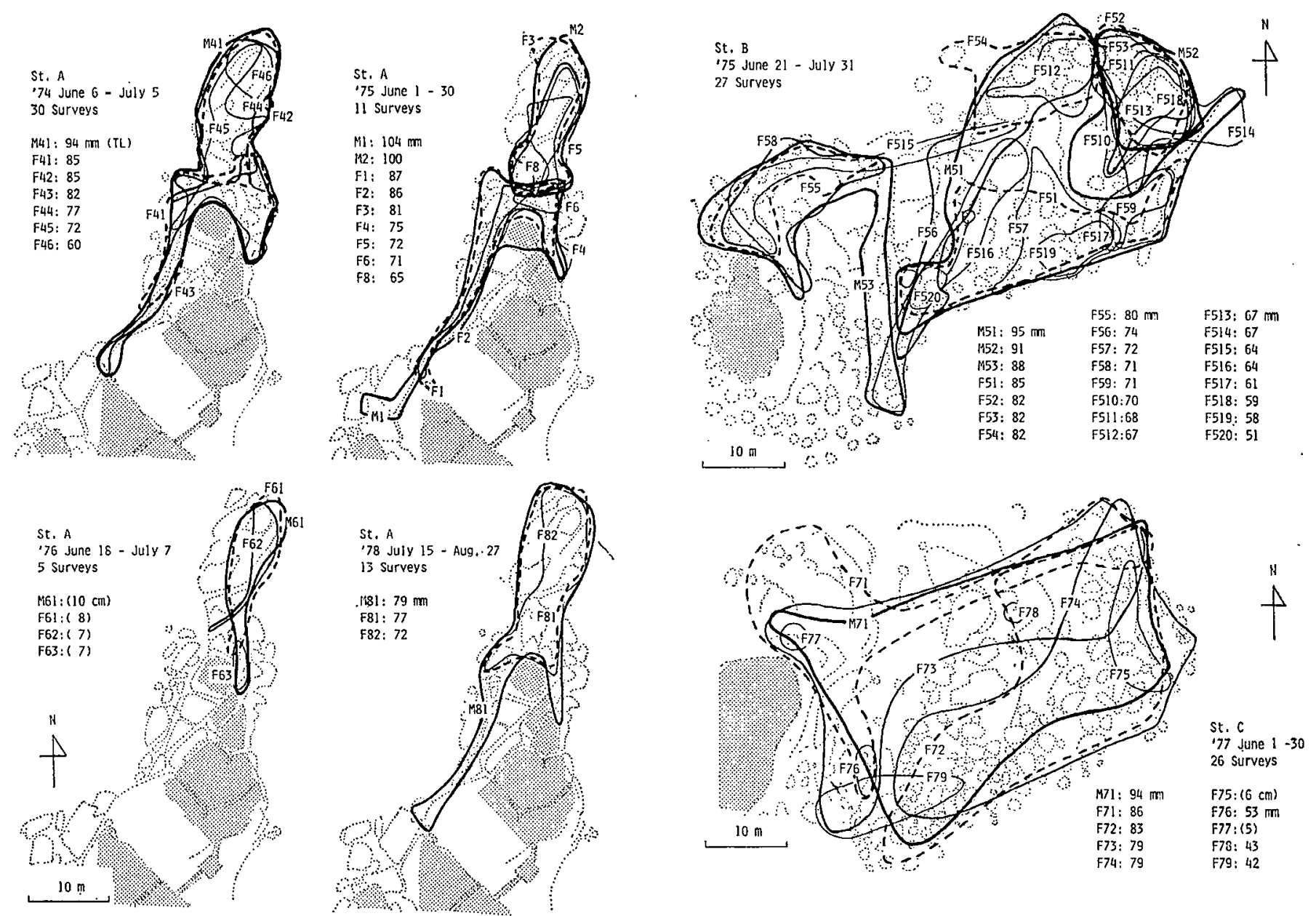

田

Fig. 3. Home ranges of $L$. dimidiatts at three stations in summer. Periods and frequencies of surveys and total lengths of individuals are also given. Dotted areas show emerged rocks at low tide. 
Home ranges of all individuals at each station in summer are shown for six cases (Fig. 3). Home ranges of the fish covered almost the whole area of submerged rocky reefs at each station. They rarely extended over the sand or rubble areas around the rocky reefs.

One to three males were found at each station, and they were always the largest individuals at that station. When there were two or three males (St. A, 1975; St. $\mathrm{B}, 1975)$, their home ranges hardly overlapped. The sizes of home ranges of males were $80-900 \mathrm{~m}^{2}(\overline{\mathrm{x}}=310, \mathrm{n}=9$; Table 1). Larger males did not always occupy

Table 1. Home-range sizes of 9 males shown in Fig. 3, and number of females within them. For types of polygynous groups; L: linaer type; B: branching type (sec text for detail).

\begin{tabular}{cccccc}
\hline \hline $\begin{array}{c}\text { Name of } \\
\text { males }\end{array}$ & $\begin{array}{c}\text { Total length } \\
(\mathrm{mm})\end{array}$ & $\begin{array}{c}\text { Range size } \\
\left(\mathrm{m}^{2}\right)\end{array}$ & $\begin{array}{c}\text { Number of } \\
\text { females }\end{array}$ & $\begin{array}{c}\text { Density }(\hat{0}+\%) \\
\left.\text { per } 100 \mathrm{~m}^{2}\right)\end{array}$ & $\begin{array}{c}\text { Type of } \\
\text { groups }\end{array}$ \\
\hline M41 & 94 & 248 & 6 & 2.8 & B \\
M1 & 104 & 136 & 4 & 3.7 & L \\
M2 & 100 & 112 & 4 & 4.5 & L \\
M61 & ca. 100 & 80 & 3 & 5.0 & B \\
M81 & 79 & 236 & 2 & 1.3 & L \\
M51 & 95 & 633 & 12 & 2.1 & B \\
M52 & 91 & 144 & 7 & 5.6 & L \\
M53 & 88 & 300 & 4 & 1.7 & L \\
M71 & 94 & 900 & 9 & 1.1 & B \\
\hline
\end{tabular}

larger ranges $(\mathrm{r}=-0.050, \mathrm{P}>0.1)$. Within the male's home range, two to twelve females were found $(\bar{x}=6, n=9$; Table 1$)$. Their home ranges largely overlapped that of the male. The number of females was generally larger when the home range of the male was larger $(r=0.750, P<0.02)$. A male and females within the male's home range are thus regarded as composing a "polygynous group", and each group will be designated by the individual name of the male in it hereafter.

Females in a polygynous group had either largely or hardly overlapping home ranges (Fig. 3 and also see Fig. 4). In M1, M2, M81, M52 and M53 groups, almost all females largely overlapped their home ranges. These polygynous groups are designated as "linear types". On the other hand, in other groups home ranges of some of the females hardly ovrelapped, and such groups are called "branching types": the home ranges of the males, M41, M51 and M71, were divided among several of the largest females for their respective home ranges; those of the largest females, F51 and F61, were further divided between the second largest females; also those of the second largest females, F56, F73 and F74, were apportioned between the smaller females.

Some females extended their ranges crossing over the range border between two males, as well as over the borders of larger females (Fig. 3 and Fig. 4; also see Table 3). Smaller females were more apt to establish their home ranges crossing other's range borders than larger ones (Table $2 ; \mathrm{P}=0.048$, Fisher's exact probability test). 


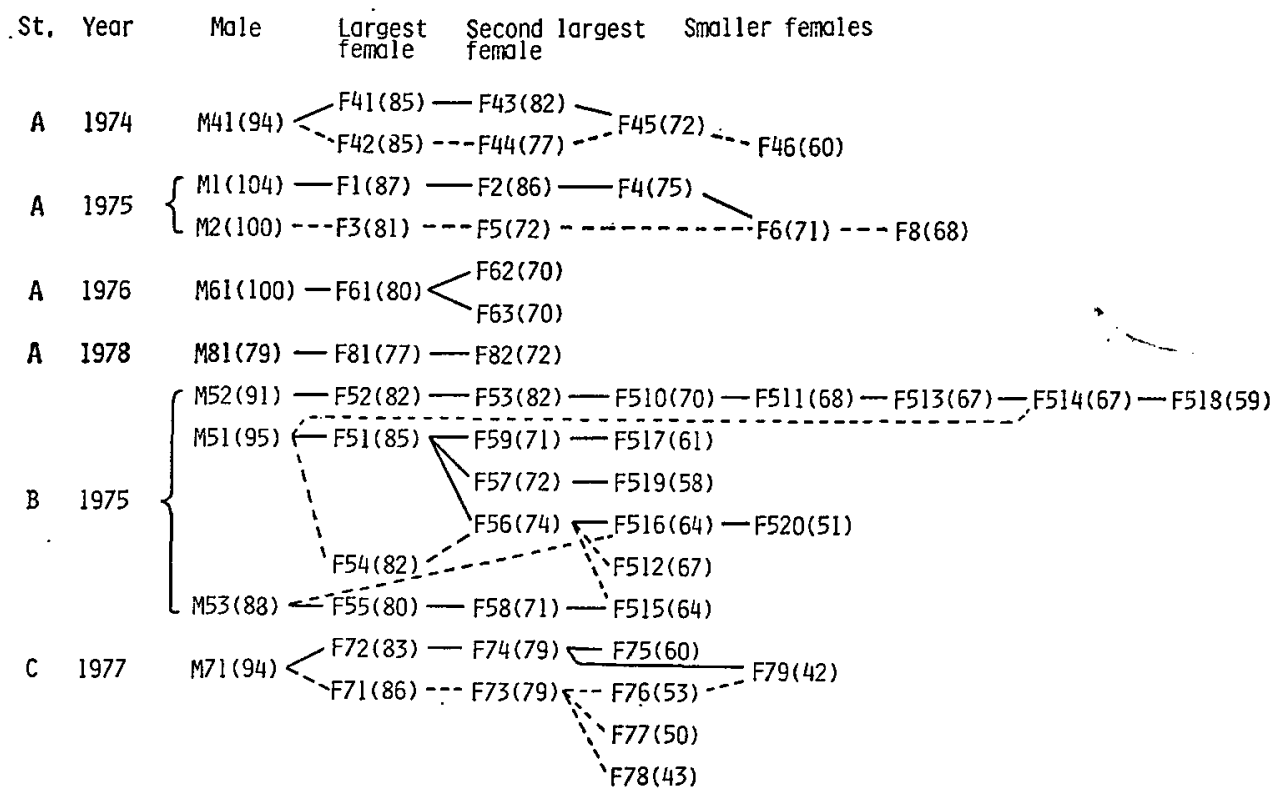

Fig. 4. Schematic representation of home-range overlap among fishes shown in Fig. 3. Rangeoverlapping fishes are linked by the same line.

Table 2. The rate of crossing over range borders between larger individuals for each size class. The rate is calculated as follows: Number of individuals crossing over the range border $\times 100$ Total number of individuals in each size class

\begin{tabular}{lccccc}
\hline \multirow{2}{*}{ Size class } & \multirow{2}{*}{$\begin{array}{c}\text { Total number } \\
\text { of individuals }\end{array}$} & \multicolumn{4}{c}{$\begin{array}{c}\text { Number of individuals (rate) crossing the range } \\
\text { borders between }\end{array}$} \\
\cline { 3 - 6 } & 12 & Males & $\begin{array}{c}\text { Largest } \\
\text { females }\end{array}$ & $\begin{array}{c}\text { Second largest } \\
\text { females }\end{array}$ & Total \\
\hline $\begin{array}{l}\text { Largest female } \\
\begin{array}{l}\text { Second largest } \\
\text { female }\end{array}\end{array}$ & 14 & 0 & - & - & $0(0)$ \\
Smaller female & 21 & $4(19.0)$ & $6(28.6)$ & $6(28.6)$ & $6(28.6)$ \\
\hline Total & $4(8.5)$ & $7(20.0)$ & $6(28.6)$ & \\
\hline
\end{tabular}

From the viewpoint of the degree of home-range overlap as mentioned above, individuals of a polygynous group can be divided into sub-groups which are composed of range-overlapping individuals. Such sub-groups will be called "primary groups" from now on. In Fig. 4 the members belonging to the same primary group are linked by a line. A linear-type polygynous group is thus in itself a primary group, and a branching-type polygynous group consists of two or more primary groups.

\section{Relationship between home-range overlap and size difference}

The state of home-range overlap within a polygynous group, or whether it is of linear type or of branching type, does not seem to be directly related to the size of 
the male's home range or to the number of females in it (see Table 1).

When an area was divided by two or more individuals, the size-difference between them was usually very small: the size-differences in total length between neighbouring males within one station were 4-7 mm $(n=3)$; those between neighbouring largest females within a male's home range were $0-3 \mathrm{~mm}(\mathbf{n}=3)$; and those between neighbouring second largest females within a largest female's home range were $0-2 \mathrm{~mm}(\mathrm{n}=3)$. On the other hand, when an individual extended its home range crossing over the range border between larger ones, there was usually no individual of its similar size in the extended area (Table 3). The results of analysis on all possible pairs in Fig. 3 show the tendency that two individuals differing only slightly in size more often segregated their home ranges (Fig. $5 ; \mathrm{n}=383, \mathrm{P}<0.01$,

Table 3. Individuals whose home ranges crossed over range borders between larger ones, with the differences of body size between them and the nearest-size individual of them in the overlapping areas on each side of the borders.

\begin{tabular}{|c|c|c|c|c|c|c|c|}
\hline $\begin{array}{l}\text { Individual name } \\
\text { (TL } \mathrm{mm} \text { ) }\end{array}$ & $\begin{array}{l}\text { F56 } \\
(74)\end{array}$ & $\begin{array}{l}\text { F45 } \\
(72)\end{array}$ & $\begin{array}{l}\text { F6 } \\
(71)\end{array}$ & $\begin{array}{l}\text { F514 } \\
(67)\end{array}$ & $\begin{array}{l}\text { F515 } \\
(64)\end{array}$ & $\begin{array}{l}\text { F516 } \\
(64)\end{array}$ & $\begin{array}{l}\text { F79 } \\
(42)\end{array}$ \\
\hline $\begin{array}{r}\text { Size difference } \\
(\mathrm{mm})\end{array}$ & $\left\{\begin{array}{r}7 \\
10\end{array}\right.$ & $\begin{array}{l}5 \\
8\end{array}$ & $\begin{array}{l}1 \\
4\end{array}$ & $\begin{array}{r}0 \\
28\end{array}$ & $\begin{array}{r}7 \\
10\end{array}$ & $\begin{array}{l}10 \\
24\end{array}$ & $\begin{array}{l}11 \\
37\end{array}$ \\
\hline
\end{tabular}

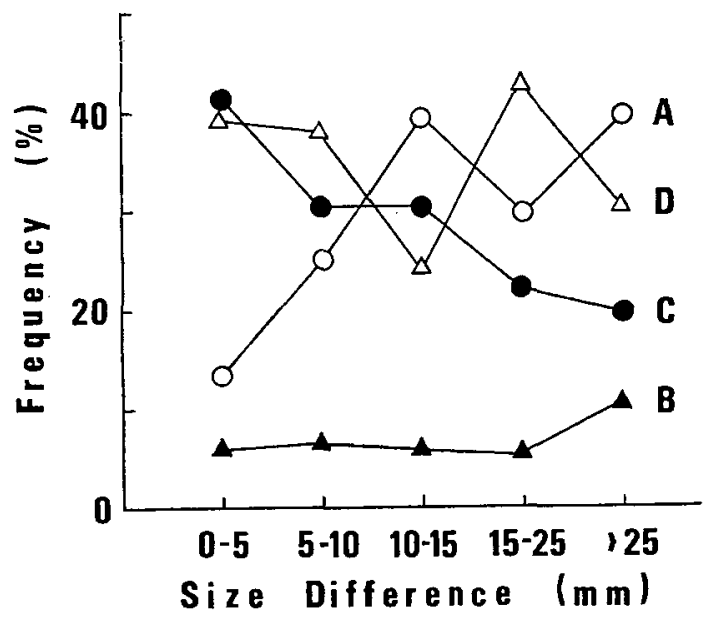

Fig. 5. Frequencies for each type of home-range overlap in relation to the degree of difference in total length in 383 pairs of individuals given in Fig. 3. For types of home-range overlap; Type A: almost overlapping, or one of the home ranges including the other; Type B: partly overlapping; Type C: scarcely overlapping but adjoining; Type D: apart from each other.

$\chi^{2}$-test). This tendency is discernible more among larger individuals than among smaller ones (Table $4 ; \mathrm{n}=83, \mathrm{P}<0.05, \chi^{2}$-test).

In 11 cases $(13.3 \%)$, two individuals of similar body size had largely overlapping home ranges (see Fig. 3 and Table 4). These exceptional cases can be viewed in relation to their neighbouring individuals. For example, F52 and F53 (both 82 
Table 4. Frequencies for each type of home-range overlap ( $A \sim D$ in Fig. 5) between two individuals which differed by less than $5 \mathrm{~mm}$ in total length, in relation to their total lengths.

\begin{tabular}{|c|c|c|c|c|c|c|c|}
\hline \multirow{2}{*}{$\begin{array}{l}\text { Total length of } \\
\text { the larger one } \\
(\mathrm{mm})\end{array}$} & \multicolumn{4}{|c|}{ Type of home range overlap } & \multirow{2}{*}{ Total } & \multirow{2}{*}{$\frac{\mathrm{C}}{\mathrm{A}+\mathrm{B}+\mathrm{G}} \times 100$} & \multirow{2}{*}{$\begin{array}{r}\frac{\mathrm{C}}{\text { Total }} \times 100 \\
(\%)\end{array}$} \\
\hline & A & B & G & $\mathrm{D}$ & & & \\
\hline $50 \sim 60$ & 0 & 1 & 0 & 2 & 3 & 0 & 0 \\
\hline $60 \sim 70$ & 2 & 3 & 8 & 9 & 22 & 61.5 & 36.4 \\
\hline $70 \sim 80$ & 4 & 1 & 12 & 15 & 32 & 70.6 & 37.5 \\
\hline $80 \sim 90$ & 5 & 0 & 13 & 4 & 22 & 72.2 & 59.1 \\
\hline $90 \sim 100$ & 0 & 0 & 1 & 1 & 2 & 100.0 & 50.0 \\
\hline $100 \sim 110$ & 0 & 0 & 2 & 0 & 2 & 100.0 & 100.0 \\
\hline Total & 11 & 5 & 36 & 31 & 83 & 69.2 & 43.4 \\
\hline
\end{tabular}

$\mathrm{mm}$ in total length) had similar-sized females, F54 (82 mm) and F51 (85 mm), in the neighbouring areas, and probably the latter inhibited the former's movement. F511 (68 $\mathrm{mm})$, F513 $(67 \mathrm{~mm})$ and F514 $(67 \mathrm{~mm})$ also had similar-sized neighbours, F59 $(71 \mathrm{~mm})$ and $\mathrm{F} 512(67 \mathrm{~mm})$. F2 $(86 \mathrm{~mm})$, whose home range overlapped that of similar-sized F1 $(87 \mathrm{~mm})$, moved from the neighoubring area where it had been attacked by a smaller female, F3 $(81 \mathrm{~mm})$. F6 $(71 \mathrm{~mm})$ overlapped its home range with that of F5 $(72 \mathrm{~mm})$, but later moved into the neighbouring area where it established its home range overlapping that of F4 $(75 \mathrm{~mm})$. (The two cases above will be described and examined in detail in a later section "Dynamics in social relationships".)

Thus, the pattern of distribution of home ranges in an area seems to be generally determined by relative body size among individuals there.

\section{Relationships within Primary Groups}

In this section, social relationships within primary groups, i.e. among individuals whose home ranges largely overlapped, are described.

\section{Temporary aggregation}

L. dimidiatus did not form a stable school. However, a few individuals were sometimes found gathering and swimming together. In $78.1 \%$ of total 1378 cases, which were obtained at the beginning of each observation for each individual, the fish were found soiltary. In the remaining cases, two to five individuals, mostly two, were found in aggregations within one-meter distance from each other (Fig. 6). A male was found in $66.2 \%$ of all aggregations. The frequency of aggregations which included a male increased according to the increase of the number of individuals in an aggregation (Fig. 6).

Frequencies of interclass aggregations were calculated for each size class in primary groups shown in Fig. 3, and averages for an individual in each size class are shown in Table 5. Larger individuals, especially males, were more often found in 


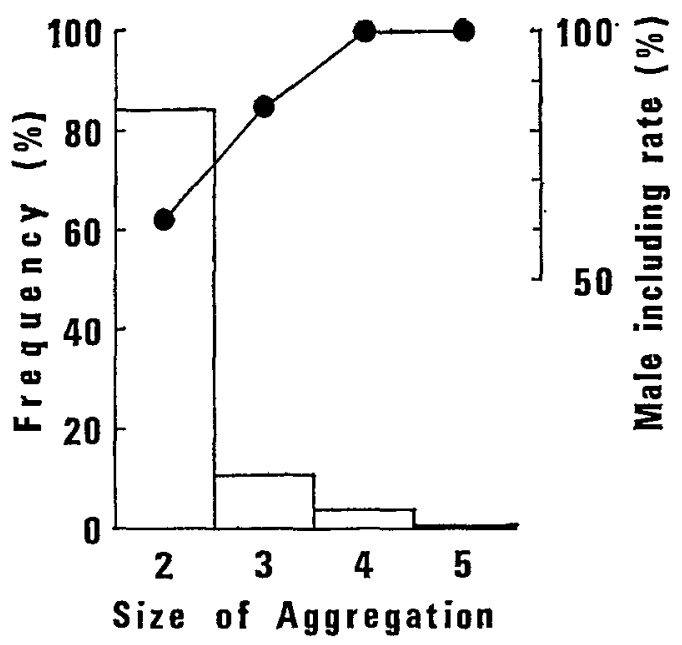

Fig. 6. Distribution of the number of individuals in an aggregation, and frequencies of aggregations which included a male for each size of aggregations. Total number of aggregations observed was 302 .

Table 5. Interclass aggregating rates within primary groups. Averages of 11 primary groups shown in Fig. 3 are given. The aggregating rate for an individual (A) with another one (B) is calculated as follows:

Number of occasions when A was seen with B $\times 100$

Total number of observations for $\mathrm{A}$

\begin{tabular}{lcccccc}
\hline \hline \multirow{2}{*}{ Size class } & Total number & \multicolumn{5}{c}{ Aggregating rate with } \\
\cline { 5 - 8 } & of observations & Male & $\begin{array}{c}\text { Largest } \\
\text { female }\end{array}$ & $\begin{array}{c}\text { Second largest } \\
\text { female }\end{array}$ & $\begin{array}{l}\text { Smaller } \\
\text { female }\end{array}$ & Total \\
\hline Male & 344 & - & 26.1 & 12.2 & 7.0 & 55.7 \\
Largest female & 392 & 26.3 & - & 8.2 & 3.0 & 34.0 \\
Second largest female & 442 & 14.5 & 8.5 & - & 7.6 & 28.4 \\
Smaller female & 651 & 10.4 & 4.0 & 9.7 & 12.4 & 28.3 \\
\hline
\end{tabular}

aggregation than smaller ones $\left(\mathrm{P}<0.001, \chi^{2}\right.$-test $)$. Males aggregated more often with larger females than with smaller ones $\left(\mathrm{P}<0.001, \chi^{2}\right.$-test $) . \quad$ Largest females and second largest females aggregated more often with males than with other females $\left(\mathrm{P}<0.001\right.$ and $\mathrm{P}<0.01, \chi^{2}$-test $)$. However, smaller females aggregated more often with other smaller females than with males and larger females $\left(P<0.001, \chi^{2}\right.$-test $)$. The frequency of aggregation between a male and a largest female was highest among varied interclass aggregations. It is notable that though the home range of the second largest female was usually extended almost entirely over that of the largest female, the aggregating rate with the male differed largely between them.

\section{Behaviours in encounters and spatial distribution}

Encounters between two or more individuals of the same primary group, followed by differing behavioural responses, were frequently observed. According to 
the sex and number of individuals participating in each encounter, these were grouped into seven types (Table 6). About half of 805 encounters observed were those between a male and a female, and a male was involved in $76.0 \%$ of all the encounters.

Various behaviours observed on encounter are shown for each type of encounter in Table 7, and characteristic behaviours are described respectively as follows.

Table 6. Seven types of encounters within primary groups and their frequencies, observed at the three stations in the period from 1974 to 1978 . Encounters suh such as "females vs. females" and "a male and females vs. females" were not observed in the present study.

\begin{tabular}{lrr}
\hline \multicolumn{1}{c}{$\begin{array}{c}\text { Composition of individuals } \\
\text { in encounters }\end{array}$} & Number of observations & Freuqency in total (\%) \\
\hline A male vs. a female & 390 & 48.4 \\
A male vs. females & 54 & 6.7 \\
A female vs. a female & 171 & 21.2 \\
A female vs. females & 22 & 2.7 \\
A male and a female vs. a female & 151 & 18.8 \\
A male and a female vs. females & 7 & 0.9 \\
A male and females vs. a female & 10 & 1.2 \\
\hline Total & 805 & \\
\hline
\end{tabular}

Male vs. Female Encounter: In $42.1 \%$ of the encounters $(\mathbf{n}=390)$ there were no overt displays. Among the overt displays exhibited, the "flutter-run" (Robertson, 1974; "passing and quivering" of Labroides phthirophagus in Youngbluth, 1968) by the male to the female was most common (30.3\%), followed by "attack" ("rushing-at" and "chasing" of Robertson, 1974) by the male against the female (6.4\%). Females less frequently exhibited overt displays than males $\left(\mathrm{P}<0.001, \chi^{2}\right.$-test $)$, although they sometimes displayed "body-sigmoid" (Robertson, 1974; "sigmoid-posture" of L. phthirophagus in Youngbluth, 1968) against males.

Male vs. multiple Females Encounter: The flutter-run of the male against the female was most frequent $(27.8 \%, \mathrm{n}=54)$, similar to the previous encounter $\left(\mathrm{P}>0.8, \chi^{2}-\right.$ test). Attacks by the male were observed almost as often (7.4\%) as in the preceding encounter $\left(\mathrm{P}>0.98, \chi^{2}\right.$-text). The male exerted the flutter-run more often against the larger female (13 cases) than against the smaller one ( 8 cases) of the two females, and it directed the attack more often against the smaller female (4 cases) than against the larger one (none); however, these differences were not significant $(P=0.192$ and $\mathbf{P}=0.063$, Test of a binominal proportion).

Female vs. Female Encounter: In as much as $43.3 \%$ of the total encounters $(n=171)$, attacks were exhibited by the larger female against the smaller one. This rate of attack was significantly higher than that in the encounters between a male and a female $\left(\mathrm{P}<0.001, \chi^{2}\right.$-test). Although very rarely, females even did mutual "mouthgape" (Robertson, 1974), which was usually seen in fights between the individuals of different primary groups (see the later section).

Female vs. multiple Females Encounter: Attacks were often observed (31.8\%, $\mathrm{n}=22)$, as in the preceding encounter $\left(\mathrm{P}>0.3, \chi^{2}\right.$-test). 
Table 7. Frequencies of each behaviour in respective types of encounters shown in Table 6 .

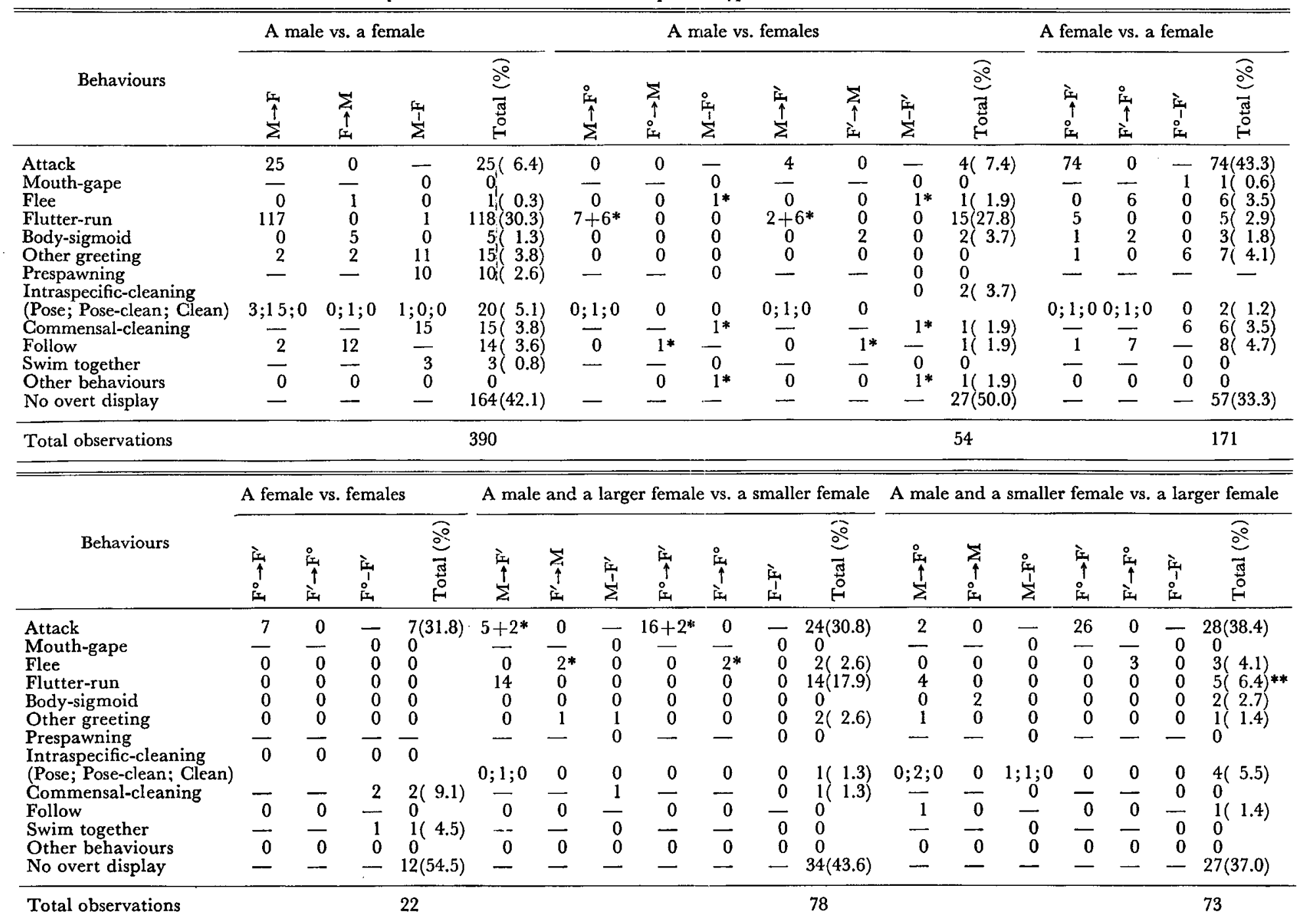

$\mathrm{M}$ : male; $\mathrm{F}$ : female. $\mathrm{F}^{\circ}$ : the larger female, and $\mathrm{F}^{\prime}:$ the smaller female of the two in each encounter.
${ }^{*}$ seen in the same encounter. 
Male and Female vs. Female Encounter: In Table 7, behaviours in the encounters are shown respectively for the "case L" where a male and a large female met with a smaller female, and for the "case $S$ " where the former female was smaller than the latter. In both cases, attacks (mostly between females) were often observed ( $30.8 \%$, $\mathrm{n}=78$ in "case $\mathrm{L}$ "; $38.4 \%, \mathrm{n}=73$ in "case $\mathrm{S}$ "), and flutter-runs by the male were subsequent ( $17.9 \%$ and $6.4 \%$ ). Attacks by the male were not exhibited against its partner and were always against the solitary female $(n=9, P=0.002$, Test of a binominal proportion). Flutter-runs by the male were also almost always exhibited against the solitary female except for one case $(n=19, P=0.00004$, Test of a binominal proportion).

Frequencies of attack by the male against the female did not differ significantly between "case L" and "case S" $(9.0 \%$ and $2.7 \% ; \mathrm{P}=0.204$, Fisher's exact probability test). Also, no significant difference was found between these frequencies and that $(6.4 \%)$ in the encounter between a male and a female (for "case L": P> $0.5, \chi^{2}$-test; for "case $\mathrm{S}$ ": $\mathrm{P}=0.341$, Fisher's exact probability test). Frequencies of attack between females in "case L" $(23.1 \%)$ and "case S" $(35.6 \%)$ did not differ significantly $\left(\mathrm{P}>0.05, \chi^{2}\right.$-test). However, the frequency in "case $\mathrm{L}$ " was significantly lower than that $(43.3 \%)$ in the encounter between a female and a female $\left(\mathrm{P}<0.01, \chi^{2}\right.$-test $)$.

The male displayed flutter-runs somewhat more frequently in "case L" (17.9\%) than in "case $S$ " $(6.4 \%)\left(P>0.05, \chi\right.$ - $^{2}$ test $)$. However, these frequencies were significantly lower than that in the encounter between a male and a female $(30.3 \%)$ $\left(\mathrm{P}<0.001, \chi^{2}\right.$-test $)$.

Other types of encountres (the last two cases in Table 6) were less frequently observed, and are not shown in Table 7. No overt dsiplay was observed in most of these encounters, but attacks (by the male against the female or between females) were sometimes observed.

To sum up the behaviours in encounters, individuals exhibited no overt displays to each other on nearly half of all encounters. Among overt displays, the flutter-run was most frequently observed between a male and a female, and the attack most frequently between females. The frequencies of these behaviours varied according to the composition of members in the encounter.

Frequencies of attack and flutter-run are shown for each size class (Table 8). Males displayed flutter-runs and attacks more frequently in the encounters with the smaller females than in those with larger females $\left(\mathrm{P}<0.02, \chi^{2}\right.$-test). Similarly, attacks by females occurred more frequently in encounters with the smaller females than in those with larger ones $\left(P<0.02, \chi^{2}\right.$-test). Among females only the largest female displayed flutter-runs, but much less frequently than the male did. In contrast to the aggregating rates mentioned before (see Table 5), aggression occurred less frequently in encounters among individuals which often met with each other.

Traces of solitary movements in each individual and the locations of encounters within a primary group are shown for a branching-type polygynous group at St. A in 1974, in Fig. 7 and Fig. 8 respectively. As already mentioned (Fig. 3 and Fig. 

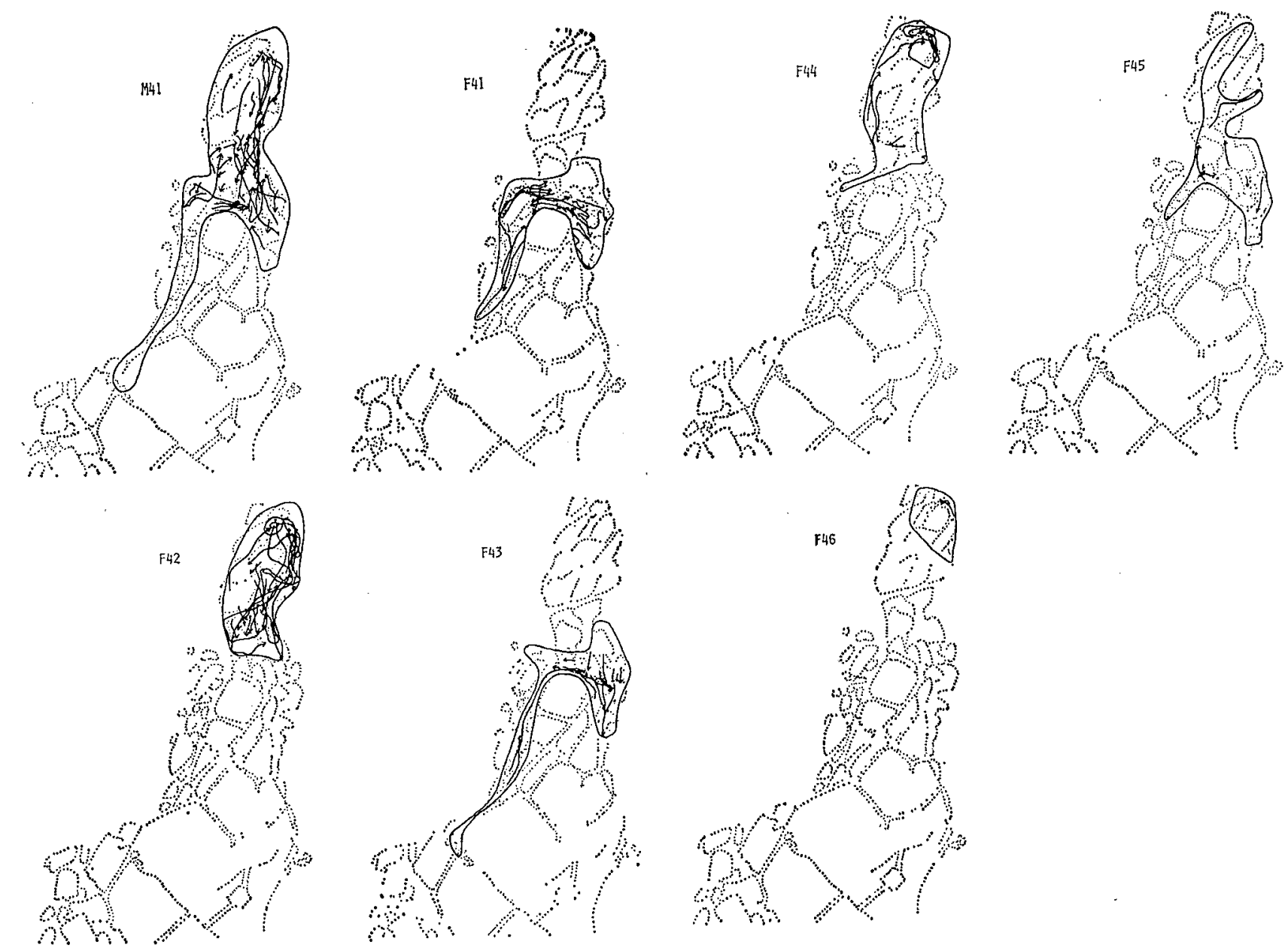

हू.

Fig. 7: Traces of solitary movements of each individual at St. A in the period from June 6 to July 5 in 1974. Outlines of home ranges of each individual are also shown. 

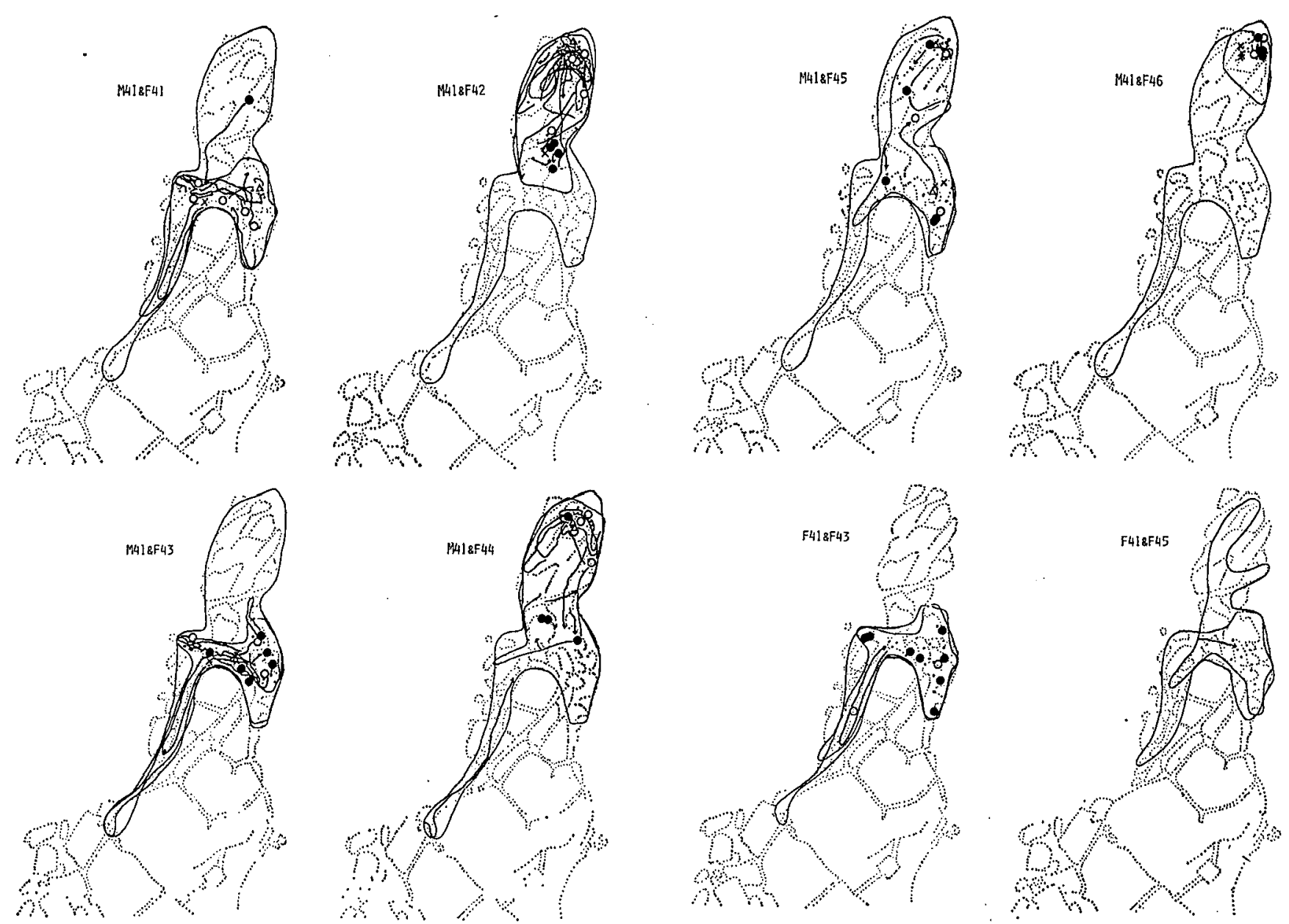

굴

Fig. 8(a). Locations of encounters and traces of mutual swimming for each pair of two individuals, with locations of aggressive and greeting behaviours between the two, at St. A in the period from June 6 to July 5 in 1974 . Outlines of home ranges are also given (narrow lines). 

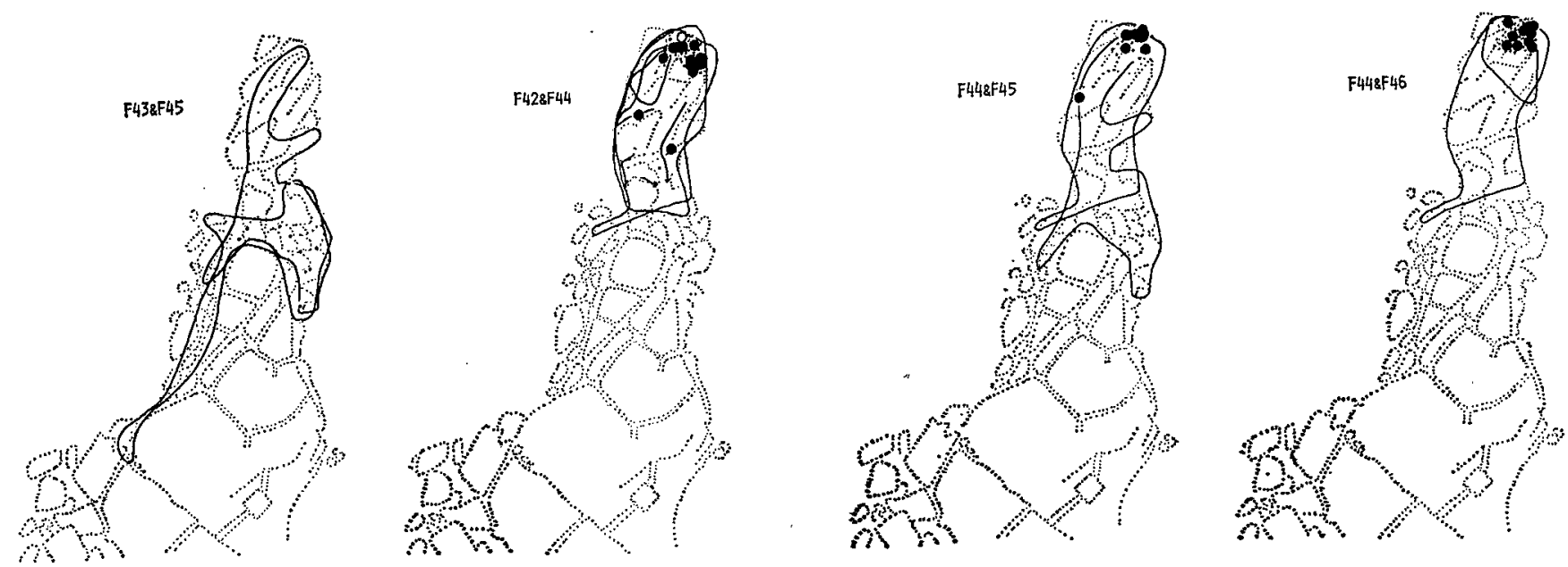

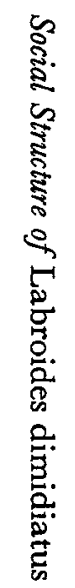
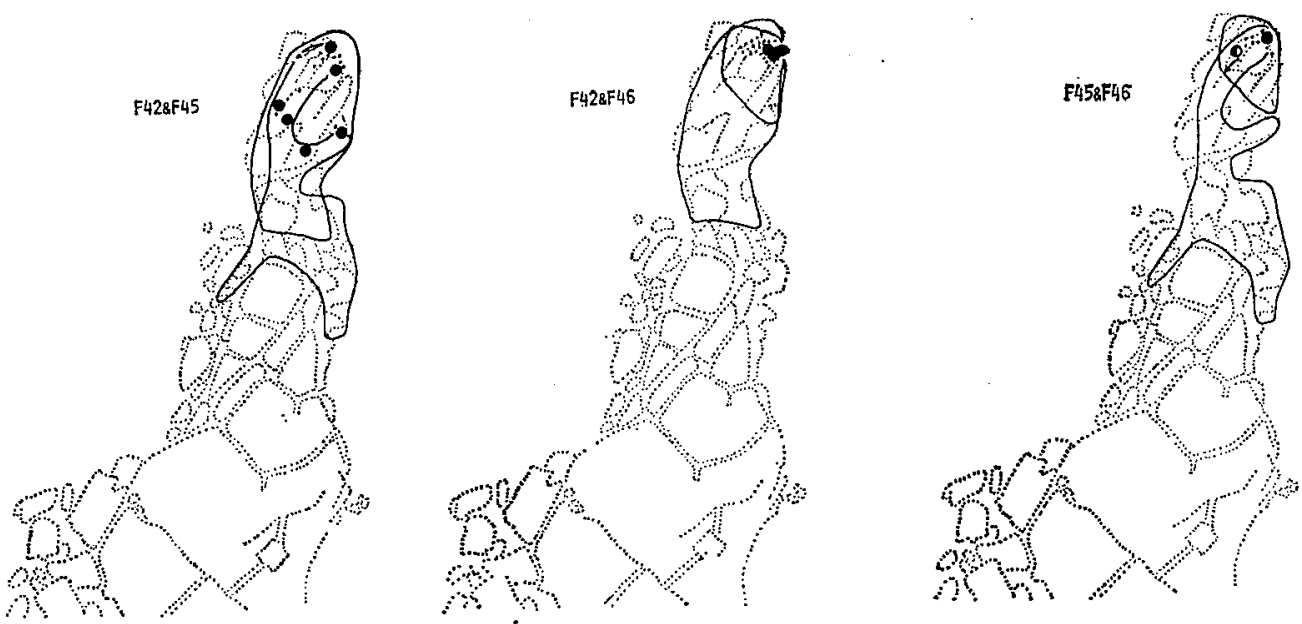

- Attack

- Mouth-gope

- Flutter-run

$\triangle$ Body-slgmold

$x$ Intraspecif lc cleanlng

Fig. 8(b). Explanation see Fig. 8(a). 
Table 8. Frequencies of attacks and flutter-runs on encounters between a male and a female, and those between a female and a female, shown for each size class. M: male, LF: largest female, SL: second largest female, SF : smaller females.

\begin{tabular}{cccl}
\hline & Total no. encounters & Attack+mouth-gape & Flutter-run \\
\hline $\mathrm{M} \rightarrow \mathrm{LF}$ & 141 & $6(4.3 \%)$ & $35(24.8 \%)$ \\
$\mathrm{M} \rightarrow \mathrm{SL}$ & 102 & $2(2.0)$ & $28(27.5)$ \\
$\mathrm{M} \rightarrow \mathrm{SF}$ & 93 & $11(11.8)$ & $31(33.3)$ \\
\hline $\mathrm{LF} \rightarrow \mathrm{SL}$ & 66 & $19(28.8)$ & $5(7.6)$ \\
$\mathrm{LF} \rightarrow \mathrm{SF}$ & 25 & $11(44.0)$ & 0 \\
$\mathrm{SL} \rightarrow \mathrm{SF}$ & 59 & $32(54.2)$ & 0 \\
$\mathrm{SF} \rightarrow \mathrm{SF}$ & 17 & $10(58.8)$ & 0 \\
\hline
\end{tabular}

4), there were one male (M41) and six females, which formed two primary groups: the north group of F42, F44, F46, F45 and M41, and the south group of F41, F43, F45 and M41: the male M4l and the smaller female F45 belonging to both groups. The range covered by solitary movements of each individual was somewhat smaller than its home range; in other words, it sometimes extended its range when it moved with other individuals, especially the opposite sex (compare Fig. 7 and Fig. 8). Encounters between two individuals took place almost all over the overlapping area of their home ranges, and attacks as well (Fig. 8).

\section{Feeding relationships}

Most feeding behaviour (93.4\%) of $L$. dimidiatus was directed against the body surface of other fishes, i.e. "cleaning", though on a few occasions it picked at the rock surface or took benthic organisms. The examination of its gut contents also revealed that it fed mostly on ectoparasitic copepods, fish scales and mucus (see Kuwamura, 1980a).

Feeding (cleaning) occurred mostly solitarily. At St. A in 1974, 83.4\% $(n=$ 289) of cleaning took place when no other individual was found cleaning within one-meter distance from the cleaner. In a few cases $(9.0 \%)$, however, two or more individuals cleaned the same host fish at the same time (i.e. "commensal-cleaning"). The frequency of the commensal-cleaning was higher in males with females $(37.0 \%$, $\mathrm{n}=27)$ than in females $(6.1 \%, \mathrm{n}=262)\left(\mathrm{P}<0.001, \chi^{2}\right.$-test; also see Fig. 9).

The sites where feeding (mostly cleaning) behaviours of each individual were observed are shown for St. A in June, 1974 (Fig. 9) and in April to July, 1975 (Fig. 10). In 1974, within each primary group, feeding sites of its members largely overlapped each other. The overlap of feeding sites within a primary group was also found in 1975. In that year, however, those of some females, especially those of size-classes near to each other in each primary group, only slightly overlapped, even though their home ranges largely overlapped: e.g. between F2 and F3 in April, F3 and F5 in April to July, F5 and F6 in April to June, etc. (see Fig. 10). (Factors of the change of feeding sites in 1975 will be discussed in a later section.) Even in such cases, the exclusive feeding sites were seldom defended by attacks, and the 

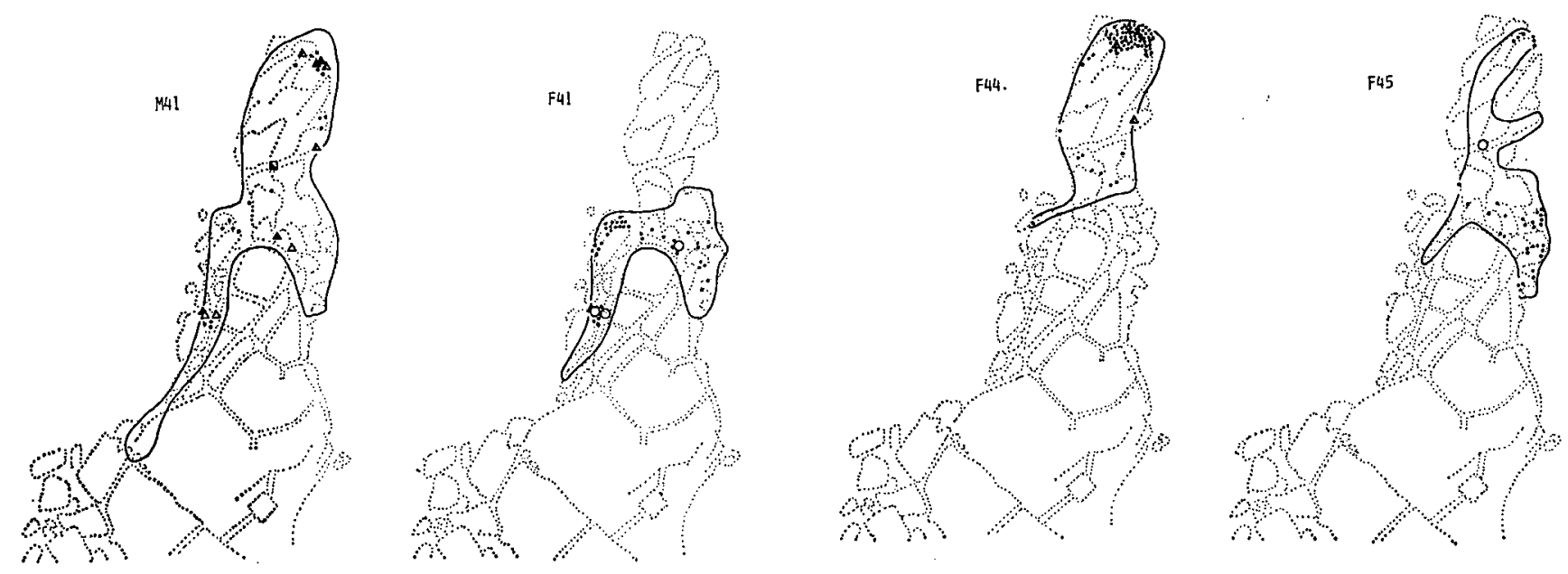

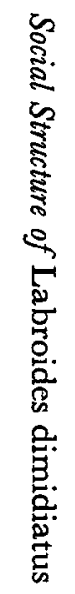
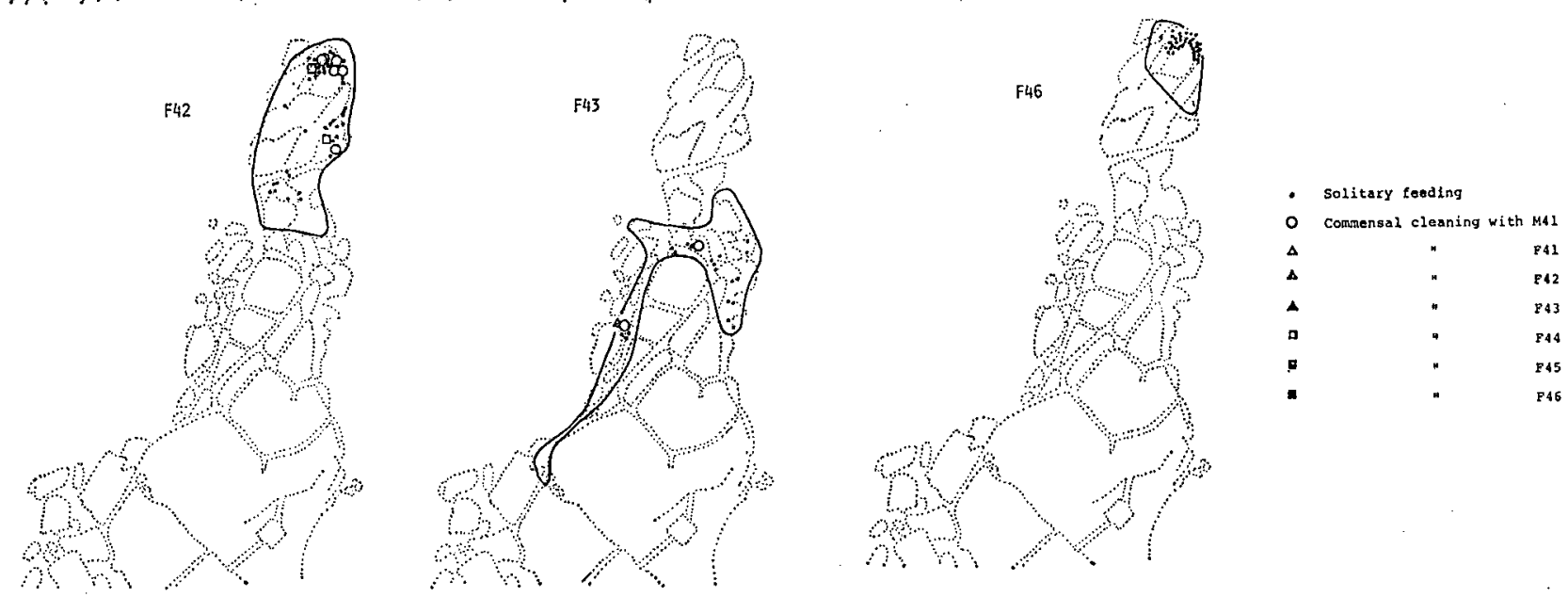

Fig. 9. Feeding sites of each individual at St. A in the periods from June 6 to July 5 in 1974. Outlines of home ranges are also shown. 

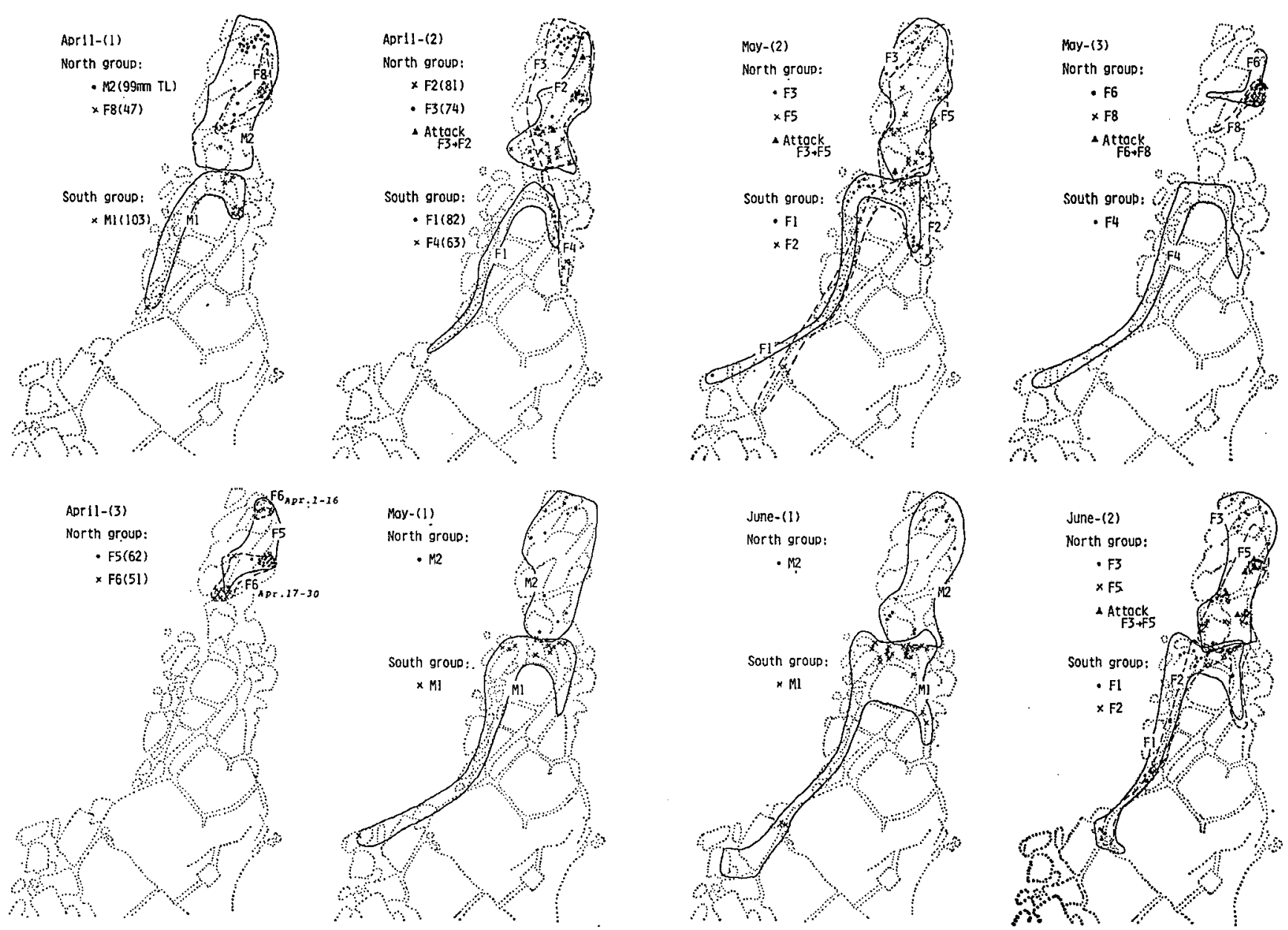

Fig. 10(a). Feeding sites of each individual at St. A in April, May, June and July of 1975 . Locations of attacks between two fishes of similar size-classes given in one map are also shown. 

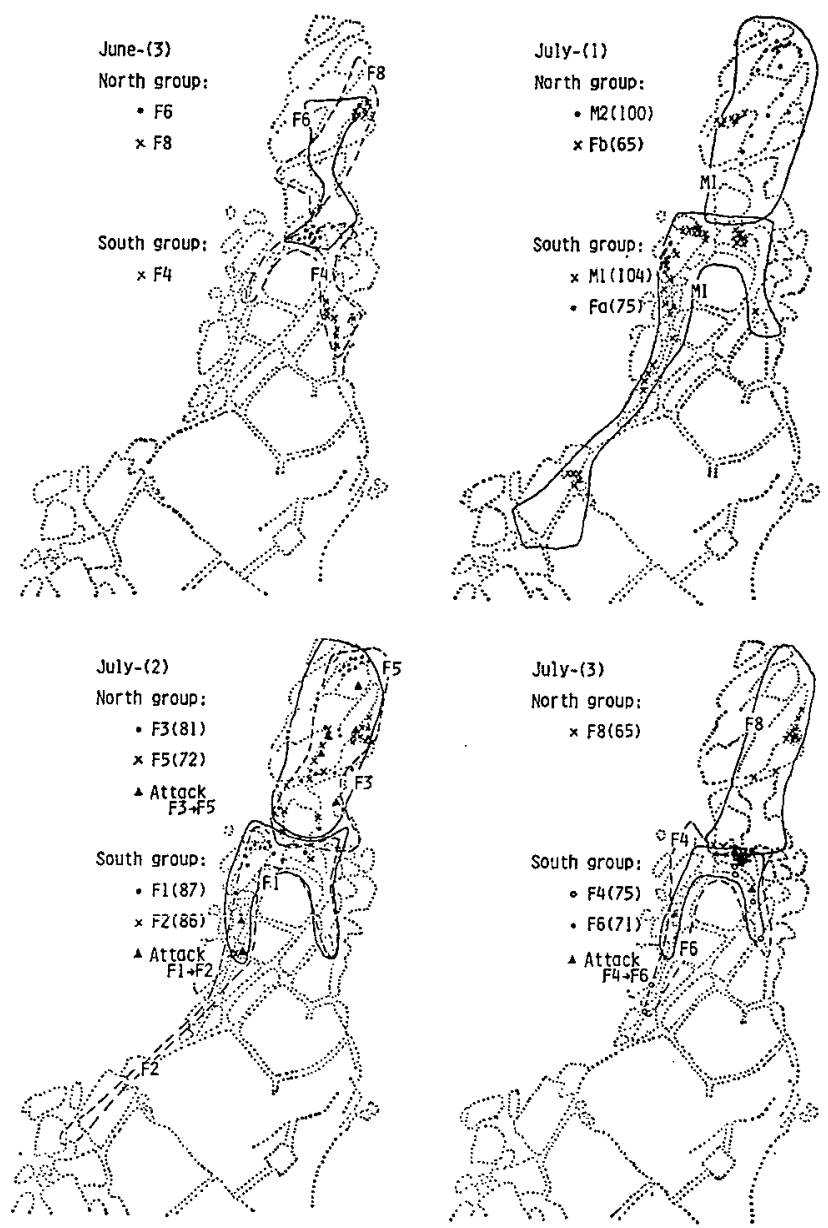

Fig. 10(b). Explanation see Fig. 10(a).

attacks were observed irrespective of place within the overlapping area of their home ranges (see Fig. 10) as in 1974 (see Fig. 8 and Fig. 9).

The behaviours during encouters when one or both of the participants were cleaning a host fish are listed in Table 9. In about half of the encounters no overt displays took place. When a male was cleaning and a female approached it, commensal-cleaning most often $(17.4 \%, \mathrm{n}=23)$ occurred, but attack and flutter-run by the male against the female were sometimes exhibited instead. When a female was cleaning and a male approached it, the flutter-run by the male was most often observed $(20.8 \%, \mathrm{n}=72)$, and the commensal-cleaning occurred less frequently $(8.3 \%)$. However, the differences in the frequencies of commensal-cleaning and flutter-run between the two cases were not significant $(P=0.375$ and $P=0.318$ respectively, Fisher's exact probability test). Some other displays such as "intraspecific-cleaning" (see p. 142) also resulted from the encounters.

In encounters between females, commensal-cleaning took place almost as often 
Table 9. Behaviours in the encounters when one or both individuals had been cleaning. Symbols of sex are the same as in Table 7.

\begin{tabular}{|c|c|c|c|c|c|c|}
\hline \multirow{2}{*}{ Behaviour } & \multicolumn{3}{|c|}{$\mathrm{M}-\mathrm{F}$ encounters } & \multicolumn{3}{|c|}{$\mathrm{F}-\mathrm{F}$ encounters } \\
\hline & $M$ cleaning & F cleaning & $\begin{array}{l}\text { both } \\
\text { cleaning }\end{array}$ & $\mathrm{F}^{\circ}$ cleaning & $F^{\prime}$ cleaning & $\begin{array}{l}\text { both } \\
\text { cleaning }\end{array}$ \\
\hline Commensal-cleaning & $4(17.4 \%)$ & $6(8.3)$ & 0 & $2(7.1)$ & $6(14.0)$ & 0 \\
\hline Attack & $2(8.7)$ & 0 & $1(14.3)$ & $15(53.6)$ & $9(20.9)$ & 0 \\
\hline Flee & 0 & $2(2.8)$ & 0 & 0 & $9(20.9)$ & 0 \\
\hline Flutter-run & $2(8.7)$ & $15(20.8)$ & $1(14.3)$ & 0 & $1(2.3)$ & 0 \\
\hline Body-sigmoid & $1(4.3)$ & 0 & $2(28.6)$ & 0 & 0 & 0 \\
\hline Other greeting & $1(4.3)$ & $1(1.4)$ & 0 & 0 & 0 & 0 \\
\hline Prespawning & 0 & $1(1.4)$ & 0 & - & - & 一 \\
\hline Intraspecific-cleaning & $2(8.7)$ & $3(4.2)$ & $1(14.3)$ & 0 & 0 & 0 \\
\hline Follow & $1(4.3)$ & $1(1.4)$ & 0 & 0 & 0 & 0 \\
\hline Swim together & 0 & $1(1.4)$ & 0 & 0 & 0 & 0 \\
\hline No overt display & $10(43.5)$ & $42(58.3)$ & $2(28.6)$ & $11(39.3)$ & $18(41.9)$ & 0 \\
\hline Total observations & 23 & 72 & 7 & 28 & 43 & 0 \\
\hline
\end{tabular}

$(11.3 \%, \mathrm{n}=71)$ as in the above case $\left(\mathrm{P}>0.95, \chi^{2}\right.$-test $)$. Attacks by a larger female occurred very often $(53.6 \%, \mathrm{n}=28)$ when it was cleaning and a smaller one apporached it. When a smaller female was cleaning, attacks by a larger one took place less frequently $(20.9 \%, \mathrm{n}=43)$ than the above case $\left(\mathrm{P}<0.01, \chi^{2}\right.$-test $)$, and the smaller one often $(20.9 \%)$ fled without receiving any attack from the larger one. The frequency of attack in cleaning encounters between females $(33.8 \%, \mathrm{n}=71)$ was significantly higher than that between a male and a female $(2.9 \%, n=102)(\mathrm{P}<$ $0.001, \chi^{2}$-test). However, these frequencies did not significantly differ from those in usual encounters given in Table 7 ( $P>0.2$ and $\mathrm{P}>0.2$ respectively, $\chi^{2}$-test).

\section{Mating relationships}

Spawning in $L$. dimidiatus always took place in pairs of single males and single females. The male often courted with most females within its home range during the breeding time of the day, lasting about two hours around noon (Kuwamura, 1981a, 1981b).

The main courtship behaviour by the male was the flutter-run, and that by the female was the body-sigmoid in which its swollen abdomen was displayed towards the male. These courtship behaviours were shown, as the male and the female swam together or followed each other, and then prespawning behaviours commenced.

The usual sequence of spawning was as follows. The male took a position upon the female ("straddling" of Robertson, 1974), and the two slowly rose obliquely upwards away from the substrate for less than a few meters. Then the velocity of the upward swimming increased abruptly ("upward-rush" of Robertson, 1974), and at the top of the upward-rush the gametes were released, and then the two descended towards the substrate. However, in some cases, when the male began straddling the female, the latter slipped away from the usual position, and the two began circling 
("circling" of Robertson, 1974). The two gradually rose slowly away from the substrate in ascending spirals, with the male always above the female ("spiralling" of Robertson, 1974), and this was followed by the rapid upward-rush and spawning.

Prespawning behaviours, i.e. straddling and circling, did not always result in the upward-rush and spawning, but were often interrupted and repeated again and again before spawning occurred. The courtship behaviours, i.e.the flutter-run and body-sigmoid, were often inserted between prespawning behaviours; on the contrary, in a few cases, prespawning behaviours were immediately assumed without any courtship behaviours (see Table 7). The upward-rush did not always result in releasing gametes ("pseudospawning" of Robertson, 1974). The male often attacked its partner when the upward-rush was not fully completed, as well as in the preparatory phases of spawning in several cases.

The sites where spawning and prespawning behaviours were observed are shown for St. A in 1974 (Fig. 11) and 1975 (Fig. 12). In each primary group, females

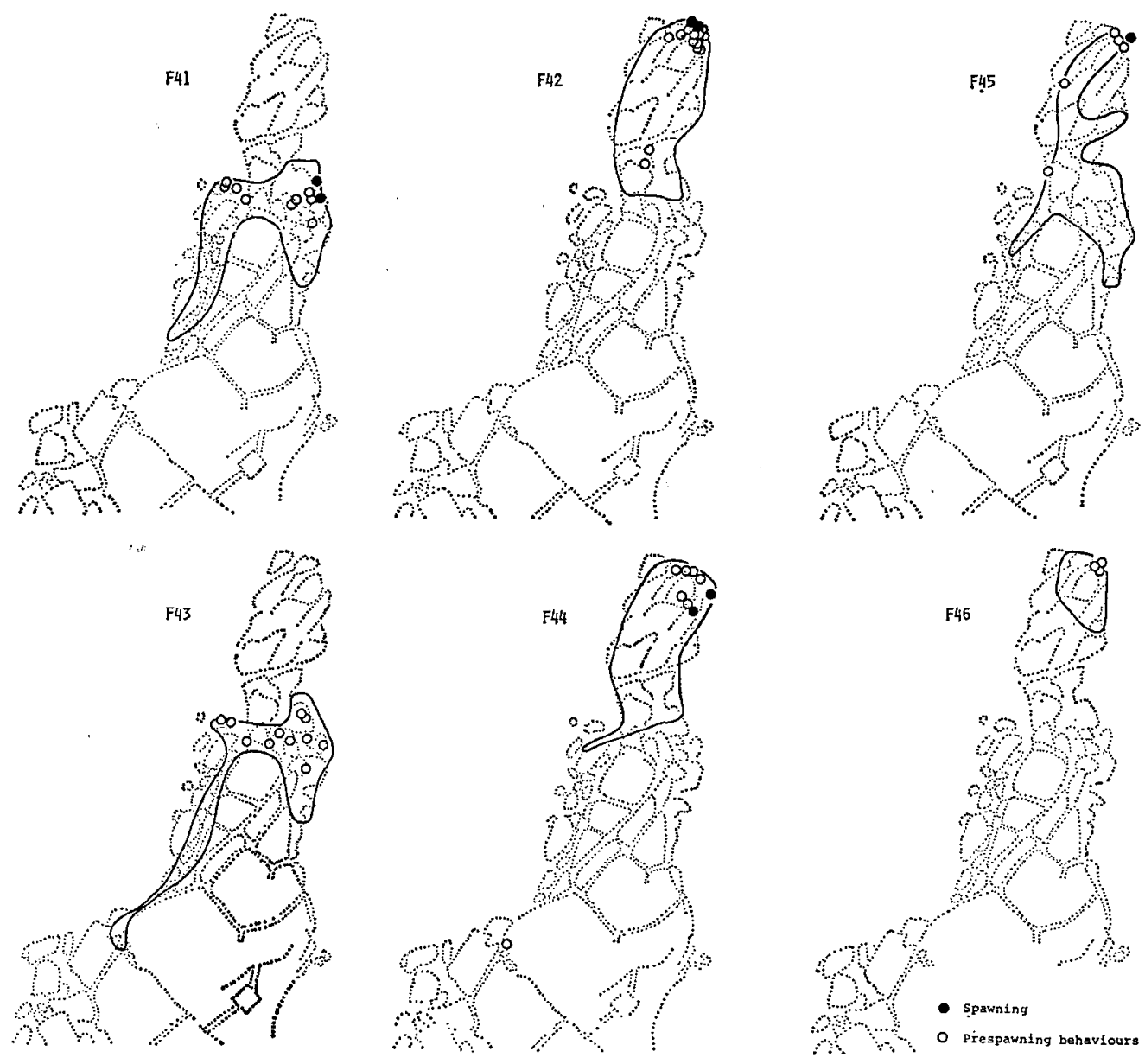

Fig. 11. Sites of mating behaviours for each female at St. A in the period from June 6 to July 5 in 1974. Outlines of home ranges are also shown. 

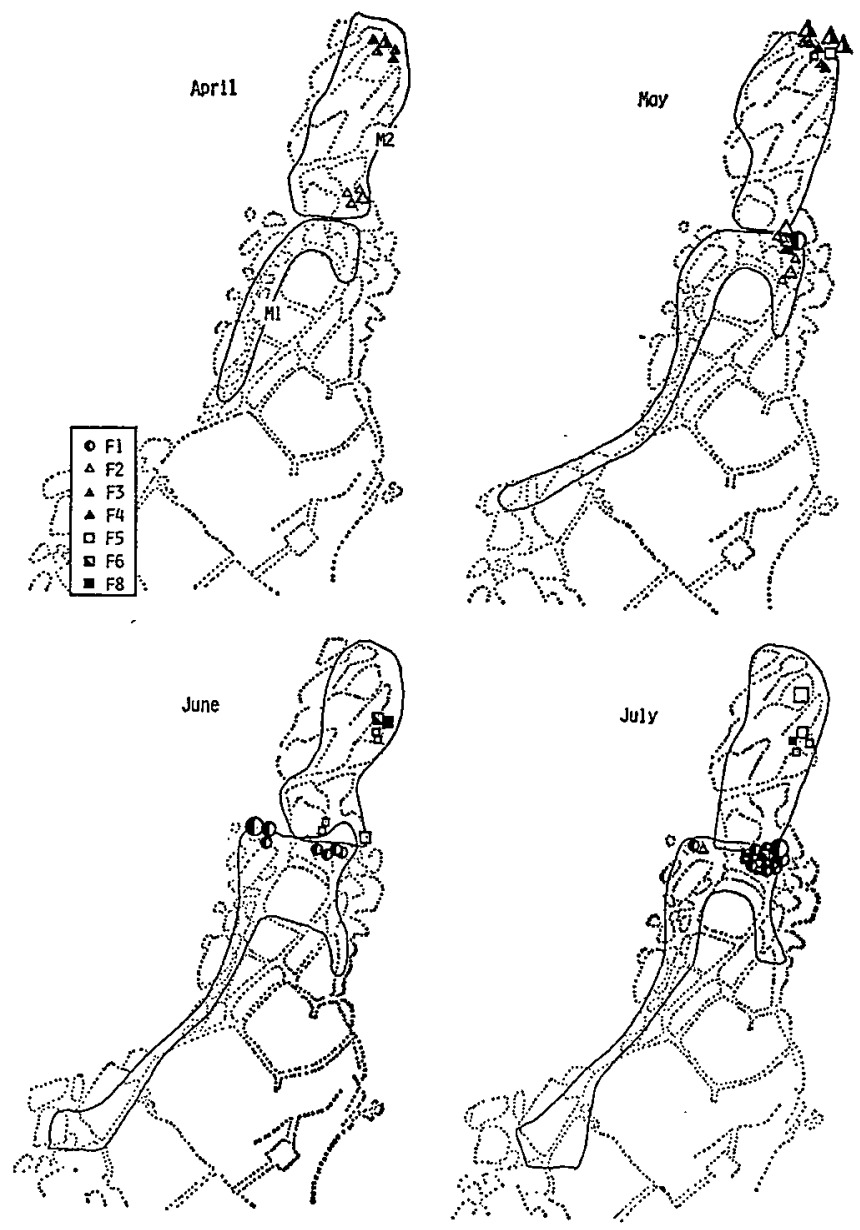

Fig. 12. Sites of mating behaviours for each female at St. 'A in April, May, June and July in 1975. Large symbols: spawning; middle-size symbols: pseudospawning; small symbols: prespawning behaviours.

had common spawning sites, near the offshore side of their home ranges. Prespawning behaviours were also performed mostly concentrated near the spawning sites. To cite an excellent example, a female (F45), which belonged to two primary groups in 1974, concentrated its spawning acts at the offshore side of the range of the offshore group (Fig. 11), while its feeding activity was performed mostly within the range of the inshore group (Fig. 9).

During the spawning sequence, the pair often met with other females. The behaviours in such encounters and whether the female partner was changed or not after the encounter are shown in Table 10 (also see Table 7). Attacks by larger females against smaller ones were often observed. The male often displayed flutterruns against females in these aggressive encounters. Aggression between females 
Table 10. Change of the female partner in the encounters between a pair and another female, with behaviours before the change.

\begin{tabular}{|c|c|c|c|c|c|c|}
\hline \multirow{2}{*}{ Preceding behaviours } & \multicolumn{3}{|c|}{$\mathbf{M} \& \mathrm{~F}^{\circ}$ vs. $\mathbf{F}^{\prime}$} & \multicolumn{3}{|c|}{$\mathrm{M} \& \mathrm{~F}^{\prime}$ vs. $\mathrm{F}^{\circ}$} \\
\hline & not changed & changed & Total & not changed & changed & Total \\
\hline Attack $\mathrm{F}^{\circ} \rightarrow \mathrm{F}^{\prime}$ & 14 & 4 & 18 & 13 & 7 & 20 \\
\hline $\mathrm{M} \rightarrow \mathrm{F}^{\circ}$ & 0 & 0 & 0 & 1 & 1 & 2 \\
\hline $\mathrm{M} \rightarrow \mathrm{F}^{\prime}$ & 3 & 1 & 4 & 0 & 1 & 1 \\
\hline Flutter-run $\mathrm{M} \rightarrow \mathrm{F}^{\circ}$ & 0 & 0 & 0 & 0 & 2 & 2 \\
\hline $\mathrm{M} \rightarrow \mathrm{F}^{\prime}$ & 5 & 3 & 8 & 0 & 0 & 0 \\
\hline Body-sigmoid $\mathrm{F}^{\circ} \rightarrow \mathrm{M}$ & 0 & 1 & 1 & 1 & 0 & 1 \\
\hline$F^{\prime} \rightarrow M$ & 1 & 0 & 1 & 0 & 0 & 0 \\
\hline Pose; clean $\mathrm{M}-\mathrm{F}^{\prime}$ & 0 & 1 & 1 & 0 & 0 & 0 \\
\hline No overt display & 13 & 2 & 15 & 9 & 5 & 14 \\
\hline Total observations & $\begin{array}{c}36 \\
(75.0 \%)\end{array}$ & $\begin{array}{l}12 \\
(25.0 \%)\end{array}$ & 48 & $\begin{array}{l}24 \\
(60.0 \%)\end{array}$ & $\begin{array}{c}16 \\
(40.0 \%)\end{array}$ & 40 \\
\hline
\end{tabular}

was not always followed by a change of partners, whereas such a change sometimes occurred even without any aggression. A male's change of female partner occurred somewhat more often $(40.0 \%, \mathrm{n}=40)$ when the female of the pair was smaller than the solitary female, than when the former was larger than the latter $(25.0 \%, n=48)$, but the difference was not significant $\left(\mathrm{P}>0.2, z^{2}\right.$-test $)$.

\section{Aggression, appeasement and dominance hierarchy}

Occurrence of aggressive behaviours, i.e. the attack and mouth-gape, among members of a primary group is shown for several groups (Table 11). Although there were occasional pairs of individuals showing no aggression to each other, there generally existed a linear peck-right within a group.

Aggression by the lower-ranking individual against the higher-ranking one was exceptionally observed in the following few cases: F45 exhibited a short attack against F44 (St. A in 1974); F518 made a weak counter-attack against F511 (St. B in 1975); F45 and F46 mutually mouth-gaped (St. A in 1974); M52 and F52 mutually mouth-gaped (St. B in 1975). Except for the second case, these were between individuals of neighbouring ranks. Except for these, aggression was exhibited onesidedly by the higher-ranking individual against the lower-ranking one, without any counter-attack or mouth-gape.

Larger individuals usually dominated smaller ones, except for one instance, i.e. F3 (74 mm in total length) dominated F2 $(81 \mathrm{~mm})$ in April, 1975 at St. A, before the latter moved its home range into the neighbouring group in May. Thus, within a primary group there was a size-based, linear peck-right with the male at its top.

Aggression occurred in various situations. Behaviours occurring just before aggression are listed in Table 12. Aggression was often exhibited just on meeting or in coexisting without any overt display. Prespawning and pseudospawning also 
Table 11. Sociograms in five primary groups. Numbers of attack and mouth-gape (in parentheses) between individuals of respective pairs are shown.

St. A '74 June-July

(North Group)

\begin{tabular}{c|rrrrr|c}
\hline & M41 & F42 & F44 & F45 & F46 & $\begin{array}{c}\text { Total } \\
\text { loss }\end{array}$ \\
\hline M41 & $*$ & & & & & 0 \\
F42 & 3 & $*$ & & & & 3 \\
F44 & 4 & 13 & $*$ & 1 & & 18 \\
F45 & 5 & 6 & 9 & $*$ & $(1)$ & $20(1)$ \\
F46 & 4 & 4 & 10 & $1(1)$ & $*$ & $19(1)$ \\
\hline $\begin{array}{c}\text { Total } \\
\text { win }\end{array}$ & 16 & 23 & 19 & $2(1)$ & $0(1)$ & \\
\hline
\end{tabular}

(South Group)

\begin{tabular}{c|cccc|c}
\hline \hline & M41 & F41 & F43 & F45 & $\begin{array}{c}\text { Total } \\
\text { loss }\end{array}$ \\
\hline M41 & $*$ & & & & 0 \\
F41 & 1 & $*$ & & & 1 \\
F43 & 6 & 9 & $*$ & & 15 \\
F45 & 5 & & & $*$ & 5 \\
\hline $\begin{array}{c}\text { Total } \\
\text { win }\end{array}$ & 12 & 9 & 0 & 0 & \\
\hline
\end{tabular}

St. A '75 June

(North Group)

\begin{tabular}{l|ccccc|c}
\hline \hline & M2 & F3 & F5 & F6 & F8 & $\begin{array}{c}\text { Total } \\
\text { loss }\end{array}$ \\
\hline M2 & $*$ & & & & & 0 \\
F3 & 1 & $*$ & & & & 1 \\
F5 & & 5 & $*$ & & & 5 \\
F6 & & 1 & & $*$ & & 1 \\
F8 & 2 & 1 & 1 & & $*$ & 4 \\
\hline $\begin{array}{c}\text { Total } \\
\text { win }\end{array}$ & 3 & 7 & 1 & 0 & 0 & \\
\hline
\end{tabular}

(South Group)

\begin{tabular}{l|ccccc|c}
\hline & M1 & F1 & F2 & F4 & F6 & $\begin{array}{c}\text { Total } \\
\text { loss }\end{array}$ \\
\hline M1 & $*$ & & & & & 0 \\
F1 & 5 & $*$ & & & & 5 \\
F2 & 1 & & $*$ & & & 1 \\
F4 & & & & $*$ & & 0 \\
F6 & & 1 & & & $*$ & 1 \\
\hline $\begin{array}{c}\text { Total } \\
\text { win }\end{array}$ & 6 & 1 & 0 & 0 & 0 & \\
\hline
\end{tabular}

St. B '75 June-July

(East Group)

\begin{tabular}{l|llllllll|l}
\hline \hline & M52 & F52 & F53 & F510 & F511 & F513 & F514 & F518 & $\begin{array}{l}\text { Total } \\
\text { loss }\end{array}$ \\
\hline M52 & $*$ & $(4)$ & & & & & & & $0(4)$ \\
F52 & $2(4)$ & $*$ & & & & & & & $2(4)$ \\
F53 & & 2 & $*$ & & & & & & 2 \\
F510 & 1 & 2 & & $*$ & & & & & 3 \\
F511 & 4 & & 1 & & $*$ & & & 1 & 6 \\
F513 & 6 & 2 & 1 & & & $*$ & & & 9 \\
F514 & 1 & & & 2 & & & $*$ & & 3 \\
F518 & & & & 1 & 1 & & 1 & $*$ & 3 \\
\hline $\begin{array}{c}\text { Total } \\
\text { win }\end{array}$ & $14(4)$ & $6(4)$ & 2 & 3 & 1 & 0 & 1 & 1 & \\
\hline
\end{tabular}

brought about aggression both from the male against the female and between females. Cleaning behaviours often elicited aggression between females. Intraspecific cleaning (inspecting and cleaning by the female) also often resulted in aggression by the male; especially when the male was not posing, and the female picked at the body of the male too vigorously, or in the sequence of repeated attacks as mentioned below.

Behaviours just after aggression are also shown in Table 13. In many cases, even if aggression occurred, no overt display took place, and mating or cleaning often commenced again. Intraspecific cleaning (posing by the male and inspecting and 
Table 12. Behaviours just before aggression in primary groups. Frequencies of each behaviour are shown for respective types of aggregation in which attacks occurred.

\begin{tabular}{|c|c|c|c|c|c|}
\hline \multirow{2}{*}{ Preceding behaviours } & \multicolumn{2}{|c|}{$M$ attack $F$} & \multicolumn{3}{|c|}{ F attack F } \\
\hline & in $\mathrm{MF}$ & MFF & FF & FFF & MFF \\
\hline Attack $\mathrm{M} \rightarrow \mathrm{F}^{\circ}$ & & 1 & & & 1 \\
\hline $\mathrm{M} \rightarrow \mathrm{F}^{\prime}$ & 1 & & & & 2 \\
\hline$F^{\circ} \rightarrow F$ & & & & & 1 \\
\hline $\mathbf{F} \rightarrow \mathrm{F}^{\prime}$ & & & & & 1 \\
\hline $\mathbf{F}^{\circ} \rightarrow \mathrm{F}^{\prime}$ & & & 1 & & \\
\hline $\mathrm{F}^{\prime} \rightarrow$ other sp. & 2 & & & & \\
\hline Mouth-gape M-F' & 2 & & & & \\
\hline Flee $F^{\prime}$ & 1 & & 2 & 1 & 2 \\
\hline Flutter-run $\mathrm{M} \rightarrow \mathrm{F}^{\circ}$ & & & & & 2 \\
\hline $\mathbf{M} \rightarrow \mathrm{F}^{\prime}$ & 2 & & & & 4 \\
\hline $\mathbf{M} \rightarrow \mathbf{F}$ & & 2 & & & \\
\hline Body-sigmoid $\mathrm{F}^{\circ} \rightarrow \mathrm{M}$ & & & & & 1 \\
\hline $\mathrm{F}^{\prime} \rightarrow \mathrm{M}$ & & & & & 1 \\
\hline $\mathrm{F}^{\prime} \rightarrow \mathrm{F}^{\circ}$ & . & & 1 & & \\
\hline Other greeting & & 1 & & & 1 \\
\hline Prespawning $\overline{\mathbf{M}}-\overline{\mathbf{F}}^{-}$ & & & & & 9 \\
\hline $\mathrm{M}-\mathrm{F}^{\prime}$ & 7 & & & & 13 \\
\hline $\mathbf{M}-\mathbf{F}$ & & 6 & & & \\
\hline Pseudospawning $\mathbf{M}-\mathbf{F}^{\prime}$ & 5 & & & & \\
\hline Follow $\mathrm{M} \rightarrow \mathrm{F}^{\prime}$ & 2 & & & & 1 \\
\hline$F^{\prime} \rightarrow M$ & 1 & 1 & & & 1 \\
\hline$F^{\prime} \rightarrow F^{\circ}$ & & & & 1 & \\
\hline$F^{\prime} \rightarrow F$ & & 1 & & & \\
\hline Pose; clean $\mathrm{M}-\mathrm{F}^{\prime}$ & 10 & & & & \\
\hline$F^{\circ}-F^{\prime}$ & & & 1 & & \\
\hline $\mathbf{M}-\mathbf{F}$ & & 1 & & & \\
\hline Mutual clean $\mathbf{M}-\mathbf{F}$ & & 1 & & & \\
\hline Cleaning $\mathrm{M}$ & 2 & & & & \\
\hline$F^{\circ}$ & & & 11 & & 3 \\
\hline$F^{\prime}$ & & & 9 & & 1 \\
\hline each & 1 & & & & 1 \\
\hline Commensal-cleaning $\mathrm{M}-\mathrm{F}^{\circ}$ & & & & & 1 \\
\hline $\mathbf{M}-\mathbf{F}^{\prime}$ & 1 & & & & 1 \\
\hline Coexisting & 9 & 2 & 5 & 2 & 15 \\
\hline Meeting & 9 & 9 & 30 & 5 & 18 \\
\hline No overt display & 10 & & 32 & & \\
\hline Total & 65 & 25 & 92 & 9 & 80 \\
\hline
\end{tabular}


Table 13. Behaviours just after aggression in primary groups.

\begin{tabular}{|c|c|c|c|c|c|}
\hline \multirow{2}{*}{ Succeeding behaviours } & \multicolumn{2}{|c|}{$\mathbf{M}$ attack $\mathbf{F}$} & \multicolumn{3}{|c|}{ F attack $F$} \\
\hline & in $\mathrm{MF}$ & MFF & FF & FFF & MFF \\
\hline Attack $M \rightarrow F^{\prime}$ & 2 & 1 & & & 2 \\
\hline$M \rightarrow F$ & & 1 & & & 1 \\
\hline $\mathrm{F}^{\circ} \rightarrow \mathrm{F}^{\prime}$ & & & 1 & & \\
\hline $\mathbf{F}^{\prime} \rightarrow \mathbf{F}$ & 1 & & & & \\
\hline $\mathrm{F}^{\prime} \rightarrow \mathrm{F}^{\circ}$ & & & 1 & & \\
\hline Mouth-gape $\mathbf{M}-\mathrm{F}^{\prime}$ & 1 & 1 & & & \\
\hline Flutter-run $\mathrm{M} \rightarrow \mathrm{F}^{\circ}$ & & & & 1 & 5 \\
\hline $\mathbf{M} \rightarrow \mathbf{F}^{\prime}$ & 1 & & 1 & & 2 \\
\hline $\mathrm{M} \rightarrow \mathrm{F}^{\circ} \mathrm{F}^{\prime}$ & & & 2 & & 6 \\
\hline $\mathrm{M} \rightarrow \mathrm{F}$ & 1 & & & & \\
\hline Body-sigmoid $F^{\prime} \rightarrow M$ & 2 & & 1 & & 2 \\
\hline$F^{\prime} \rightarrow F^{\circ}$ & & & 2 & & 1 \\
\hline Other greeting $\mathrm{F}^{\prime}$ & 1 & & 1 & & \\
\hline Prespawning $\mathrm{M}-\mathrm{F}^{\circ}$ & & & & & 10 \\
\hline $\mathrm{M}-\mathrm{F}^{\prime}$ & 2 & 1 & & & 11 \\
\hline $\mathrm{M}-\mathrm{F}$ & & 5 & & & \\
\hline Follow $\mathrm{M} \rightarrow \mathrm{F}^{\prime}$ & 2 & & & & \\
\hline $\mathrm{M} \rightarrow \mathrm{F}^{\circ}$ & & & & & 1 \\
\hline $\mathrm{F}^{\circ} \rightarrow \mathrm{M}$ & & & & & 3 \\
\hline $\mathrm{F}^{\prime} \rightarrow \mathrm{M}$ & 3 & 1 & & & \\
\hline$F^{\prime} \rightarrow F^{\circ}$ & & & 2 & & 1 \\
\hline Swim together both & 3 & & 1 & & 2 \\
\hline$F^{\circ}-F$ & & & 1 & & 1 \\
\hline$F^{\circ}-M$ & & & & & 2 \\
\hline Pose; clean attacker-attackee & 14 & 1 & 3 & & 1 \\
\hline Cleaning attacker & 2 & 2 & 6 & 1 & 5 \\
\hline attackee & 3 & 1 & 5 & 2 & 1 \\
\hline each & 3 & & 2 & 1 & 3 \\
\hline No overt display & 24 & 11 & 63 & 4 & 20 \\
\hline Total & 65 & 25 & 92 & 9 & 80 \\
\hline
\end{tabular}

cleaning by the female) was also often observed. While fleeing from the male after being attacked by it, the female stopped to wait for the male, and when the male caught up with it, the female began to inspect the body of the male, the latter stopping to pose. Thus, aggression by the male seems to have been appeased by the inspecting by the female. Sometimes the male attacked the female again after being cleaned for a moment, and cleaning and attacks were repeated several times in some cases. Between females such cleaning after aggresison was also observed, but less frequently than between two sexes. Though intraspecific cleaning itself was observed in various contexts of encounters other than aggressive ones, a considerable number of the total bouts occurred after aggression (Table 14). 
Table 14. Behaviours just before intraspecific cleaning.

$P$ : pose; $\mathrm{C}$ : clean or inspect; $\mathrm{x}$ : no response.

\begin{tabular}{|c|c|c|c|c|c|c|c|c|c|c|c|c|c|}
\hline \multirow[b]{2}{*}{ Preceding Behaviours } & \multicolumn{9}{|c|}{ Male-female } & \multicolumn{4}{|c|}{ Female-female } \\
\hline & $\stackrel{i}{x}^{x}$ & $\begin{array}{l}0 \\
1 \\
2\end{array}$ & 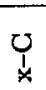 & $\begin{array}{l}\overrightarrow{1}_{1} \\
2_{1}\end{array}$ & $R_{\substack{1 \\
x}}$ & $\frac{1}{0}$ & $u_{0}^{x}$ & $\begin{array}{l}0 \\
0 \\
0\end{array}$ & $\underset{ث}{\text { 吾 }}$ & $\begin{array}{l}U \\
I \\
\sim\end{array}$ & 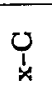 & $\frac{1}{0}$ & 胥 \\
\hline Meeting & 4 & 12 & 3 & 2 & 1 & & & 1 & 23 & 3 & & & 3 \\
\hline Coexisting & 2 & 6 & 1 & 5 & & 2 & & & 16 & & & 1 & 1 \\
\hline Swim together & 1 & 1 & & 1 & & & & & 3 & & & & \\
\hline Follow $\mathrm{F} \rightarrow \mathrm{M}$ & 1 & 1 & & & & 1 & & & 3 & & & & \\
\hline Flutter-run $\mathrm{M} \rightarrow \mathrm{F}$ & 2 & 4 & 2 & 1 & & 2 & 2 & & 13 & & & & \\
\hline Body-sigmoid $F \rightarrow M$ & & 4 & & & & & & & 4 & & & & \\
\hline Other greeting $M \rightarrow F$ & & 1 & & & & & & & 1 & & & & \\
\hline Prespawning & 1 & 1 & & 1 & & 1 & & & 4 & & & & \\
\hline Commensal-cleaning & & 1 & & & & & 1 & & 2 & & & & \\
\hline Cleaning $\mathbf{M}$ & & & 1 & & & 1 & & & 2 & & & & \\
\hline $\mathbf{F}$ & 4 & 1 & & & & & & & 5 & & & & \\
\hline each & & 1 & & & & 1 & & & 2 & & & & \\
\hline Pose; clean M-F & & & & & 1 & 3 & & & 4 & & & & \\
\hline F-M & 1 & & & & & & & & 1 & & & & \\
\hline Mutlual pose & & 1 & & & & 1 & & & 2 & & & & \\
\hline Attack & & 14 & 1 & & & & & & 15 & 3 & 1 & & 4 \\
\hline Total & 16 & 48 & 8 & 10 & 2 & 12 & 3 & 1 & 100 & 6 & 1 & 1 & 8 \\
\hline
\end{tabular}

In aggression between females, the male sometimes displayed the flutter-run against one or both of the females (Table 13), and then the aggression ceased. Thus, the male's flutter-run has the effect of breaking up the agonistic interaction between females.

To sum up the relationships within a primary group, the members of it usually made common use of the mating and feeding sites. Even if feeding areas were used somewhat exclusively by some females, no territorial defense was evidenced between them. Aggression among group members occurred not restricted to a particular place or area, and the larger individual was always dominant over the smaller. This did not absolutely prevent smaller females from feeding or mating. Appeasement behaviours were sometimes exhibited in the context of aggression among group members. These facts strongly suggest that a primary group was organized by a linear size-based dominance hierarchy.

\section{Relationships between Primary Groups}

In this section social relationships between individuals whose home ranges hardly overlapped, i.e. belonging to different primary groups, are treated. The interactions between neighbouring polygynous groups (i.e. on and beyond the border of males) and those between primary groups within a branching-type polygynous group (i.e. on and beyond the border of females in a male's home range) are described separately. 


\section{Interactions between polygynous groups}

Two or three polygynous groups were found at St. A in 1975 and at St. B in 1975 (see Fig. 3 and Fig. 4). Actual encounters between individuals of neighbouring polygynous groups at their border area were observed only at St. A, partly because observations were less intensively conducted at St. B in that year. About half

Table 15. Examples of intergroup encounters around the range border between males. All cases were observed at St. A in 1975. *: individuals which came later, ${ }^{\circ}$ : interactions which occurred at first. See Fig. 13 for positions of interactions.

\begin{tabular}{|c|c|c|c|c|c|c|c|}
\hline \multirow{4}{*}{ Case Date } & \multirow{4}{*}{$\begin{array}{l}\text { Fishes involved in } \\
\text { the encounter }\end{array}$} & \multicolumn{5}{|c|}{ Interactions between } & \multirow{4}{*}{$\begin{array}{l}\text { Duration } \\
\text { time of the } \\
\text { encounter } \\
\text { (minutes) }\end{array}$} \\
\hline & & \multicolumn{2}{|c|}{ Males } & & \multicolumn{2}{|c|}{ Male Females } & \\
\hline & & Att & & Mouth-gape & $\&$ & & \\
\hline & & $\mathrm{M} 1 \rightarrow \mathrm{M} 2$ & $\mathrm{M} 2 \rightarrow \mathrm{MI}$ & $\mathrm{M} 1 \leftrightarrow \mathrm{M} 2$ & female & & \\
\hline 1. Jun. 2 & M1 -M2 & 0 & 0 & 0 & - & - & $<1$ \\
\hline 2. May 2 & $\mathrm{M} 1-\mathrm{M} 2 *$ & 0 & $\left(2^{\circ}\right)$ & 0 & 一 & - & $<1$ \\
\hline 3. Jun. 19 & $\mathbf{M} 1 *-\mathbf{M} 2$ & 1 & $1^{\circ}$ & 0 & - & - & 1 \\
\hline 4. May 23 & $\mathrm{M} 1-\mathrm{M} 2$ & $1^{\circ}$ & $1^{\circ}$ & 0 & - & - & 3 \\
\hline 5. Jun. 9 & $\mathrm{M} 1-\mathrm{M} 2 *$ & 1 & $1^{\circ}$ & 0 & - & - & 1 \\
\hline 6. May 8 & $\mathrm{M} 1-\mathrm{M} 2 *$ & 1 & $1^{\circ}$ & 1 & 一 & - & 1 \\
\hline 7. Jul. 5 & $M 1-M 2$ & 1 & 1 & $1^{\circ}$ & - & - & 2 \\
\hline 8. Jul. 6 & $\mathrm{M} 1+\mathrm{F} 1-\mathrm{M} 2 *$ & 0 & 0 & 0 & 0 & - & $<1$ \\
\hline 9. Jun. 2 & $\mathrm{M} 1+\mathrm{F} 2-\mathrm{M} 2 *$ & $1^{\circ}$ & 1 & 0 & 0 & - & 1 \\
\hline 10. Jul. 6 & $\mathrm{M} 1+\mathrm{F} 6-\mathrm{M} 2 *$ & $2^{\circ}$ & 1 & 0 & 0 & - & 1 \\
\hline 11. Jun. 10 & $\mathrm{M} 1+\mathrm{F} 2-\mathrm{M} 2+\mathrm{F} 3$ & 0 & 0 & 0 & 0 & 0 & $<1$ \\
\hline 12. Jun. 9 & $\mathrm{M} 1+\mathrm{F} 1-\mathrm{M} 2+\mathrm{F} 3$ & 0 & $1^{\circ}$ & 0 & 0 & 0 & $<1$ \\
\hline 13. Jun. 10 & $\mathrm{M} 1+\mathrm{F} 1-\mathrm{M} 2+\mathrm{F} 3$ & 0 & $1^{\circ}$ & 0 & 0 & 0 & $<1$ \\
\hline 14. Jun. 19 & $\begin{array}{c}\mathrm{M} 1+\mathrm{F} 4^{*}-\mathrm{M} 2+\mathrm{F} 3 \\
+\mathrm{F} 5^{*}+\mathrm{F} 6^{*}\end{array}$ & 8 & $10^{\circ}$ & 3 & $+\neq$ & 0 & 15 \\
\hline 15. May 24 & $\mathrm{Ml}+\mathrm{F} 4-\mathrm{F}^{*}$ & - & 一 & - & 十物 & 0 & $<1$ \\
\hline
\end{tabular}

丰 Attack $\mathrm{Ml} \rightarrow \mathrm{F} 3$ (3 times), F3 $\rightarrow \mathrm{Ml}(8), \mathrm{M} 2 \rightarrow \mathrm{F} 4$ (1); Mouth-gape $\mathrm{Ml} \leftrightarrow \mathrm{F} 3$ (2); Flutter-run $\mathrm{Ml} \rightarrow \mathrm{F} 5(3)$.

陆 Flutter-run M1 $\rightarrow$ F3 (1).

of these encounters $(n=15)$ were those between two males (cases 1-7 in Table 15). Females of one or both groups, together with their males, participated in the rest of the encounters (cases 8-14), except for one case where the male of one group was not involved (case 15).

In four of 15 cases no actual fight occurred between members of the two groups. In one of these cases, each male moved around near the border at a distance of a few meters from each other, and then, as one male left the border, the other did soon after (case 1). In another case, one of the males tried to attack the other male, but the latter did not respond (case 2). In the remaining two cases, one or both males were courting with their females, and did not seem to react to the presence of the other male just beyond the border (cases 8 and 11).

Inter-group fights were observed in the other 11 cases (see Table 15 and Fig. 13). The border fights usually commenced with an attack by one of the males 


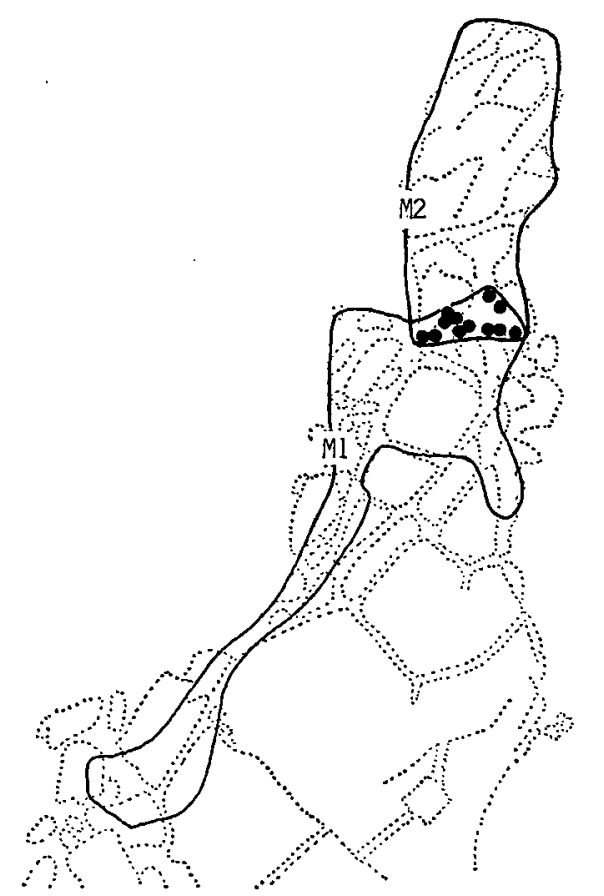

Fig. 13. Locations of intergroup border fights at St. A in the period from April to July in 1975. Outlines of home ranges of two males are also shown.

against the other. Most fights were attacks and mouth-gapes between males. No fight was observed between females, although females of both groups encountered in five cases (cases 11-15). Males sometimes attacked or displayed flutter-runs against females of other group (cases 14 and 15). Only in one case (case 15), a female (F3: $81 \mathrm{~mm}$ in total length; the dominant female of one group) attacked and mouth-gaped against the male ( $\mathrm{MI}: 104 \mathrm{~mm}$ ) of the other group, repeating this behaviour several times.

Most of the border encounters ceased within a few minutes, and then participants left the border. However, in one case (case 15) reciprocal attacks and mouth-gapes between males and between a male and a female continued for as long as 15 minutes (see Table 15).

Intrusions by individuals into the range of other group rarely occurred, even if there was no individual from the other group at the border area. Males often approached the border, but usually stopped near it and turned away from it (e.g. see the trace of movements near the border in Fig. 2). Intrusions were observed in six cases for males (cases 1-6 in Table 16) and eight cases for females (cases 7-14). Traces of movements of the intruders are shown in Fig. 14.

Three cases of intrusions by a male occurred when its neighbouring male was absent as a result of having been collected for tagging (cases 5 and 6 in Table 16 and Fig. 14), or was not observed on that day probably because it hid itself in a rock 
Table 16. Examples of intrusions by males (Nos. 1-6) and females (Nos. 7-14) beyond the range border between males, with interactions between the intruder and residents. XX: the resident was absent as it had been collected for tagging, X: not observed on that day, - : no encounter, t: meeting without any overt display, A: attack, M: mouth-gape, F: flutter-run, B: body-sigmoid, P: prespawning, S: spawning. Behaviours of intruders are shown by small letter, and those of residents by capital letter. *: just after returning of the resident which was collected for tagging. See Fig. 14 for the trace of movements of intruders.

\begin{tabular}{|c|c|c|c|c|c|c|c|c|c|c|c|}
\hline \multirow{2}{*}{ Case } & \multirow{2}{*}{ St. } & \multirow{2}{*}{ Date } & \multicolumn{3}{|c|}{ Intruder } & \multicolumn{6}{|c|}{ Interactions with residents } \\
\hline & & & Name & $\begin{array}{c}\mathrm{TL} \\
(\mathrm{mm})\end{array}$ & $\begin{array}{l}\text { Size } \\
\text { class }\end{array}$ & Name (TL) & & & & & \\
\hline$\frac{1 .}{2 .}$ & $\begin{array}{l}\mathrm{A} \\
\mathrm{A}\end{array}$ & $\begin{array}{l}\text { Apr. } 13, ' 75 \\
\text { Apr. } 25, ' 75\end{array}$ & $\begin{array}{l}\text { M1 } \\
\text { M1 }\end{array}$ & $\begin{array}{r}03 \\
103\end{array}$ & $\begin{array}{l}\mathrm{M} \\
\mathrm{M}\end{array}$ & $\begin{array}{l}\mathrm{Ml}(99) \\
\mathrm{X} \\
\mathrm{mMA}\end{array}$ & $\begin{array}{c}\mathrm{F} 2(81) \\
+ \\
\mathrm{a}\end{array}$ & $\begin{array}{c}\text { F3(74) } \\
\text { X } \\
\text { mMA }\end{array}$ & $\begin{array}{c}\text { F5(62) } \\
\text { f } \\
--\end{array}$ & $\begin{array}{c}\text { F6(51) } \\
+ \\
-\end{array}$ & $\begin{array}{c}\text { F8(47) } \\
\stackrel{-}{-}\end{array}$ \\
\hline $\begin{array}{l}3 . \\
4 .\end{array}$ & $\begin{array}{l}\mathrm{C} \\
\mathrm{C}\end{array}$ & $\begin{array}{l}\text { Jun. 17, '77 } \\
\text { Jun. } 23, ' 77\end{array}$ & $\begin{array}{l}\text { no } \\
\text { no }\end{array}$ & $\begin{array}{l}\text { ca. } 100 \\
\text { ca. } 100\end{array}$ & $\begin{array}{l}\mathbf{M} \\
\mathbf{M}\end{array}$ & $\frac{\mathrm{M} 71(94)}{\overline{(a)}}$ & $\begin{array}{c}\text { F71(86) } \\
+\end{array}$ & $\begin{array}{l}\mathrm{F} 72(83) \\
\mathrm{f} \\
\mathrm{X}\end{array}$ & $\begin{array}{c}\text { F73(79) } \\
-\end{array}$ & $\begin{array}{c}\text { F74(79) } \\
=\end{array}$ & \\
\hline 5. & $\mathrm{~A}$ & Jul. $\quad 10,{ }^{\prime} 75$ & MI & 104 & $\mathbf{M}$ & $\begin{array}{c}\mathrm{M} 2(100) \\
\mathrm{XX}\end{array}$ & $\begin{array}{c}\mathrm{F} 3(81) \\
\mathrm{aA}\end{array}$ & $\begin{array}{c}\text { F5(72) } \\
\text { faA }\end{array}$ & $\underset{A}{F 8(68)}$ & & \\
\hline 6. & $\mathrm{~B}$ & Jun. $17,{ }^{\prime} 75$ & M52 & 91 & $\mathbf{M}$ & $\underset{\mathrm{XX}}{\operatorname{M51(95)}}$ & $\begin{array}{c}\text { F51(85) } \\
\mathrm{XX}\end{array}$ & $\begin{array}{l}\mathrm{F} 57(72) \\
\left.\mathrm{XX}(\mathrm{fsS})^{*}\right)\end{array}$ & $\begin{array}{l}\mathrm{F} 59(71) \\
\mathrm{XX}\left(\mathrm{fpP}^{*}\right)\end{array}$ & $\begin{array}{r}\mathrm{F} 517(61) \\
\times X\left(\mathrm{f}^{*}\right)\end{array}$ & $\begin{array}{r}\mathrm{F} 519(58) \\
\mathrm{XX}\left(\mathrm{f}^{*}\right)\end{array}$ \\
\hline 7. & A & May $15, ' 75$ & F4 & 63 & $\mathrm{SF}$ & $\underset{\mathrm{A}}{\mathrm{M} 2(99)}$ & $\begin{array}{c}\text { F3(74) } \\
+\end{array}$ & F5(62) & F6(51) & F8(47) & \\
\hline $\begin{array}{l}8 . \\
9 .\end{array}$ & $\begin{array}{l}\mathrm{A} \\
\mathrm{A}\end{array}$ & $\begin{array}{l}\text { May } 24, ' 75 \\
\text { May } 24, ' 75\end{array}$ & $\begin{array}{l}\text { F5 } \\
\text { F5 }\end{array}$ & $\begin{array}{l}62 \\
62\end{array}$ & $\begin{array}{l}\text { SL } \\
\text { SL }\end{array}$ & $\begin{array}{l}\text { M1(103) } \\
\quad-\end{array}$ & $\begin{array}{c}\mathrm{F} 1(82) \\
-\end{array}$ & $\begin{array}{c}\mathrm{F} 2(81) \\
- \\
-\end{array}$ & $\begin{array}{c}\mathrm{F} 4(63) \\
\mathrm{mM} \\
-\end{array}$ & & \\
\hline $\begin{array}{l}10 . \\
11 . \\
12 . \\
13 .\end{array}$ & $\begin{array}{l}\text { B', } \\
\text { B } \\
\text { B } \\
\text { B }\end{array}$ & $\begin{array}{l}\text { Jun. } 30, ' 75 \\
\text { Jun. } 30, ' 75 \\
\text { Jul. } 12,75 \\
\text { Jun. } 16,775\end{array}$ & $\begin{array}{l}\text { F510 } \\
\text { F513 } \\
\text { F513 } \\
\text { F510 }\end{array}$ & $\begin{array}{l}70 \\
67 \\
67 \\
70\end{array}$ & $\begin{array}{l}\text { SF } \\
\text { SF } \\
\text { SF }\end{array}$ & $\begin{array}{l}\text { M51(95) } \\
= \\
= \\
=\end{array}$ & $\begin{array}{c}\mathrm{F} 54(82) \\
\mathrm{A} \\
\overline{-} \\
\mathrm{XX}\end{array}$ & $\begin{array}{c}\text { F56(74) } \\
= \\
=\end{array}$ & $\begin{array}{c}\mathrm{F} 512(67) \\
= \\
\overline{-} \\
\mathrm{XX}\left(\mathrm{a}^{*}\right)\end{array}$ & 制 & \\
\hline 14. & $\mathrm{~B}$ & Jun. 19, '75 & F54 & 82 & $\mathrm{LF}$ & $\begin{array}{c}\mathrm{M} 53(88) \\
-\end{array}$ & $\begin{array}{l}\mathrm{F} 55(80) \\
\mathrm{XX}(+*)\end{array}$ & $\begin{array}{c}\mathrm{F} 58(71) \\
\mathrm{XX}\end{array}$ & $\begin{array}{c}\text { F515(64) } \\
-\end{array}$ & & \\
\hline
\end{tabular}

精 The male (M52) of this female followed and chased the latter into their native home range. 

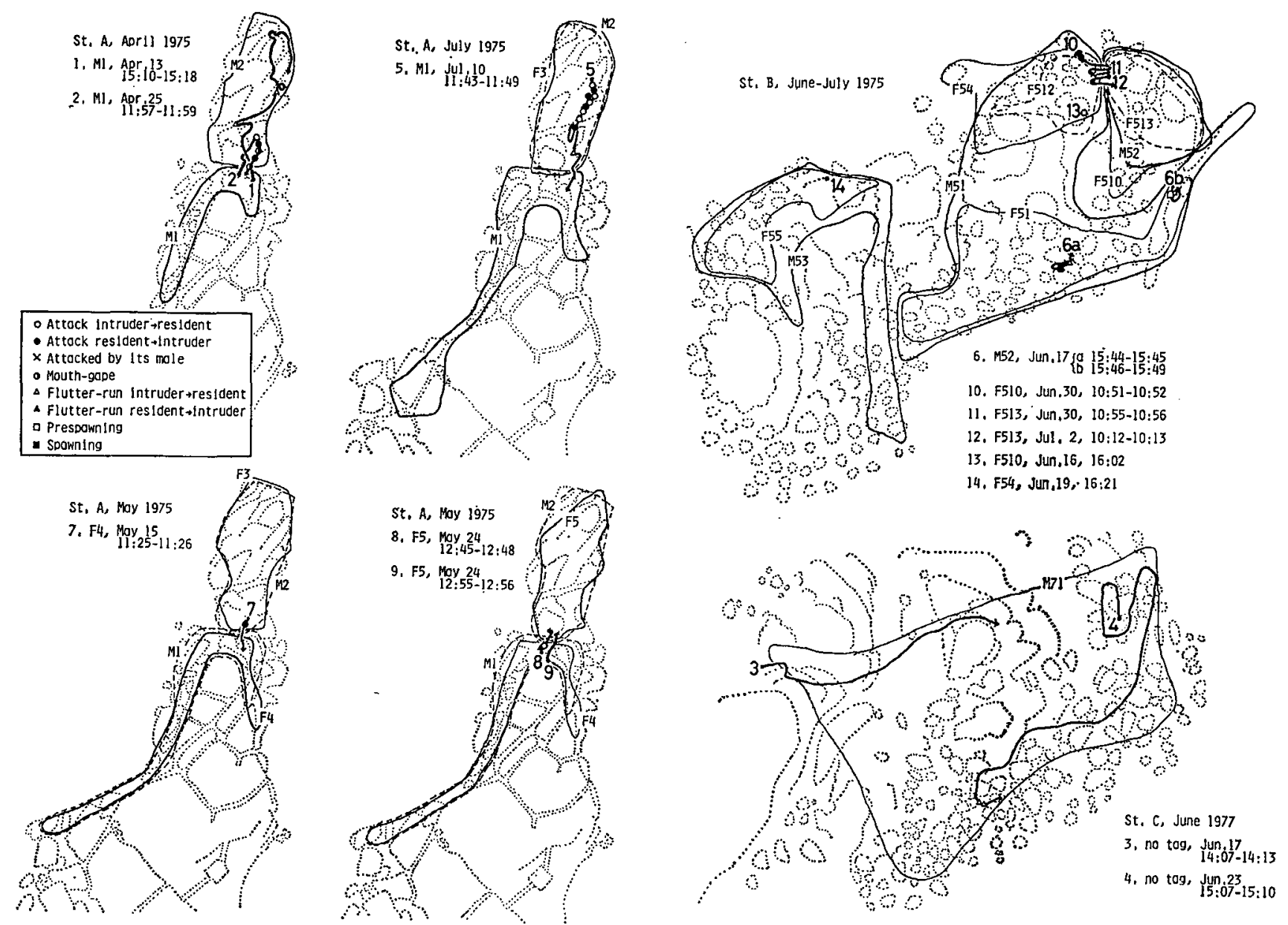

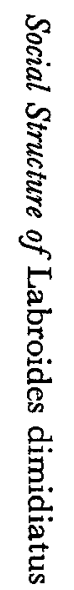

Fig. 14. Traces of movements of individuals intruding beyond the range border between males, with locations of interactions between them and residents. Home ranges of the intruders and those of the residents of similar size-classes to them are also illustrated. Case numbers put in the maps are the same as in Table 16. 
crevice as it was at the beginning of the socially active season (case 1, and also see Kuwamura, 1981a). Flutter-runs by the intruding male against the resident females were observed in those three cases. In one case (case 5), the intruding male (M1) was attacked and chased out by the resident females which were much smaller than it. In this case the largest female (F3) had behaviourally sex-changed within one hour after collection of its male (M2) on July 9. On the next day, F3 exhibited border fights against the other male (M1), and after several minutes, the latter intruded.

In the remaining three cases (cases 2, 3 and 4), the resident male was present when the intrusions occurred. In one of these cases (case 3), the intruding male did not encounter the resident male. When they encountered, the resident male (and its females) immediately attacked the intruder (case 2); or it fled away from the intruder, the latter pursuing it (case 4). The intruder in the last case was a nontagged male which was observed only twice (i.e. in cases 3 and 4) during the observation period of over a month. Although it was much larger and stronger than the resident male, the latter could function as a male probably because the former rarely intruded into its home range.

Among intrusions by females, two cases occurred when residents of similar sizeclasses were absent due to collecting for tagging (cases 13 and 14 in Table 16 and Fig. 14). In the other six cases (cases 7-12), females intruded though neighbouring females were present. In three of these cases (cases 7, 8 and 10), the intruding female encountered a resident female: no aggression occurred between them (case 7); mouth-gape between the intruder and the resident of similar size-class took place (case 8 ); or the intruder was attacked by a larger female (case 10). When the intruding female encountered resident males, the latter attacked (cases 7 and 10) or displayed the flutter-run (case 8). In one case (case 11), the intruding female was followed by its own male, and then the male chased it back to their home range; the male continued attacks against it, even after returning to their home range. This was the only case in which the male actively tried to detain its female within its range.

\section{Interactions between primary groups of one polygynous group}

Branching-type polygynous groups were found at St. A in 1974 and 1976, at St. B in 1975 and at St. C in 1977 (see Fig. 3 and Fig. 4). Border fights, as were observed around the border of males' ranges, were not observed at the border of females' ranges within a male's home range. However, females rarely swam into the ranges of their neighbour females (e.g. see the trace of movements near the border in Fig. 7). Even when home ranges of females belonging to different primary groups were partly overlapped (e.g. St. G in Fig. 3), they never interacted with each other at the overlapping area, seemingly to deliberately avoid the encounter.

Intrusions of females beyond their range border were observed in five cases (Table 17 and Fig. 15). In two of these cases, intrusions occurred when females of similar size-class to the intruder were absent due to collecting for tagging (cases 4 
Table 17. Examples of intrusions by females beyond the range border between females within a male's home range, with interactions between the intruder and residents. Abbreviations are the same as in Table 16. See Fig. 15 for the trace of movements of intruders.

\begin{tabular}{|c|c|c|c|c|c|c|}
\hline \multirow{2}{*}{ Case } & \multirow{2}{*}{ St. } & \multirow{2}{*}{ Date } & \multicolumn{2}{|r|}{ Intruder } & & \\
\hline & & & Name & $\begin{array}{c}\mathrm{TL} \\
(\mathrm{mm})\end{array}$ & $\begin{array}{l}\text { Size } \\
\text { class }\end{array}$ & \\
\hline 1. & $\begin{array}{l}\mathrm{A} \\
\mathrm{A}\end{array}$ & $\begin{array}{l}\text { Jun. 15, '74 } \\
\text { Jun. 15, '74 }\end{array}$ & $\begin{array}{l}\text { F41 } \\
\text { F43 }\end{array}$ & $\begin{array}{l}85 \\
82\end{array}$ & $\begin{array}{l}\text { LF } \\
\text { SL }\end{array}$ & \\
\hline 3. & A & Jun. 24, '74 & $\mathrm{F} 44$ & 77 & SL & \\
\hline 4. & $\mathbf{A}$ & Jun. $2,{ }^{\prime} 74$ & F41 & 85 & LF & \\
\hline \multirow[t]{2}{*}{5.} & B & Jun. 16, '75 & F51 & 85 & LF & \\
\hline & \multicolumn{6}{|c|}{ Interactions with residents } \\
\hline Case & \multicolumn{6}{|c|}{ Name (TL) } \\
\hline 1. & & $\begin{array}{l}141(94) \\
\text { A } \\
\text { PA }\end{array}$ & $\begin{array}{c}\mathrm{F} 42(85) \\
\mathrm{A} \\
-\end{array}$ & $\begin{array}{c}\mathrm{F} 44(77) \\
+ \\
\mathrm{A}\end{array}$ & $\begin{array}{c}\mathrm{F} 45(72) \\
-\end{array}$ & $\begin{array}{c}F 46(60) \\
-\end{array}$ \\
\hline 3. & & $\begin{array}{l}\text { I41(94) } \\
+\end{array}$ & F41(85) & F43(82) & $\mathrm{F} 45(72)$ & \\
\hline 4. & & $\begin{array}{l}\text { I41(94) } \\
+\end{array}$ & $\begin{array}{c}\text { F42(85) } \\
\text { XX }\end{array}$ & F44(77) & $\begin{array}{c}\mathrm{F} 45(72) \\
-\end{array}$ & $\begin{array}{c}F 46(60) \\
\text { XX }\end{array}$ \\
\hline 5. & & ${ }_{F}^{[51(95)}$ & $\begin{array}{l}\mathrm{F} 54(82) \\
\mathrm{XX}\left(\mathrm{mM} A^{*}\right)\end{array}$ & $\begin{array}{c}\mathrm{F} 56(74) \\
-\end{array}$ & $\underset{\mathrm{XX}}{\mathrm{F} 512(67)}$ & \\
\hline
\end{tabular}

and 5 in Table 17 and Fig. 15). Other cases were observed when resident females were present. In one such case, the intruder swam together with its male, but did not meet with resident females (case 3). In another case (case 1), the female intruded solitarily and encountered a pair consisting of its male and the resident female of its similar size-class; then it was attacked and pursued towards the border by them. In the remaining case (case 2), the female intruded, courting with its male; then the male began to attack it, and a resident female of its similar size-class also approached and chased it towards the border.

\section{Territoriality}

As described above, intrusion beyond the range border occurred in a few occasions, either between polygynous groups or between primary groups in a polygynous group. In such cases, the intruders were often attacked by the residents. Compared with aggression within a primary group, which occurred based on body size, it is notable that the residents often chased out the intruders, even if the latter were larger than the former (e.g. cases 2 and 5 in Table 16; cases 2 and 5 in Table 17; and also see border fights in Table 15). That is, the effect of prior residence predominated over the difference of body size in these cases. Therefore, the relationship between primary groups, either of the same polygynous group or of different ones, can be regarded as territoriality. 

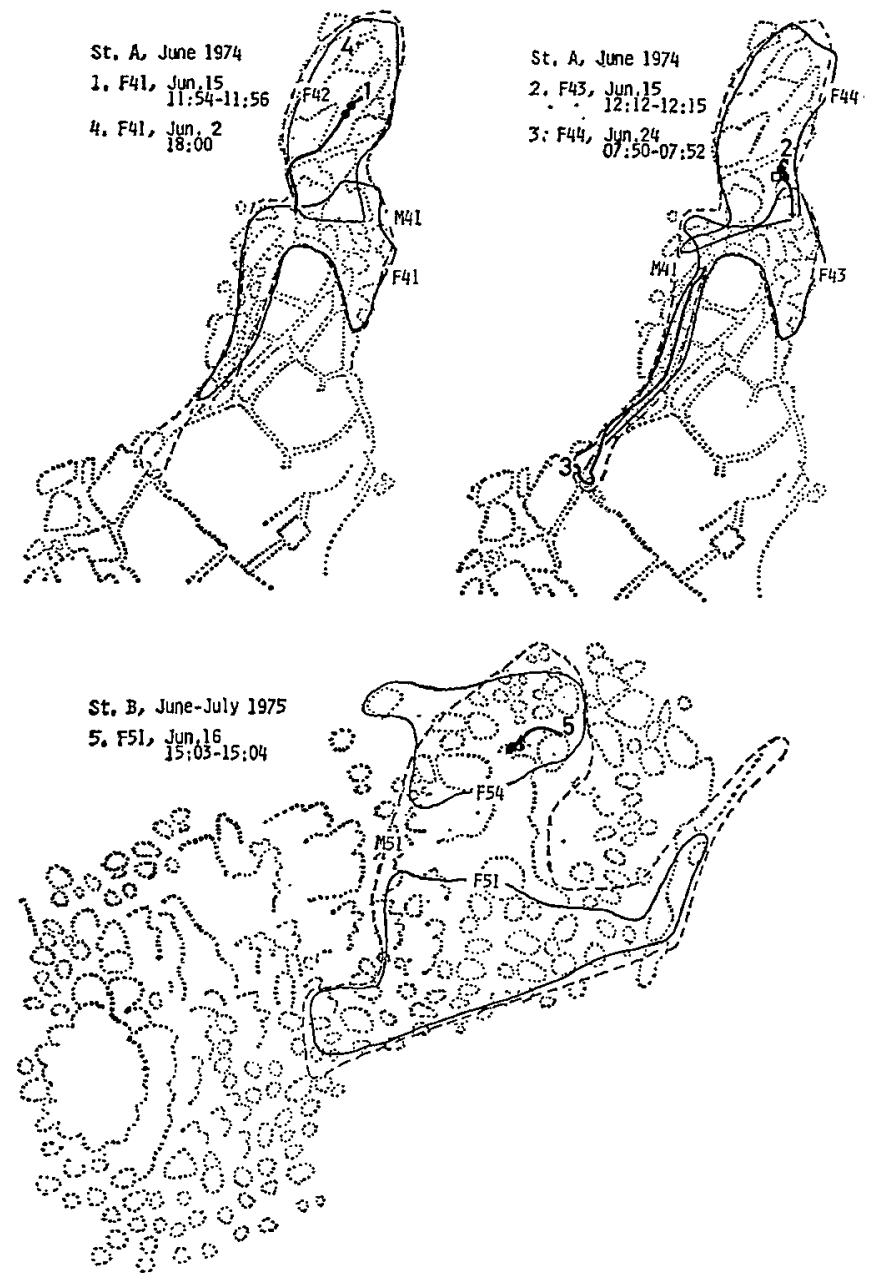

Fig. 15. Traces of movements of females intruding beyond the range border between females within a male's home range. Locations of interactions between the intruders and residents are also given. Home ranges of the intruders, those of the residents of similar sizeclasses and those of males are also illustrated. Case numbers put in the maps are the same as in Table 17.

When an individual was absent, removed or hiding, the intruder was always an individual of the same size-class (e.g. cases 1, 5, 6, 13 and 14 in Table 16; cases 4 and 5 in Table 17). Moreover, when an intruder met with a resident of the same size-class, the former was always attacked (or mouth-gaped) by the latter (e.g. cases 2 and 8 in Table 16; cases 1 and 2 in Table 17; but one exception of case 4 in Table 16). These facts suggest that the territorial relationship is most intensive between individuals of similar body size.

The territorial relationship between males considerably differed from that between females. As is mentioned elsewhere, males frequently exhibited actual fights 
on encounters at their range border (see Table 15), while such border fights were seldom observed between females, either at the borders of males' ranges or at those of females' ranges within a male's home range. That is, the relationship between males was territorial accompanied with frequent defense of their ranges, while that between females was territorial without actual defense at borders. The relationship between a male and a female also differed from the relationships between females and between males. Females sometimes attacked males of other groups; especially, the dominant female joined even in border fights between males (e.g. F3 of case 14 in Table 15). Males also attacked females of other groups, but sometimes displayed flutter-runs, which were displays often used in courtship within a primary group. Therefore, it seems that males do not always try to chase out females of other groups, but try to gain them as their mates. The case, in which a male tried to detain its female, which intruded into the area of another group, within its range (case 11 in Table 16), also suggests this. The tendency that males try to acquire more mates must be related to the fact that the actual and frequent border fights occurred only between males.

\section{Dynamics in Social Relationships}

\section{Social factors affecting the change of home range}

Females sometimes changed the position of their home ranges, as has been described for St. A in 1975 (see Kuwamura, 1981a; and also Fig. 10). In this section, social factors affecting such movement of females are examined. For example, two females (F2 and F6) changed their groups in the period from April to July of 1975 at St. A, in the following process. A female F2, which changed groups in May, had already segregated most of its feeding area from that of the dominant female F3 in the north group in April (Fig. 10). Although F2 was larger by $7 \mathrm{~mm}$ in total length than F3, the latter dominated over the former in March and April; as already mentioned, this was the single exceptional case of a larger individual being dominated by a smaller one. F2 may have been obliged to move its home range on account of the presence of the smaller but stronger female F3. After movement in May, F2 largely overlapped its home range with that of the residents of the south group, though its feeding area was somewhat restricted, separated from those of the resident females (F1 and F4) (Fig. 10). Although actual attacks by and against F2 were rarely observed, except for the attack from FI in July, F2 seemed to get and maintain the second rank among the females of the group until it disappeared in July. The difference of body size between F2 and the dominant female F1 was only $1 \mathrm{~mm}$, but the difference of strength between them seems to have been much larger, as the former was weaker than the much smaller female F3.

In another case, a female F6 (51 mm in total length in March) had fed in an area separate from F5 (62 mm in March) in the north group from April to June, though their home ranges largely overlapped (Fig. 10 and Kuwamura, 1981a). In 
the middle of June, F6 moved its whole home range into the south part, and accordingly $\mathrm{F} 5$ enlarged its feeding area over the area which $\mathrm{F} 6$ used previously. The difference in total length of these fish decreased to as little as $1 \mathrm{~mm}$ in July $(71 \mathrm{~mm}$ in F6, and $72 \mathrm{~mm}$ in F5). The gain in body size of the smaller fish, which may at the same time imply a gain in strength, may have at last brought out the segregation of the home ranges between the two. In the south group, F6 was able to establish its home range as the lowest-ranking female of the group, without receiving any vigorous attacks from the residents.

Thus, the movement of females can be explained by a change of relationships between members of neighbouring ranks. It is suggested that when the difference in strength between two individuals of a primary group becomes little, a social relationship between them changes from a dominance relationship to a territorial one.

\section{Introducing experiment in the aquarium}

To analyse behaviours against intruders and to determine the effect of prior residence and the reorganization of a dominance hierarchy, an experiment was conducted in an exhibition tank of the laboratory. Two individuals of $L$. dimidiatus, i. e. $\alpha(75 \mathrm{~mm}$ in standard length) and $\beta(55 \mathrm{~mm} \mathrm{SL})$, which were collected at the offshore reef in the vicinity of the laboratory on June 9, 1973 and reared in a 50 liter tank for several days, were introduced into the experiment tank (Fig. 16) on

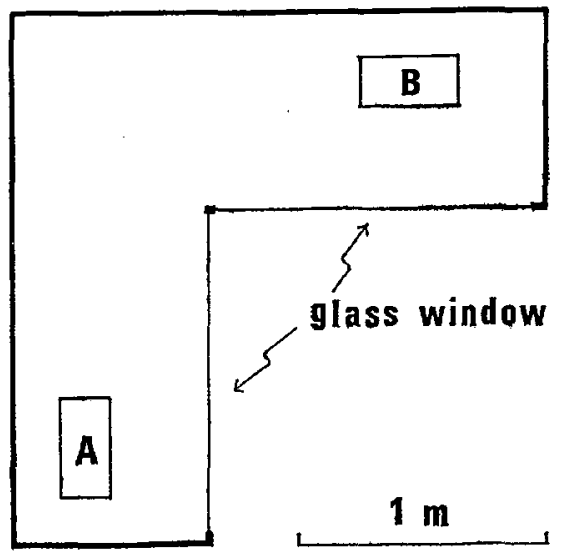

Fig. 16. A tank used for the introducing experiment, viewed from the top. The depth of water was about one meter. A, B: concrete blocks.

June 14. The tank was already occupied by several fishes, such as Epinephelus septemfasciatus, E. moara, Goniistius zonatus, etc. On September 2, two more individuals of $L$. dimidiatus, i. e. $r(67 \mathrm{~mm} \mathrm{SL})$ and $\delta(62 \mathrm{~mm} \mathrm{SL})$, which were collected at another offshore reef on August 30, were newly introduced into the tank. The four individuals were individually discriminated by means of their size difference $(\alpha>$ $\gamma>\delta>\beta$ ) and fin-cut-markings in $\gamma$ and $\delta$. Observations for ten minutes or so were carried out nearly every day from September 2 to 20 , and every several 
days at other periods.

The area in the experiment tank was inevitably much smaller than the usual home range of an individual in the sea, but the individuals kept in the tank exhibited nearly normal behaviour in feeding and courtship.

When two individuals ( $\gamma$ and $\delta$ ) were newly introduced, they were attacked by the residents $(\alpha$ and $\beta$ ). The intruders did not exhibit any counter-attack, and established their home ranges at a restricted area around shelter blocks (A and B in Fig. 16) at first. Although most attacks were exhibited by the male ( $\alpha$, the resident female $(\beta)$, which was the smallest of the four, also attacked the intruders. This fact clearly suggests the effect of prior residence.

The intruders gradually enlarged their home ranges: the smaller one $(\delta)$ was able to enlarge its range earlier than the larger one $(r)$, probably because the attacks by $\alpha$ were less vigorously exhibited against $\delta$. When the smaller intruder had already enlarged its range, while the larger one still restricted its range around the shelter block, the smaller attacked the larger several times. These attacks also seem to have resulted from the effect of prior residence by the smaller intruder.

After two weeks or so, when both intruders had already enlarged their home ranges to include the entire tank, aggressive encounters had decreased, and the dominance hierarchy among the four had been perfectly reorganized (as $\alpha>\gamma>\delta>\beta$ ) according to their body size. Subsequently courtship and prespawning behaviours were often observed between the male $(\alpha)$ and the three females.

In this experiment, the intruders could not move out of the tank, although they might have in a natural environment. In such a case, the relationship among the residents and the intruders is shown to be gradually reorganized into a dominance hierarchy according to their body size, although the effect of prior residence predominates at first.

\section{Transfer experiments in the field}

Artificial transfer of individuals into St. A, which was an isolated reef surrounded by sand (see Fig. 1), was conducted five times (Table 18 and Fig. 17). Two males and three females were collected either at St. B or at the offshore reefs, and they were released at St. A within a week after collection.

In the five expreiments, the newly introduced individuals were almost always attacked by the residents, especially by the male and the largest female but even by the smaller residents; except for one case in which the intruder ( $\mathrm{Mb}$ ) did not meet with larger residents (case 2 in Table 18). The intruders never exhibited any counterattack, but only fled when attacked, as in the introducing experiment in aquarium.

In three cases (cases 1,4 and 5 in Table 18), the intruders succeeded in settling on the new reef, although there were residents of similar size to them. The male $\mathrm{Ma}$ (92 $\mathrm{mm}$ in total length) was not observed for about a month after being introduced, but then reappeared, settling at the south part of St. A. Then the resident male (M41: $94 \mathrm{~mm}$ ), which had covered almost the entire area in St. A till August (see Fig. 3), began to restrictits home range to the north part (see Fig. 17 for home ranges 
Table 18. Transfer experiments into St. A, with interactions between transferred fishes and residents. Abbreviations are the same as in Table 16. See Fig. 17 for the trace of movements oi transferred fishes.

\begin{tabular}{|c|c|c|c|c|c|}
\hline \multirow{2}{*}{ Case } & \multicolumn{2}{|c|}{ Transferred fish } & \multirow{2}{*}{ Site of collection } & \multirow{2}{*}{\multicolumn{2}{|c|}{$\frac{\text { Date of }}{\text { Collection Release }}$}} \\
\hline & Name & $\begin{array}{c}\mathrm{TL} \\
(\mathrm{mm}) \\
\end{array}$ & & & \\
\hline $\begin{array}{l}1 . \\
2 . \\
3 .\end{array}$ & $\begin{array}{l}\mathrm{Ma} \\
\mathrm{Mb} \\
\mathrm{Fc}\end{array}$ & $\begin{array}{l}92 \\
86 \\
80\end{array}$ & $\begin{array}{l}\text { St. B } \\
\text { St. B } \\
\text { St. B }\end{array}$ & \multicolumn{2}{|c|}{$\begin{array}{l}\text { Aug. } 7 \rightarrow 7, ' 74 \\
\text { Sep. } 17 \rightarrow 18, ' 74 \\
\text { Sep. } 17 \rightarrow 19, ' 74\end{array}$} \\
\hline 4. & $\mathbf{F a}$ & 75 & offshore reef & \multicolumn{2}{|c|}{ Jul. $23 \rightarrow 26, ' 75$} \\
\hline 5. & Fc & 65 & offshore reef & \multicolumn{2}{|c|}{ Jul. $23 \rightarrow 30, ' 75$} \\
\hline & \multicolumn{5}{|c|}{ Interactions with residents } \\
\hline & \multicolumn{5}{|c|}{ Name (TL) } \\
\hline $\begin{array}{l}1 . \\
2 . \\
3 .\end{array}$ & $\begin{array}{l}\mathrm{M} 41(94) \\
\frac{\mathrm{A}}{}\end{array}$ & $\begin{array}{c}\mathrm{F} 42(85) \\
+ \\
\mathbf{x} \\
\mathrm{x}\end{array}$ & $\begin{array}{c}\mathrm{F} 44(77) \\
+ \\
\mathrm{A}\end{array}$ & \multirow[t]{2}{*}{$\begin{array}{l}\mathrm{F} 45(72) \\
+ \\
\dot{x} \\
\mathrm{x}\end{array}$} & $\begin{array}{c}F 46(60) \\
X \\
+ \\
-\end{array}$ \\
\hline 4. & $\underset{\mathbf{F}}{\mathbf{M} 1(104)}$ & $\begin{array}{c}\mathrm{F} 1(87) \\
\mathrm{A}\end{array}$ & $\begin{array}{c}\text { F4(75) } \\
+\end{array}$ & & \\
\hline 5. & $\underset{\mathrm{A}}{\mathrm{M}}$ & F3(81) & $\begin{array}{c}\mathrm{F} 5(72) \\
+\end{array}$ & \multicolumn{2}{|l|}{$\mathrm{F} 8(65)$} \\
\hline
\end{tabular}

of the two males in September). The two males co-dominated at least for four months before winter. The female $\mathrm{Fa}(75 \mathrm{~mm})$ and $\mathrm{Fb}(65 \mathrm{~mm})$ settled as the smallest females for two to five months (see Kuwamura, 1981a, for the change of the position of their home ranges; also see Fig. 10 for their feeding sites in July). They at first restricted their home ranges to an area which was not so frequently used by the residents, and gradually enlarged them, when possible. Thus, the settled individuals got respective social status according to the relative body size, such as was observed in the aquarium experiment.

In two other cases (cases 2 and 3), the intruders could not remain on the reef even for a day. In one of the two cases, the released fish $(\mathrm{Mb})$ was not found either at the releasing place nor at its native reef after the day it was released. In the other case, the intruder $\left(F_{c}\right)$ returned to its native reef (St. B) by the next day, over a sandy bottom, covering a distance of more than $150 \mathrm{~m}$. Usually L. dimidiatus never moved over sand far away from the reef, and so this case can be taken as surprising as well as suggestive of the ability of the fish to "home". Although it is entirely unknown by what means the fish could orient to its native reef, this homing observation suggests that $L$. dimidiatus may be able to keep its home range in memory at least for a few days. The intruder Fc (case 3) was most intensively attacked by the residents among the five experiments. This probably induced the movement of it out of the releasing place.

Removing and returning experiments in the field

Interactions occurring when an individual which had been removed from its 
group was returned again on the day after removal were most intensively observed at St. A in July 1975. Seven experiments were successively conducted at intervals of 3 to 6 days (Table 19 and Fig. 18).
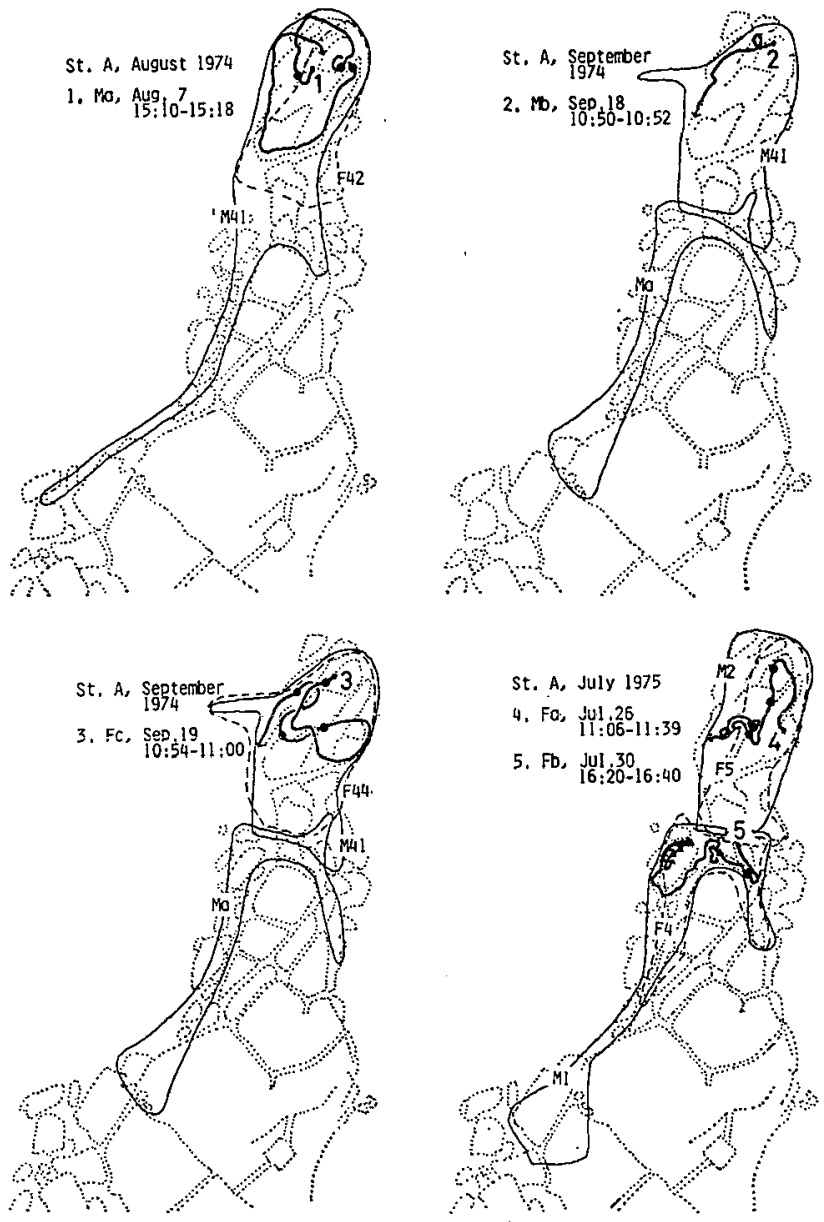

Fig. 17. Traces of movements of artificially transferred fishes, with locations of interactions between them and residents. Home ranges of the residents of similar size to the intruders and those of resident males are also given. Case numbers put in the maps are the same as in Table 18. Symbols of interactions are the same as in Fig. 14.

Individuals which were returned to their home range were almost always attacked by the residents. They were often attacked even by the smaller residents which had been dominated by them before the experiments. The returned fish almost always counter-attacked (by attacks and mouth-gapes) when they were attacked by the residents. This behaviour was quite different from that of the artificially transferred fish which never counter-attacked. This is probably because the 
Table 19. Removing and returning experiments at St. A in 1975. Interactions between returned fishes and residents are shown. Abbreviations are the same as in Table 16. See Fig. 18 for the trace of movements of returned fishes.

\begin{tabular}{|c|c|c|c|c|c|c|c|}
\hline \multirow{2}{*}{ Case } & \multicolumn{2}{|c|}{ Returned fish } & \multicolumn{5}{|c|}{ Interactions with residents } \\
\hline & Name & $\mathrm{TL}(\mathrm{mm})$ & Name (TL) & & & & \\
\hline & & & M2(100) & $\mathrm{F} 3(81)$ & F5(72) & $\mathrm{F} 8(65)$ & \\
\hline 1. & M2 & 100 & $*$ & afmMA & afA & $\mathrm{aA}$ & \\
\hline 2. & F3 & 81 & bmMAF & * & $\operatorname{amM}$ & a & \\
\hline 3. & F5 & 72 & sSF & baA & $*$ & amMA & \\
\hline \multirow[t]{2}{*}{4.} & F8 & 65 & amMA & mAM & + & * & \\
\hline & & & $\mathrm{Ml}(104)$ & F1(87) & $\mathrm{F} 2(86)$ & F4(75) & F6(71) \\
\hline 5. & $\mathrm{Fl}$ & 87 & SSF & * & $\operatorname{amM}$ & - & + \\
\hline 6. & F4 & 75 & $\mathrm{pPF}$ & A & $\mathrm{x}$ & * & + \\
\hline 7. & F6 & 71 & $\mathbf{F}$ & - & $\mathbf{x}$ & - & $*$ \\
\hline
\end{tabular}

returned fish remembered their home range, as they never moved out of their home range (Fig. 18). However, they sometimes hid themselves in rock crevices, even when attacks by the residents became very vigorous. Aggression just after release of the removed fish occurred more frequently than before the experiments (see Table $20 ; P=0.003$, Fisher's randomization test). Such a high frequency of aggression

Table 20. Frequencies of aggression before and just after returning experiments at St. A in July 1975.

\begin{tabular}{ccc}
\hline \hline \multirow{2}{*}{ Individuals } & \multicolumn{2}{c}{ Frequencies of aggression per 10 minutes } \\
\cline { 2 - 3 } & Before experiments & Just after returning \\
\hline (North group) & & \\
M2 & 0.2 & 25.5 \\
F3 & 1.5 & 17.1 \\
F5 & 0.8 & 7.5 \\
F8 & 1.5 & 5.0 \\
(South group) & & \\
M1 & 0.4 & - \\
F1 & 0.5 & 2.0 \\
F4 & 0.3 & 0 \\
F6 & 0.2 & 2.9 \\
\hline
\end{tabular}

between the returned fish and residents seems to have resulted because they had not interacted for a day; as attacks within a primary group in natural condition also occurred more frequently among members which had less frequent contacts with each other (see Table 5 and 8).

Such aggression, however, usually decreased within an hour. In all cases, except one case in which the returned fish (F6) was captured by the lizardfish Synodus variegatus within two minutes after being released (case 7 in Table 19), the returned 

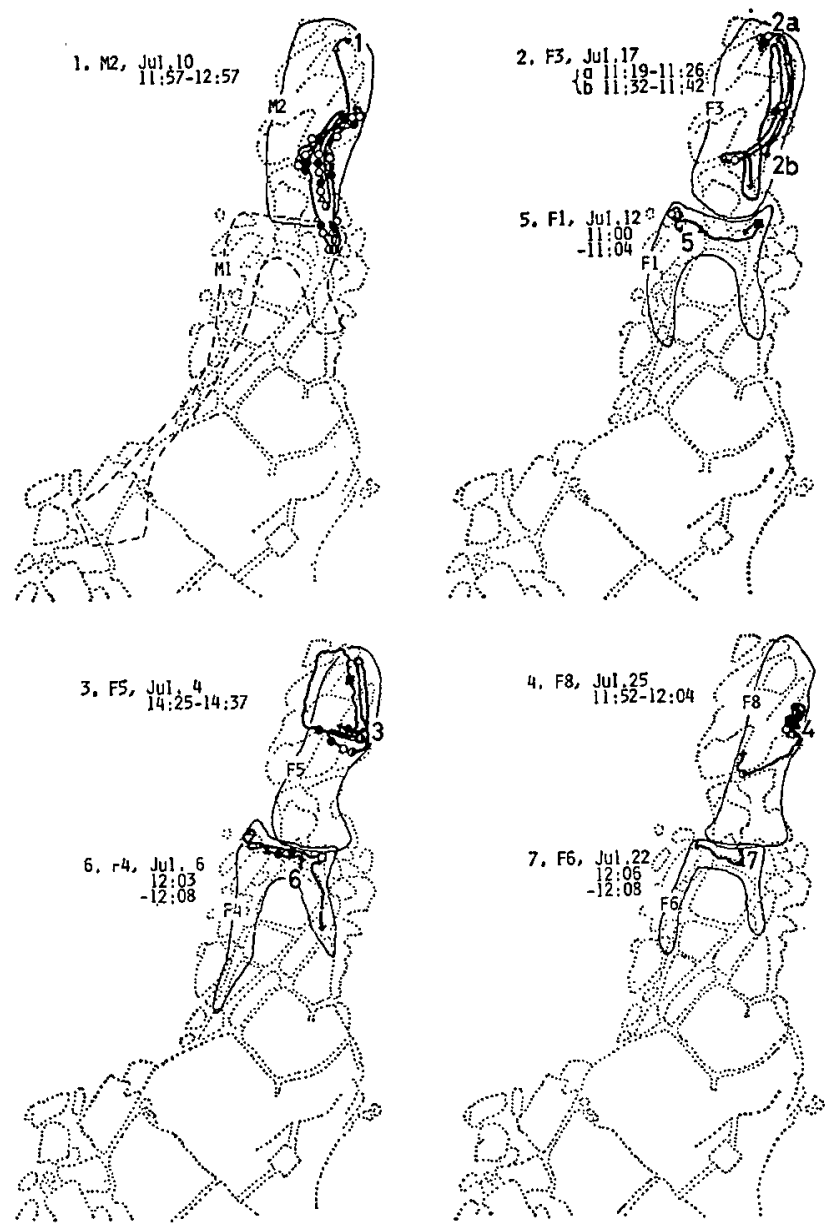

Fig. 18. Traces of movements of removed individuals just after being returned to their native reefs after one day's absence, in July 1975 at St. A. Locations of interactions between them and residents are shown. Home ranges of the returned fish in July, except the day of releasing, are also illustrated. Case numbers are the same as in Table 19.

fish recovered their home ranges at least within one day after being released. They also recovered their social status by that time: that is, the dominance hierarchy was reorganized according to body size as before the experiments. It is remarkable that the reorganization of the dominance hierarchy occurred far more rapidly in this case than in the introducing experiment in the aquarium.

Resident males did not always attack the intruding females, as in case of natural intrusions (see Table 16 and 17) and in the transfer expreiments in the field (case 4 in Table 18). Mating behaviours were also sometimes observed shortly after females were released (see Table 19 and also case 6 in Table 16). On the other hand, when a male (M1) was released, no mating behaviour was observed. In this case, 
the largest female (F3) of the residents had already behaviourally sex-changed to a male when the male was returned. However, F3 ceased to exhibit male displays and behaved as a female from the next day.

In case of natural intrusions, when an intruder met with a resident of its similar size-class, the former was always attacked by the latter (see Table 16 and 17). On the contrary, the intruders were not always attacked by the residents of a similar (or the nearest) size-class in the transfer experiments (cases 4 and 5 in Table 18) and in the removing and returning experiments (cases 4 and 6 in Table 19). However, even in such exceptional cases, the intruders were always attacked by the larger residents, and so it seems that the similar size-class residents could omit their attacks in such situations.

\section{Discussion}

\section{Social Structure of $L$. dimidiatus}

Social unit: social groups and primary groups

Social organization of Labroides dimidiatus has been studied in detail at Heron Island (Robertson, 1972, 1974; Robertson and Choat, 1974; Robertson and Hoffman, 1977) and to some degree at Aldabra Island (Potts, 1973; Robertson and Hoffman, 1977). Robertson considers that the basic social unit of the species is a "social group" which consists of a male and a harem of females living within the male's territory. The composition of social groups is stable over long periods of time, and sexual activity is essentially restricted to members of the same social group. Males control the process of sex reversal within social groups. Potts' (1973) observations at Aldabra Island are quite different from the above, but Robertson (Robertson and Hoffman, 1977) later found the same social groups there as at Heron Island (see discussion in the later section for detail).

During the present study at Shirahama, "polygynous groups" were recognized based on the home range overlap at first. The group consisted of a male and females whose home ranges largely overlapped the male's home range. Males were territorial to each other, and mating occurred within the polygynous groups. A male was once observed to take back his female to its territory when the female moved out of it. The composition of polygynous groups was considerably stable during the warmer periods, although some females moved their home ranges into other groups on a few occasions (also see Kuwamura, 1981a). Therefore, "polygynous groups" recognized in the present study are unduoubtedly the same social unit as "social groups" recognized by Robertson. Social groups (=polygynous groups) are the basic social unit from the viewpoint of matnig system; in other words, $L$. dimidiatus has a haremic mating system.

Home ranges of females within a social group did not always overlap (present study, and also see Robertson, 1972, 1974). As Ambrose (1965) emphasized the significance of the face-to-face groups as the nucleus of all forms of social organization 
in human beings, social relationships between individuals whose home ranges largely overlap seem to be quite different, both in quantity and quality, from those between individuals whose home ranges hardly overlap. It is upon this recognition that, in the present paper, the difference in home range overlap has been paid special attention, and the social group in which all females overlapped their home ranges (i.e. "linear type") has been discriminated from that in which some females did not overlap their home ranges (i.e. "branching type"). I have therefore treated individuals whose home ranges largely overlapped as consisting a "primary group" and analysed intra- and inter-group relationships.

Social relationships within primary groups were found to be considerably different, both in quality and quantity, from those between primary groups. (1) Members of a primary group had much more interactions between them than with members of other primary groups. (2) Within a primary group, larger individuals always dominated over smaller ones, irrespective of place (i.e. the presence of a sizebased dominance hierarchy). On the contrary, between primary groups aggression occurred depending upon the place: border fights occurred or residents chased out intruding individuals of other groups by the effect of prior residence, irrespective of body size (i.e. the presence of territoriality). (3) Intraspecific cleaning, which was often used as appeasement, was restricted to members of the same primary group (see further discussion in Kuwamura, 1980b). Concerning border fights and intrusions (both under natural and experimental conditions), residents of a primary group never attacked each other, but always attacked individuals of other groups. These facts suggest that members of a primary group can discriminate individuals of their group from those of other groups.

As there were such great differences between social relationships within primary groups and those between them, it is strongly suggested that a primary group should be regarded as the "face-to-face group" (in Ambrose's sense, 1965) and therefore the most basic social unit of $L$. dimidiatus.

Size principle: most basic social structure

During the present study it was found that home ranges of individuals of similar body size hardly overlapped, while those of different body size often greatly overlapped. Robertson (1972, 1974) has also noticed a similar tendency at Heron Island.

The degree of difference in body size affected not only spatial relationships but also social relationships. Territorial relationships were most apparent between similar-sized individuals; e.g. when an individual was temporarily absent, the intruder was always an individual of similar body size to it. On the contrary, among individuals of different body size a dominance hierarchy based on body size was present, when home ranges greatly overlapped.

When feeding sites were used somewhat separately between some females of the same primary group, they were mostly females of similar body size in the primary group. When the difference in body size between them became very slight by the 
gain in body size of the smaller fish, one of them moved its whole home range into the neighbouring primary group: that is, the relationship between them changed from a dominance hierarchy to territoriality according to the change in the degree of size difference.

Thus the degree of size difference between two individuals seems primarily to determine the social relationship between the two. I call this phenomenon the "size principle", which seems to be the most basic principle in the social structure of $L$. dimidiatus. Number of males in an area and different types of social groups can be explained by the size principle (see p. 125-126).

As the relationship between body size and social relationship indicates, the body size in this species can be taken to represent the strength of an individual. This is often the case with many other fishes (Sale, 1978). Therefore, it may be concluded, in other words, that social organization of $L$. dimidiatus is based on the segregation of equipotent individuals. In contrast to this, in schooling fishes equipotent individuals are more ready to aggregate and swim together (Breder, 1959; Keenleyside, 1979). Thus, the character of the "size principle" may be different among fish species: the body size seems to affect social relationships of a species in species-specific pattern depending upon its mode of life.

\section{Feeding territoriality?}

Feeding territoriality of females has been regarded to be essential to the haremic system of L. dimidiatus (Robertson and Hoffman, 1977; Warner and Robertson, 1978). However, do females of the species really have feeding territories?

Potts (1973) observed "territories" of solitary juveniles and sub-adults or of adult pairs in L. dimidiatus at Aldabra Island. Although he called the cleaning ranges of individuals "territories", the borders of defended areas were not clearly recognized, and the ranges sometimes overlapped. The areas of ranges of L dimidiatus reported by him were very small as compared with home ranges at Heron Island and Shirahama, probably because long-term individual discrimination was lacking in his study. As he observed no mating behaviours, he concluded that the function of the "territories" was that of feeding ranges. However, from the lack of the long-term individual marking and of observations on the mating system, his conclusion seems to be premature. In fact, Robertson (Robertson and Hoffman, 1977) later found the same haremic groups there as those of Heron Island (and Shirahama). Although Fricke (1980) cited L. dimidiatus as an example of the presence of plasticity in mating system within a species (i.e. polygynous at Heron Island, and solitary or monogamous at Aldabra and in the Red Sea (Slobodkin and Fishelson, 1974)), this view seems to be a superficial one. Even at Shirahama, if individuals had not been tagged, the species might have been regarded as a solitary or monogamous species; for in most cases (ca. 80\%), the fish were observed in solitary, and when not solitarily, most aggregations (ca. 80\%) consited of two individuals (see the section of "Temporary aggregation").

It has been reported that within a social group, females are scattered about at 
fixed feeding areas, which they defend against equally sized or smaller females (Robertson, 1972, 1974; Robertson and Hoffman, 1977). However, even at Heron Island, feeding areas of very large females almost always overlapped those of very small females, and moreover at the patch reefs of the island feeding areas of most females within a social group overlapped each other (see Robertson, 1974). These are similar to the present observations at Shirahama. At Shirahama, females of the same primary group, i.e. whose home ranges overlapped, usually had common feeding areas, but sometimes feeding areas were somewhat separately used among them. Aggression was often observed while feeding, but attacks always occurred by larger females at smaller ones (i.e. according to body size) irrespective of place. That is, there was no "space-related-dominance" (see Wilson, 1975). Therefore, it does not seem to be proper to call feeding areas of females in a primary group as "territories".

It should be emphasized that segregation of home ranges occurred between equal-sized individuals and that of feeding areas occurred mostly between nearest size females of a primary group. That is, segregation of feeding areas within a primary group is regarded as latent territoriality between similar sized individuals, according to the "size principle". The function of segregation (or territoriality) between similar sized individuals is discussed in the following section.

Social structure and its function

From the foregoing discussion, the social structure of $L$. dimidiatus can be recognized and summarized as in Fig. 19. Firstly, the size principle determines the social

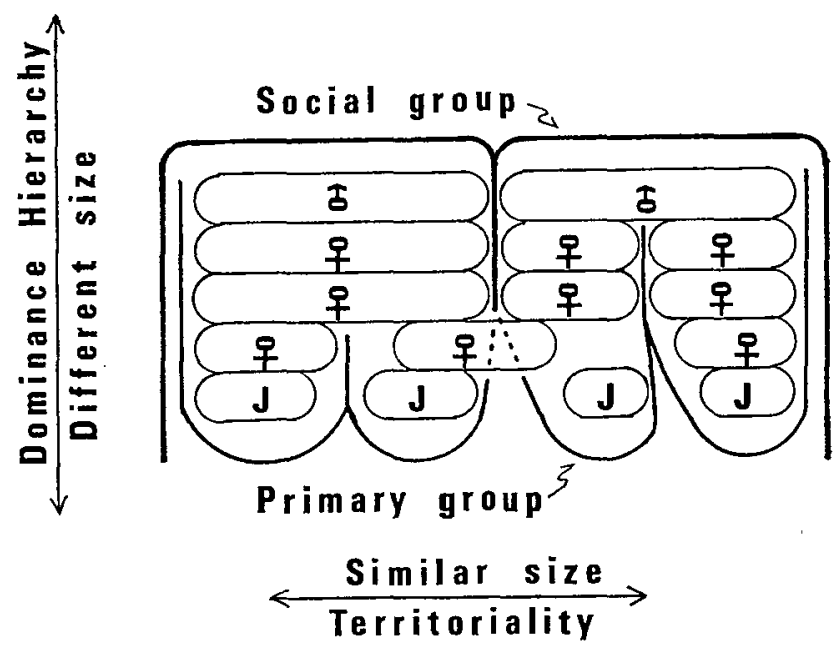

Fig. 19. A schematic representation of the social structure of $L$. dimediatus. See text for detail.

relationship between two individuals: social relationships between similar sized individuals become territorial, and those between different sized individuals become a dominance hierarchy. Secondly, through stable residence of individuals at an area (or "site-attachment" of Fricke, 1975a, 1975b, 1977), members of the same 
primary group come to have different social relationships, both in quantity and quality, from those between primary groups. That is, there is a dominance hierarchy within primary groups and territoriality between primary groups. It is notable that such social grouping is rigid for larger individuals but rather elastic for smaller ones, as the size principle is more clearly established among larger ones, and smaller ones have more mobile and unstable home ranges than larger ones.

In this social system, the territoriality and dominance hierarchy function cooperatively. The unity of a primary group in which dominance hierarchy is present is based to a considerable degree on the territoriality between primary groups. Imanishi (1951) has already suggested that territoriality and dominance hierarchy are cooperating systems in mammalian societies, and that a herd (or group) of mammals would be divided, without territoriality between herds. It should be emphasized that the method of group formation (either by intergroup territoriality or others) must be examined first, before the presence of a dominance hierarchy in a group is discussed. In $L$. dimidiatus, by the territoriality between equipotent individuals only "different-potent" individuals form a group within an area, which must be prerequisite to the presence of the dominance hierarchy within the group.

The function of the dominance hierarchy in L. dimidiatus has been considered as the social control of sex reversal (Robertson, 1972, 1974). The male in each social group suppresses the tendency of its females to change sex by actively dominating them. The fact that males had more frequent contacts with larger females than smaller ones may be explained as follows: larger females have the possibility to change sex earlier than smaller ones and should be dominated more actively. When a male of a social group died or was removed, only the largest female(s) of the group changed sex (Robertson, 1972, 1974; and present study). Therefore, larger females also suppress the tendency of smaller females to change sex by dominating them. It has been suggested that sex-changing individuals have higher fitness in producing offspring in a haremic society (Robertson, 1972; Robertson and Choat, 1974; Choat and Robertson, 1975; Warner, 1975; etc.).

The function of the territoriality in L. dimidiatus seems to differ between males and females. Active border fights often took place only between males but not between females. The main function of territoriality between males seems to be acquisition of females, as has been already suggested (Robertson, 1972, 1974; Robertson and Hoffman, 1977). Males tried to detain their females within their home range, and moreover, males sometimes accepted females of other groups (both under natural and experimental conditions). However, females never accepted other males so long as their male was present. Aggressiveness of females at other males may be explained by a "drive to become dominant" (see Moyer, 1980c). Such different behaviour against other-group members between males and females have also been explained by Trivers (1972) as follows: males, with a minimal energy expenditure in zygote production, can spawn repeatedly daily, whereas females with a considerable energy investment in zygote production, can spawn much less frequently, thus becoming discriminating in their choice of mates. 
The main function of territoriality between females has been regarded as defense of food or feeding areas (Robertson, 1972, 1974; Robertson and Hoffman, 1977). However, as already discussed, its main function seems to be expelling equipotent females and to maintain as high a social status as possible in a primary group, for the territoriality was most apparent between equally-sized individuals ("sizeprinciple").

Therefore, in $L$. dimidiatus the dominance hierarchy and territoriality function in cooperation mainly to control protogynous sex reversal within a harem. As sexchanging individuals have higher fitness in producing offspring (Robertson and Choat, 1974; Warner, 1975; etc.), females which expel competitors prior to sex change may be at an advantage. Females can expel equally-sized individuals, occasionally even larger individuals, by the effect of prior residence. To expel all smaller females may not be advantageous, because they will become its mates in future when the female changes sex after the death of its male. Therefore, competition seems to be most strong between equipotent females. The presence of the size principle, in this species is, thus, easily explained. The reaosn why smaller individuals were loosely organized in this species may be as follows. They have a rather long time until they change sex, and competition between them is yet weaker. It may be more advantageous in some cases for them to search for groups which are more advantageous for their sex change. Such movements by them are not suppressed by larger individuals, probably because the latter do not regard them as actual competitors or do regard them as future potential mates.

Thus, the social control of sex-change in a harem of $L$. dimidiatus can smoothly take place, especially because of the existence of a haremic structure composed of primary groups based on the size principle.

\section{A Comparison of Social and Mating Systems in Labrids}

Among labrid fishes, se $\mathrm{v}_{\mathrm{v}}$ eral species are known to spawn demersal eggs on rock surfaces or in nests (Soljan, 1930a, 1930b, 1931; Fiedler, 1964), and a few species appear to be gonochoristic (Dipper and Pullin, 1979; Diener, 1976, after Robertson and Warner, 1978). However, most labrid species have protogynous hermaphrodites and spawn pelagic eggs in the mid-water, similar to the present species $L$. dimidiatus. The social and mating systems of these free-spawning and protogynous labrids are compared, and factors affecting the development of harems in them are discussed in this section.

Table 21 shows labrid species whose social and mating systems have been studied relatively in detail. Types of the social/mating systems can be classified based on the combination of behaviours of males and females. As to the behaviour of males, presence (either permanent or temporal) or absence of territories should be payed attention to. Among protogynous labrids there are rather many species which have gonochoristic males (i.e. primray males: born as males) besides sex-changed males (i.e. secondary males). These are called "diandric" species, and those which have 
Table 21. Social and mating systems and their ecological factors in free-spawning and protogynous labrid species. +: present; - : absent.

\begin{tabular}{lcccccc}
\hline \multicolumn{1}{c}{ Species } & $\begin{array}{c}\text { Max. } \\
\text { S.L. }\end{array}$ & $\begin{array}{c}\text { Golour } \\
\text { dichro- } \\
\text { matism }\end{array}$ & $\begin{array}{c}\text { Sexual } \\
\text { pattern }\end{array}$ & $\begin{array}{c}\text { Relative } \\
\text { density }\end{array}$ & Food & $\begin{array}{c}\text { Foraging } \\
\text { behaviour }\end{array}$ \\
\hline Labroides dimidiatus & 9 & - & monandry & + & ectoparasite & solitary \\
Bodianus rufus & 24 & - & monandry & + & benthos & solitary \\
Coris dorsomaculata & 15 & + & monandry & + & benthos & solitary \\
Pteragogus flagellifera & 16 & + & monandry & + & benthos* & solitary \\
Cirrhilabrus temminckii & 12 & + & monandry & ++ & plankton & gregarious \\
Halichoeres maculipinna & 12 & + & diandry & +++ & benthos & gregarious \\
Thalassoma bisfasciatum & 12 & + & diandry & +++ & plankton + benthos & gregarious \\
Thalassoma lunare & 13 & + & diandry & +++ & plankton + benthos & gregarious \\
Thalassoma cupido & 15 & + & diandry & +++ & benthos* & gregarious \\
Halichoeres bivittatus & 15 & + & diandry & +++ & benthos & gregarious \\
Halichoeres tenuispinis & 12 & + & diandry & +++ & benthos* & gregarious \\
Pseudolabrus japonicus & 16 & + & diandry & ++ & benthos* & solitary \\
Halichoeres melanochir & 15 & - & monandry & + & benthos & solitary \\
Halichoeres garnoti & 16 & + & monandry & + & plankton + benthos & solitary \\
Clepticus parrae & 19 & + & monandry & +++ & plankton & gregarious \\
\hline
\end{tabular}

1. Feddern, 1965; 2. Meyer, 1977; 3. Moyer, 1974; 4. Moyer and Shepared, 1975; 5. Moyer and Yogo, 1982; 6. Nakazono, 1979; 7. Nakazono and Tsukahara, 1974; 8. Reinboth, 1973; 9. Robertson, 1972; 10. Robertson, 1974; 11. Robertson and Choat,

only secondary males are called "monandric" species (see Reinboth, 1970; Warner and Robertson, 1978; etc.). Most primary males in diandric species are drabcoloured (initial phase), like females, and smaller than bright-coloured (terminal phase) secondary males. The former males usually take different reproductive strategies from the latter (see Warner et al., 1975; etc.). As to the behaviour of females, I pay attention to the degree of residence in a certain feeding area; in other words, whether they spawn within their normal feeding ranges or migrate to the fixed spawning sites. Based on various combinations of these behaviours of males and females, the social/mating systems of labrids hitherto known can be grouped into five types as follows (see Table 21 and Fig. 20).

Harem: Males from permanent territories (at least during the spawning season: e.g. Pteragogus flagellifera (Nakazono, 1979)), and only pair spawnings occur between the male and resident females within its territory, as in $L$. dimidiatus. Most of haremic species are monandric. However, Halichoeres maculipinna is a diandric species, and has a very different structure of harems from othres. Within a territory of a bright large male, there are a few subordinate bright males which are non-functional in spawning, and a number of drab small males, along with several dozens of females (Thresher, 1979). Initial-phase males often participate with pair spawnings (i.e. "streaking", see Thresher, 1979). This species and another one, Cirrhilabrus temminckii, are gregarious species which usually forage in aggregation, but all others 
(Table 21. continued)

\begin{tabular}{|c|c|c|c|c|c|c|c|}
\hline \multirow{2}{*}{$\begin{array}{l}\text { Spawning } \\
\text { site }\end{array}$} & \multirow{2}{*}{$\begin{array}{c}\text { Daily } \\
\text { spawning } \\
\text { migration }\end{array}$} & \multicolumn{3}{|c|}{ Spawning behaviour } & \multirow{2}{*}{$\begin{array}{l}\text { Territory } \\
\text { of males }\end{array}$} & \multirow{2}{*}{$\begin{array}{c}\text { Type of } \\
\text { social and } \\
\text { mating systems }\end{array}$} & \multirow{2}{*}{ Sources } \\
\hline & & pair & $\begin{array}{l}\text { streak- } \\
\text { ing }\end{array}$ & group & & & \\
\hline \multirow{2}{*}{$\begin{array}{l}\text { offshore part within } \\
\text { foraging area } \\
\text { within foraging area }\end{array}$} & - & + & - & 一 & +permanent & Harem & $9,10,11,12,19$ \\
\hline & - & + & - & - & tpermanent & Harem & 17 \\
\hline \multirow{3}{*}{$\begin{array}{l}\text { within foraging area } \\
\text { reef edge within } \\
\text { foraging area } \\
\text { within foraging area }\end{array}$} & - & + & - & - & + permanent & Harem & 16 \\
\hline & - & + & - & - & +permanent & Harem & 6,7 \\
\hline & - & + & - & - & $+?$ & Harem & $4,13,14$ \\
\hline $\begin{array}{l}\left\{\begin{array}{l}\text { within foraging area } \\
\text { reef edge }\end{array}\right. \\
\text { reef edge }\end{array}$ & $\begin{array}{l}\bar{t} \\
+ \\
+\end{array}$ & $\begin{array}{l}+ \\
+ \\
+\end{array}$ & $\begin{array}{l}+ \\
+ \\
+\end{array}$ & $\begin{array}{l}\overline{+} \\
+\end{array}$ & $\begin{array}{l}\text { +permanent } \\
\text { + temporary } \\
\text { +temporary }\end{array}$ & $\begin{array}{l}\text { Harem } \\
\text { Lek-group } \\
\text { Lek-group }\end{array}$ & $\begin{array}{l}15 \\
17 \\
1,8,12,17,18\end{array}$ \\
\hline reef edge & + & + & + & + & +temporary & Lek-group & 11 \\
\hline reef edge & + & + & + & + & +temporary & Lek-group & 2,3 \\
\hline reet edge & + & + & + & + & +temporary & Lek-group & 17 \\
\hline reef edge & + & + & - & + & tpermanent? & L.ek-group & 6 \\
\hline reef edge & + & + & + & - & tpermanent? & Lek-streak & 6 \\
\hline outside reef & + & + & - & - & +temporary & Lek & 5 \\
\hline \multirow{2}{*}{$\begin{array}{l}\text { within foraging area } \\
\text { reef edge within } \\
\text { foraging area }\end{array}$} & - & + & - & - & - & Non-territorial & 15,17 \\
\hline & 一 & + & - & - & 一 & Non-territorial & 12,17 \\
\hline
\end{tabular}

1974; 12. Robertson and Hoffman, 1977; 13. Suzuki et al., 1977; 14. Suzuki et al., 1981; 15. Thresher, 1979b; 16. Tribble, 1982; 17. Warner and Robertson, 1978; 18. Warner et al., 1975; 19. Present study; *Yamaoka, 1978.

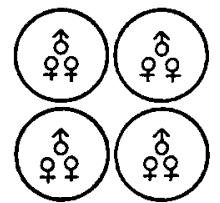

Harem

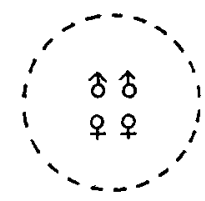

Non-territory

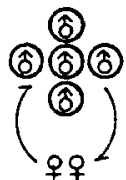

Lek

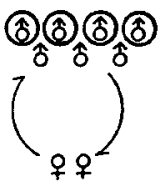

Lek-streak

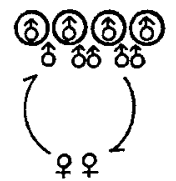

Lek-group

Fig. 20. Five types of social and mating systems in free-spawning and protogynous labrids. Circles show male's territories. Dotted circles indicate non-territorial bome ranges. Arrows show daily spawning migrations. See text for detail.

are solitary species (see Table 21).

Non-territory: Different from the above type, males (and also females) do not defend territories in at least two species. Only pair spawnings occur, either elsewhere (Halichoeres garnoti: Thresher, 1979) or at specific areas, i.e. the down current edges of reefs (Clepticus parrae: Robertson and Hoffman, 1977), within normal foraging ranges of relatively large size. Both species are monandric, but the former is solitary and the latter is gregarious.

Lek: I use the term "lek" in relatively strict sense as discussed by Moyer and Yogo (1982; but for the broad sense, see Loiselle and Barlow, 1978). To my knowledge, no fish species is known to form leks in the strict sense; however Halichoeres melanochir's mating system differs from a lek in the strict sense only in minor ways (Moyer and 
Yogo, 1982). This is a monandric and solitary species, and different from the above types, both males and females migrate from normal foraging areas to a fixed spawning site at the spawning time every day. Males establish territories there and pair-spawn with visiting females.

Lek-streak: This type is observed in a diandric, solitary species Pseudolabrus japonicus (Nakazono, 1979). It is similar to the above type, but differs in the frequent occurrence of "streakings" by non-territorial drab males as well as pair-spawnings by a territorial bright male and a female. Territories of males are established at offshore reef edges where spawnings occur. These territories have been suggested to be rather permanent during the spawning season, but most of females do not reside in a male's territory and migrate from the inshore foraging areas (Nakazono, 1979).

Lek-group: This type is also characterized by the spawning migration to reef edges as the above two cases, but differs in the presence of "group spawnings" (see Warner et al., 1975; etc.) by initial-phase males: many initial-phase small males aggregate and pursue a few females, and then a female spawns with several males. Pair spawnings by terminal-phase large males which establish temporal territories and streakings by non-territorial initial-phase males also occur. All species in this type are diandric and gregarious (see Table 21). Halichoeres tenuispinis partly differs from others: territories of males have been suggested to be rather permanent during the spawning season, and some females reside in these territories; moreover, streakings have not been observed (Nakazono, 1979).

By comparing haremic species with others, the conditions essential to the development of harems are examined. Non-territorial species spawn within normal foraging areas like haremic species, but their foraging areas are relatively larger than the latter. Home ranges of a non-territorial species, H. garnoti, are about five times as large as those of a haremic species H. maculipinna in the same locality (Thresher, 1979). Another non-territorial species $C$. parrae feeds on plankton forming a large school in the mid-water, and therefore has large foraging ranges (Robertson and Hoffman, 1977; Warner and Robertson, 1978). The large size of feeding ranges in these species probably prevents males from monopolizing females. In other words, if feeding ranges are relatively small, males may be able to monopolize resident females, and harems can be formed.

The main difference between haremic species and lekking ones ("lek", "lekstreak" and "lek-group" types) is whether the spawning migration is present or absent. It has been suggested that the areas where most labrids concentrate their spawning activity are those that provide the best chance of eggs being carried off a reef and away from reef-based egg predators (Randall and Randall, 1963; Robertson and Hoffman, 1977; also see Johannes, 1978; Barlow, 1981). Even a haremic species $L$. dimidiatus seems to prefer offshore parts of the normal home ranges for spawning sites (Robertson, 1974 and present study).

Even when spawning activities are restricted to such areas as above, harems may be able to be formed, if the spawning sites contain enough food to maintain a whole population in the locality. P. flagellifera forms harems at the reef edges only 
during the breeding season (Nakazono, 1979). In the same locality, a "lek-streak" species $P$. japonicus and a "lek-group" species $H$. tenuispinis also concentrate their spawning activities at the reef edges. The population density of $P$. flagellifera is lowest among the three species (Nakazono, 1979). That is, a low-density species may be able to form harems, even if spawning sites are rather restricted in a locality, as it can maintain populations even in the limited spawning sites.

On the other hand, high-density species seem to be able to establish harems only when spawning sites are not limited. A gregarious species $H$. manculipinna migrates to spawn at the outer rims of reefs ("lek-group" type) at the San Blas Islands (Warner and Robertson, 1978), while it spawns elsewhere in "harems" at Florida (Thresher, 1979). Two other species studied by Thresher (1979) at Florida also spawn throughout their normal home ranges, and most of labrids studied by Warner and Robertson (1978) at the San Blas Islands migrate to spawn at the reef edges. Therefore, the geographical variation in the social/mating system of $H$. maculipinna is probably due to the difference in the ditsribution of available spawning sites of the species in two localities.

As discussed above (also see Fig. 21), harems may be formed, if a species does

Foraging behaviour

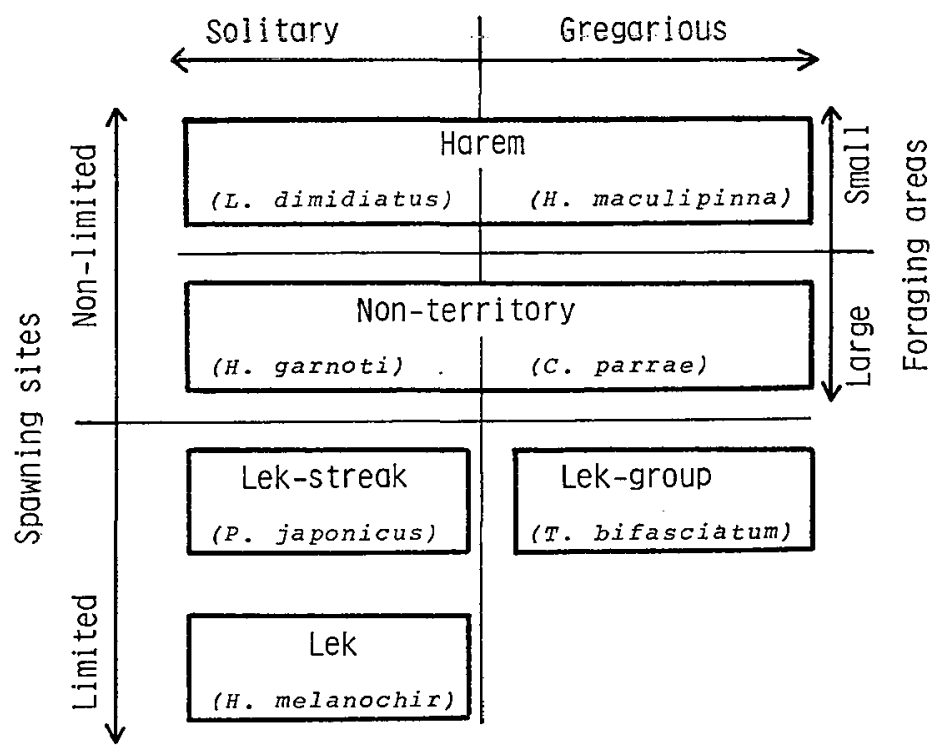

Fig. 21. Relationships between several ecological factors and social/mating systems of labrids. Representative species in each type of the social/ mating systems are given in parentheses.

not restrict its spawning activity to specific sites and feeds within relatively small ranges, or if its spawning sites are restricted but its density is relatively low. Therefore, protogynous labrid species which forage solitarily (low density) within small ranges, such as $L$. dimidiatus, seem to always develop haremic social/mating systems. 
In contrast to this, diandric and gregarious species may have plastic social/mating systems according to different environments: e.g. H. maculipinna (Thresher, 1979 and Warner and Robertson, 1978), and also Thalassoma bifasciatum (Warner et al., 1975; Warner and Hoffman, 1980a, 1980b). The strategy of selection of spawning sites may be affected by the degree of predation risk both on eggs and adults of a species, and the foraging strategy and density may be influenced by the distribution and abundance of its food. These ecological factors must be quantitatively examined for each species to establish the evolutionary course of labrids' social/mating systems, in the future.

\section{Structure of Harems in Fish and Control of Sex-change}

Emlen and Oring (1977) proposed a new classification of mating systems, based on the ecological and behavioural potential to monopolize mates and the means through which such monopolization takes place. They distinguished "female (or harem) defense polygyny" from "resource defense polygyny". However, as their definition requires some judgements on the above basis, $I$, at presnet, use the term "harem polygyny", in a more simple and practical sense, as to imply that an individual mates with two or more individuals relatively simultaneously, based on the pair-bond of considerable duration during a single breeding season (Selander, 1972; Wittenberger, 1979).

Table 22. Examples of haremic species in fish. For protogynous and free-spawning labrids, see Table 21.

\begin{tabular}{llllll}
\hline \multicolumn{1}{c}{ Species } & Family & Sexuality & Eggs & Behaviour & Sources \\
\hline $\begin{array}{l}\text { Harems in patchy habitat } \\
\text { Dascyllus marginatus }\end{array}$ & Pomacentridae & gonochorism & demersal & gregarious & 6,8 \\
Dascyllus aruanus & Pomacentridae & protogyny & demersal & gregarious & 5,7 \\
Paragobiodon xanthosoma & Gobiidae & protogyny & demersal & solitary & 9 \\
Paragobiodon sp. & Gobiidae & protogyny & demersal & solitary & 9 \\
Harems in continuous habitat & & & & & \\
Apistogramma trifasciatum & Cichlidae & gonochorism & demersal & solitary & 1 \\
Lactoria fornasini & Ostraciidae & gonochorism & pelagic: & gregarious & 10 \\
Sparisoma aurofrenatum & Scaridae & protogyny & pelagic & gregarious & 13 \\
Anthias squamipinnis & Serranidae & protogyny & pelagic & gregarious & $3,4,12,14,15$ \\
Labrus berggylta & Labridae & protogyny & demerasl & solitary & 16 \\
Scarus niger & Scaridae & protogyny & pelagic & solitary & 2 \\
Centropyge interrupius & Pomacentridae & protogyny & pelagic & solitary & 11 \\
Parapircis snyderi & Mugiloididae & protogyny & pelagic & solitary & 17 \\
\hline
\end{tabular}

1. Burchard, 1965; 2. Choat and Roberıson, 1975; 3. Fishelson, 1970; 4. Fishelson, 1975; 5. Fricke, 1977; 6. Fricke, 1980; 7. Fricke and Holzberg, 1974; 8. Holzberg, 1973; 9. Lassig, 1977; 10. Moyer, 1979; 11. Moyer and Nakazono, 1978a; 12. Popper and Fishelson, 1973; 13. Robertson and Warner, 1978; 14. Shapiro, 1977; 15. Shapiro, 1981; 16. Sjolander et al., 1972; 17. Suzuki et al., 1980. 
Such polygynous groups have been found also in several fishes other than protogynous and free-spawning labrids: these include gonochoristic species and demersal spawners, too (see Table 22). Territoriality between males is the common character among these. However, harems of some fishes involve additional males: nonfunctional smaller males in a gonochoristic species Lactoria fornasiri (Moyer, 1979); non-functional subordinate males and functional smaller males in a protogynous labrid H. maculipinna as mentioned in the previous section (Thresher, 1979).

The pattern of distribution of females seems to affect the stability of the polygynous group, or the ability of males to monopolize them. Firstly, habitats of these haremic species can be classified into two types: i.e. a small "patchy" habitat and a "continuous" habitat. Haremic gobies and damselfishes inhabit coral clumps, being strictly site-attached (Lassig, 1977; Holzberg, 1973; Fricke, 1977, 1980; Fricke and Holzberg, 1974: also see Table 22). These species are either gonochoristic or protogynous, but all of them are demersal spawners. In the damselfishes (protogynous Dascyllus aruanus and gonochoristic D. marginatus), when coral size is large, several males are territorial to each other within one coral, but each female never restricts its home range and spawning activity within one male's territory (Fricke, 1977, 1980). That is, males can no longer monopolize females in large corals, which are continuous habitats for them. Such plasticity in the social/mating systems has not been precisely studied in other coral-dwelling fishes. However, it seems that the patchy habitat (i.e. corals) itself assures the stability of polygynous groups and the monopolization of females by males. A similar situation has been also known in polyandrous groups of protandrous anemonefishes living in sea anemones which seem to be patchy habitats (Moyer, 1980c).

Habitats of other haremic species are not patchily distributed but rather continuous. There are three types in the pattern of distribution of females in these harems: (A) a male's territory is subdivided by individual territories of females; (B) a male's territory is subdivided by groups of females; and (C) females overlap their home ranges in a male's territory (see Fig. 22).

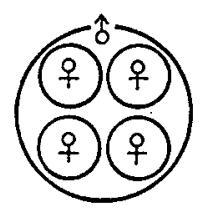

A

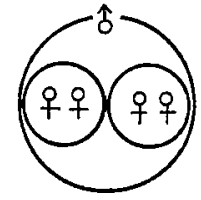

B

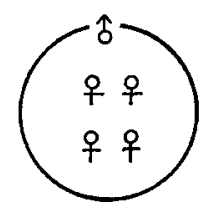

C

Fig. 22. Three types of structures of harems in fishes. Circles show territories. See text for detail.

Type-A is represented by a single species, the dwarf cichlid Apistogramma trifasciatum, a gonochoristic demersal spawner. Males of this species establish territories of a diameter of $1 \mathrm{~m}$ or more, and within a male's territory each female also establishes a smaller territory only during the period of spawning, incubation and caring for 
the young (in aquarium: Burchard, 1965). After the young grow older, females become mobile, and often cross the boundray between two males. That is, males of this species can monopolize females only when they attach to the breeding sites. Individual territories have been developed also for feeding in several fishes. However, haremic systems have not hitherto been found among those: e.g. herbivorous damselfishes spawn in temporal pairs (Clarke, 1971; etc.), and herbivorous surgeonfishes spawn in stable monogamous pairs (Roberton et al., 1979). L. dimidiatus has been regarded as an example of harems consisted of individual territories of females (Robertson, 1972; Robertson and Hoffman, 1977; etc.), but as discussed in the present paper, it does not seem to have individual feeding territories. It seems that males can not monopolize females in species which have individual feeding territories, because both sex must take the same strategy for feeding.

Type-B and type- $\mathrm{C}$ are those such as branching-type groups and linear-type groups, respectively, of $L$. dimidiatus. Only one other species has been known to belong to type-B. In H. maculipinna, which is a protogynous species like L. dimidiatus, a male's territory contains several "herds" of females (Thresher, 1979). However, these herds largely "ignored" one another and occasionally merged briefly (Thresher, 1979), and so there seems to be no such territoriality between these herds as was observed between primary groups of $L$. dimidiatus. In these speiecs of type-B, the segregation of female-groups probably facilitate monopolization by males.

At present, home ranges of females in a harem have been individually traced in detail only in the two species mentioned above. Therefore, the remaining haremic species may include both type-B and type-C. Moreover, theoretically, B-type species can develop harems of type-C, as has been observed in L. dimidiatus in the present study. Therefore, for the present, I treat B- and C-types together. There are both soiltary species and gregarious ones in these species. The method of monopolization of females by males seems to differ according to the difference in gregariousness.

Gregarious species include one gonochoristic fish, L. fornasini, but others are protogynous. Females of $L$. fornasini often form small feeding aggregations (Moyer, 1979). Other gregarious species often form larger feeding aggregations. In Anthias squamipinnis, when the size of a group becomes very large, it becomes a multi-male group, and each male can no longer monopolize females effectively (see Shapiro, 1977, 1981; etc.). That is, in these gregarious species, their clumping tendency itself assures segregation of polygynous groups, and therefore the size of them strictly affects the ability of males to monopolize females.

According to Emlen and Oring's classification (1977) these gregarious haremic species seem to be "female defense polygyny", and the haremic species in patchy habitat and those of females' individual territories seem to be "resource defense polygyny"; shelters and spawning sites seem to be critical resources to be defended by males. However, the remaining haremic fishes, i.e. solitary species in a continuous habitat, do not fit this classification; for they are not gregarious, and at the same time their harems include not only spawning sites but also all other resources; 
that is, it can not be judged whether males control access to females directly or indirectly (in Emlen and Oring's sense) in these species.

As examined in labrids in the previous section, these species have relatively small home ranges. This may partly facilitate monopolization by males. However, if females of different harems do not at all segregate with each other, it seems to be rather impossible for males to monopolize them, even though males try to detain females within their territories as observed in L. dimidiatus (Robertson, 1974 and the present study) and Centropyge interruptus (Moyer and Nakazono, 1978a). Such segregation of females of different harems has been known in a few species, e.g. the two species above, at present, partly because home ranges of females and their social encounters have not been studied in detail. I suggest that also in other solitary species in continuous habitat segregation of females occurs based on the "size principle" as observed in $L$. dimidiatus, because all these species are protogynous and the "size principle" ensures a smooth sex-change which is advantageous in protogynous species. Moreover, if the size principle is present in these species, they can form both B- and C-type harems, as shown in L. dimidiatus. In contrast to this, harems do not seem to be formed in gonochoristic species, unless they are gregarious (i.e. "female defense polygyny") or some of their critical resources are unevenly distributed or spatially clumped (i.e. "resource defense polygyny"), as Emlen and Oring (1977) have suggested.

Social control of sex-change occurs either in harems in patchy habitat or those of gregarious species according to the size-based dominance hierarchy in each group. However, it seems to occur most perfectly in the harems based on the size principle, for in the former two cases the unity of polygynous groups sometimes breaks up accordnig to environmental conditions, e.g. the size of corals or that of groups, but in the latter case it is guaranteed by the size principle itself.

\section{Acknowledgments}

The Seto Marine Biological Laboratory of Kyoto University provided the facilities for my field and aquarium studies. I thank members of the staff of the laboratory for discussing various aspects of this work. I am very grateful to Jack T. Moyer, Eiji Harada, Hiroya Kawanabe, Taizo Miura, Moritaka Nishihira and Jun'ichiro Itani for reading earlier drafts of the manuscript. Their careful critisism and helpful suggestions led to significant improvements. D. Ross Robertson helped me in obtaining a copy of his $\mathrm{Ph}$. D. Thesis on L. dimidiatus, which was absolutely necessary for the present study. I am also indebted to Katsuki Miura for his encouragement during the revision of drafts. Finally I thank my wife Reiko for assisting in arrangement of the data, discussing various aspects of this work, and especially, her consistent encouragement during the preparation of this paper. This work was partly supported by a Grant-in-Aid for Special Project Research on Biological Aspects of Optimal Strategy and Social Structure from the Japan Ministry of Education, Science and Culture. 


\section{References}

Ambrose, J.A. 1965. The study of human social organization: a review of current concepts and approaches. Symp. Zool. Soc. London, 14: 301-314.

Barlow, G.W. 1981. Patterns of parental investment, dispersal and size among coral-reef fishes. Env. Biol. Fish., 6: 65-85.

Breder, C.M. 1959. Studies on social groupings in fishes. Bull. Amer. Mus. Nat. His., 117: 397482.

Burchard, J.F. 1965. Family structure in the dwarf cichlid Apistogramma trifasciatum Eigenmann and Kennedy. Z. Tierpsychol., 22: 150-162.

Choat, J.H. and D.R. Robertson. 1975. Protogynous hermaphroditism in fishes of the family Scaridae. In R. Reinborh (ed.), Intersexuality in the Animal Kingdom. Springer-Verlag, Berlin. p. 263283.

Clarke, T.A. 1971. Territory boundaries, courtship, and social behavior in the garibaldi, Hypsypops rubicunda (Pomacentridae). Copeia, 1971: 295-299.

Diener, D.R. 1976. Hermaphroditism in fish: A comparative study of the reproductive biology and endocrinology of the California Labridae. Ph. D. Thesis, Univ. California, San Diego. 158pp.

Dipper, F.A. and R.S.V. Pullin. 1979. Gonochorism and sex-inversion in British Labridae (Pisces). J. Zool., Lond., 187: 97-112.

Emlen, S.T. and L.W. Oring. 1977. Ecology, sexual selection, and the evolution of mating systems. Science, 197: 215-223.

Feddern, H.A. 1965. The spawning, growth, and general behavior of the bluehead wrasse, Thalassoma bifasciatum (Pisces: Labridae). Bull. Mar. Sci., 15: 896-941.

Fiedler, K. 1964. Verhaltensstudien an Lippfischen der Gattung Crenilabrus (Labridae, Perciformes). Z. Tierpsychol., 21 : 521-591.

Fishelson, L. 1970. Protogynous sex reversal in the fish Anthias squamipinnis (Teleostei, Anthiidae) regulated by the presence or absence of a male fish. Nature, 227: 90-91.

1975. Ecology and physiology of sex reversal in Anthias squainipinnis (Peters), (Teleostei: Anthiidae). In R. Reinboth (ed.), Intersexuality in the Animal Kingdom. Springer-Verlag, Berlin. p. 284-294.

Fricke, H.W. 1975a. Evolution of social systems through site attachment in fish. Z. Tierpsychol., 39: 206-210.

1975b. Sozialstruktur und ökologische Spezialisierung von verwandten Fischen (Pomacentridae). Z. Tierpsychol., 39: 492-520.

1977. Community structure, social organization and ecological requirements of coral reef fish (Pomacentridae). Helgoländer wiss. Meeresunters., 30: 412-426.

1979. Mating system, resource defence and sex change in the anemonefish Amphiprion akallopisos. Z. Tierpsychol., 50: 313-326.

1980. Control of different mating systems in a coral reef fish by one environmental factor. Anim. Behav., 28: 561-569.

fish. Nature, 266: 830-832.

-_ and S. Holzberg. 1974. Social units and hermaphroditism in a pomacentrid fish. Naturwiss., $61: 367-368$.

Holzberg, S. 1973. Beobachtungen zur Ökologie und zum Sozialverhalten des Korallenbarsches Dascyllus marginatus Rüppell (Pisces; Pomacentridae). Z. Tierpsychol., 33: 492-513.

Imanishi, K. 1951. Ningen izen no shakai. Iwanami, Tokyo. 170+v pp. (In Japanese).

Ito, Y. 1978. Hikaku-seitaigaku. 2nd ed. Iwanami, Tokyo. 421pp. (In Japanese).

Johannes, R.E. 1978. Reproductive strategies of coastal marine fishes in the tropics. Env. Biol. Fish., 3: 65-84.

Keenleyside, M.H.A. 1979. Diversity and adaptation in fish behaviour. Zoophysiology, 11. SpringerVerlag, Berlin. 208pp.

Kuwamura, T. 1980a. Cleaning symbiosis among marine organisms at the shallow rocky reefs in Shirahama. Nankiseibutu, 22: 29-32. (In Japanese). 
Kuwamura, T. 1980b. Grooming of Labroides dimidiatus: biological meaning of intra- and interspecific cleaning behaviour. Anima, 90: 52-57. (In Japanese).

1981a. Life history and population fluctuation in the labrid fish, Labroides dimidiatus, near the northern limit of its range. Publ. Seto Mar. Biol. Lab., 26: 95-117.

1981b. Diurnal periodicity of spawning activity in free-spawning labrid fishes. Japan. J. Ichthyol., 28: 343-348.

Lassig, B.R. 1977. Socioecological strategies adopted by obligate coral-dwelling fishes. Proc. 3rd Int. Coral Reef Symp., p. 565-570.

Lepori, N.G. 1980. Sex differentiation, hermaphroditism and intersexuality in vertebrates including man. Piccin Medical Books, Italy. 345pp.

Loiselle, P.V. and G.W. Barlow. 1978. Do fishes lek like birds? In E.S. Reese and F.J. Lighter (eds.), Contrasts in Behavior. Wiley-Interscience, New York. p. 31-75.

Meyer, K.A. 1977. Reproductive behavior and patterns of sexuality in the Japanese labrid fish Thalassoma cupido. Japan. J. Ichthyol, 24: 101-112.

Moyer, J.T. 1974. Notes on the reproductive behavior of the wrasse Thalassoma cupido. Japan, J. Ichthyol, $21: 34-36$.

- 1979. Mating strategies and reproductive behavior of ostraciid fishes at Miyake-jima, Japan. Japan. J. Ichthyol., 26: 148-160.

1980a. Macropharyngodon moyeri. Aqualife, 3: 38-39. (In Japanese). nese).

1980b. The spawning behavior of Pseudojuloides elongatis. Aqualife, 9: 68-69. (In Japa-

- 1980c. Influence of temperate waters on the behavior of the tropical anemonefish Amphiprion clarkii at Miyake-jima, Japan. Bull. Mar. Sci., 30: 261-272.

- and A. Nakazono. 1978a. Population structure, reproeudctive behavior and protogynous hermaphroditism in the angelfish Centropyge interruptus at Miyake-jima, Japan. Japan. J. Ichthyol,, 25: 25-39.

and

1978b. Protandrous hermaphroditism in six species of the anemonefish genus Amphiprion in Japan. Japan. J. Ichthyol., 25: 101-106.

minckii. Japan. J. Ichthyol., 22: 40-42.

___ and Y. Yogo. 1982. The lek-like mating system of Halichoeres melanochir (Pisces: Labridae) at Miyake-jima, Japan. Z. Tierpsychol., $60: 209-226$.

Nakazono, A. 1979. Studies on the sex reversal and spawning behavior of five species of Japanese labrid fishes. Rep. Fish. Res. Lab. Kyushu Univ., 4: 1-64. (In Japanese with English summary).

- 1 and H. Tsukahara. 1974. Underwater observation on the spawning behavior of the wrasse, Duymaeria flagellifera (Cuvier et Valenciennes). Rep. Fish. Res. Lab. Kyushu Univ., 2: 1-11. (In Japanese with English summary).

Popper, D. and L. Fishelson. 1973. Ecology and behavior of Anthias squamipinnis (Peters, 1855) (Anthiidae, Teleostei) in the coral habitat of Eilat (Red Sea). J. Exp. Zool., 184: 409-424.

Potts, G.W. 1973. The ethology of Labroides dimidiatus (Cuv. \& Val.) (Labriade, Pisces) on Aldabra. Anim. Behav., 21: 250-291.

Randall, J.E. and H.A. Randall. 1963. The spawning and early development of the Atlantic parrot fish, Sparisoma rubipinne, with notes on other scarid and labrid fishes. Zoologica, 48: 49-60.

Reinboth, R. 1970. Intersexuality in fishes. Mem. Soc. Endocr., 18: 516-543.

1973. Dualistic reproductive behavior in the protogynous wrasse Thalassoma bifascialum and some observations on its day-night changeover. Helgoländer wiss. Meersunters., 24: 174191.

1975. Spontaneous and hormone-induced sex-inversion in wrassse (Labridae). Pubbl. Staz. Zool. Napoli, 39 (Suppl.): 550-573.

- 1980. Can sex inversion be environmentally induced? Biol. Reproduction, 22: 49-59.

Robertson, D.R. 1972. Social control of sex reversal in a coral-reef fish. Science, 177: 1007-1009. 1974. A study of the ethology and reproductive biology of the labrid fish, Labroides dimidiatus, at Heron Island, Great Barrier Reef. Ph. D. Thesis, Univ. Queensland. 295pp. 
Roberston, D.R. and J.H. Choat. 1974. Protogynous hermaphroditism and social systems in labrid fish. Proc. 2nd Int. Symp. Coral Reefs, 1: 217-225.

and S.G. Hoffman. 1977. The roles of female mate choice and predation in the mating systems of some tropical labroid fishes. Z. Tierpsychol., 45: 298-320.

- and R.R. Warner. 1978. Sexual patterns in the labroid fishes of the western Caribbean, II: The parrotfishes (Scaridae). Smithson. Contr. Zool., 255: 1-26.

- N.V.C. Polunin and K. Leighton. 1979. The behavioral ecology of three Indian Ocean surgeonfishes (Acanthurus lineatus, A. leucosternon and Zebrasoma scopas): their feeding strategies, and social and mating systems. Env. Biol. Fish., 4: 125-170.

Roede, M.J. 1972. Color as related to size, sex, and behavior in seven Caribbean labrid fish species (genera Thalassoma, Halichoeres and Hemipteronotus). Stud. Fauna Curaçao Caribb. Isl., 42: 1-266.

1975. Reversal of sex in several labrid fish species. Pubbl. Staz. Zool. Napoli, 39 (Suppl.): 595-617.

Sale, P.F. 1978. Reef fishes and other vertebrates: A comparison of social structures. In E.S. Reese and F.J. Lighter (eds.), Contrasts in Behavior. Wiley-Interscience, New York. p. 313-346.

Selander, R.K. 1972. Sexual selection and dimorphism in birds. In B. Campbell (ed.), Sexual Selection and the Descent of Man, 1871-1971. Aldine, Chicago. p. 180-230.

Shapiro, D.Y. 1977. The structure and growth of social groups of the hermaphroditic fish Anthias squamipinnis (Peters). Proc. 3rd Int. Coral Reef Symp., p. 571-577.

1981. Size, maturation and the social control of sex reversal in the coral reef fish Anthias squamipinnis. J. Zool., Lond., 193: 105-128.

Sjolander, S., H.O. Larson and J. Engstrom. 1972. On the reproductive behaviour of two labrid fishes, the ballan wrasse (Labrus berggylta) and Jago's goldsinny, (Ctenulabrus rupestris). Rev. Comp. Animal, 6: 43-51.

Slobodkin, L.B. and L. Fishelson. 1974. The effect of the cleaner-fish Labroides dimidiatus on the point diversity of fishes on the reef front at Eilat. Amer. Natur, 108: 369-376.

Smith, G.L. 1975. The evolution of hermaphroditism in fishes. In R. Reinboth (ed.) Intersexuality in the Animal Kingdom. Springer-Verlag, Berlin. p. 295-310.

Soljan, T. 1930a. Nestbau eines adriatischen Lippfisches (Crenilabrus ocellatus Forsk.). Z. Morph. Ökol. Tiere, 17: 145-153.

1930b. Die Fortpflanzung und das Wachstum von Crenilabrus ocsllatus Forsk., einem Lippfisch des Mittelmeeres. Z, wiss. Zool., 137: 150-174.

1931. Brutpflege durch Nestbau bei Crenilabrus quinquemaculatus Risso, einem adriatischen Lippfisch. Z. Morph. Ökol. Tiere, 20: 132-135.

Suzuki, K., K. Kobayashi and S. Hioki. 1977. Ecological studies of the labrid fish Cirrhilabrus temminckii in Suruga Bay. Adv. Abst. 10th Ann. Meet. Ichthyol. Soc. Japan, 29. (In Japanese).

- S. Hioki, K. Kobayashi and Y. Tanaka. 1981. Developing eggs and early larvae of the wrasses, Cirrhlabrus temminckii and Labroides dimidiatus, with a note on their spawning behaviors. J. Fac. Mar. Sci. Tech., Tokai Univ., 12: 149-165. (In Japanese with English abstract).

, Y. Shiobara and K. Kobayashi. 1980. Ecological study of the parapercid fish Parapercis snyderi in Suruga Bay, Japan. Adv. Abst. 13th Ann. Meet. Ichthyol. Soc. Japan, 41. (In Japanese).

Thresher, R.E. 1979. Social behavior and ecology of two sympatric wrasses (Labridae: Halichoeres spp.) off the coast of Florida. Mar. Biol., 53: 161-172.

Tribble, G.W. 1982. Social organization, patterns of sexuality, and behavior of the wrasse Coris dorsomaculata at Miyake-jima, Japan. Env. Biol. Fish., 7: 29-38.

Trivers, R.L. 1972. Parental investment and sexual selection. In B. Campbell (ed.) Sexual Selection and the Descnet of Man, 1871-1971. Aldine, Chicago. p. 136-179.

Warner, R.R. 1975. The adaptive significance of seuqential hermaphroditism in animals. Amer. Natur., 109: 61-82.

1978. The evolution of hermaphroditism and unisexuality in aquatic and terrestrial vertebrates. In E.S. Reese and F.J. Lighter (eds.) Contrasts in Bebavior. Wiley-Interscience, New York. p. 77-101.

- 
sexual composition in two tropical marine fishes (Thalassoma spp.). Evolution, 34: 508-518.

Warner, R.R.and S.G. Hoffman. 1980b. Population density and the economics of territorial defense in a coral reef fish. Ecology, 61: 772-780.

and D.R. Robertson. 1978. Sexual patterns in the labroid fishes of the western Caribbean, I: The wrasses (Labridae). Smithson. Contr. Zool., 254: 1-27.

and E.G. Leigh. 1975. Sex change and sexual selection. Science, 190: 633-638.

Wilson, E.O. 1975. Sociobiology. The new synthesis. Belknap Press, Harvard Univ. Press, Cambridge. $697 \mathrm{pp}$.

Wittenberger, J.F. 1979. The evolution of mating systems in birds and mammals. In P. Marler and J.G. Vandenbergh (eds.), Handbook of Behavioral Neurobiology, 3. Social Behavior and Communication. Plenum Press, New York, London. p. 271-349.

Yamaoka, K. 1978. Pharyngeal jaw structure in labrid fish. Publ. Seto Mar. Biol. Lab., 24: 409426.

Youngbluth, M.J. 1968. Aspects of the ecology and ethology of the vleaning fish, Labroides phthirophagus Randall. Z. Tierpsychol., 25: 915-932.

\section{Addendum}

After I had prepared this manuscript, a paper by Robertson (1981), discussing differences in the mating system of $H$. maculipinna in Panama and Florida, came to my attention. From his descriptions and discussion, it seems that the "size principle", as has been discussed in relation to sex schange in the present paper, is operating to some degree also in H. maculipinna in Panama.

(Robertson, D.R. 1981. The social and mating systems of two labrid fishes, Halichneres maculipinna and $H$. garnoti, off the Caribbean coast of Panama. Mar. Biol., 64: 327-340.) 